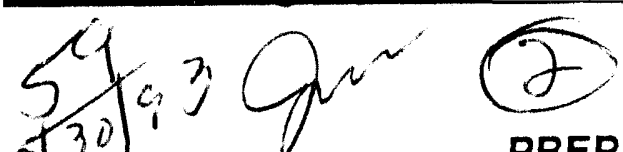
a

PREPARED FOR THE U.S. DEPARTMENT OF.ENERGY, UNDER CONTRACT DE-AC02-76-CHO-3073

PPPL-2930

PPPL-2930

UC-420,421, 426,427

A STANDARD DT SUPERSHOT SIMULATION

BY

R.V. BUDNY

SEPTEMBER, 1993

$\int \frac{D}{5} \sqrt{D} \int\left[\begin{array}{l}\text { PAINCETON } \\ \text { PLABMA PHYBICS } \\ \text { LABOAATOAY }\end{array}\right.$

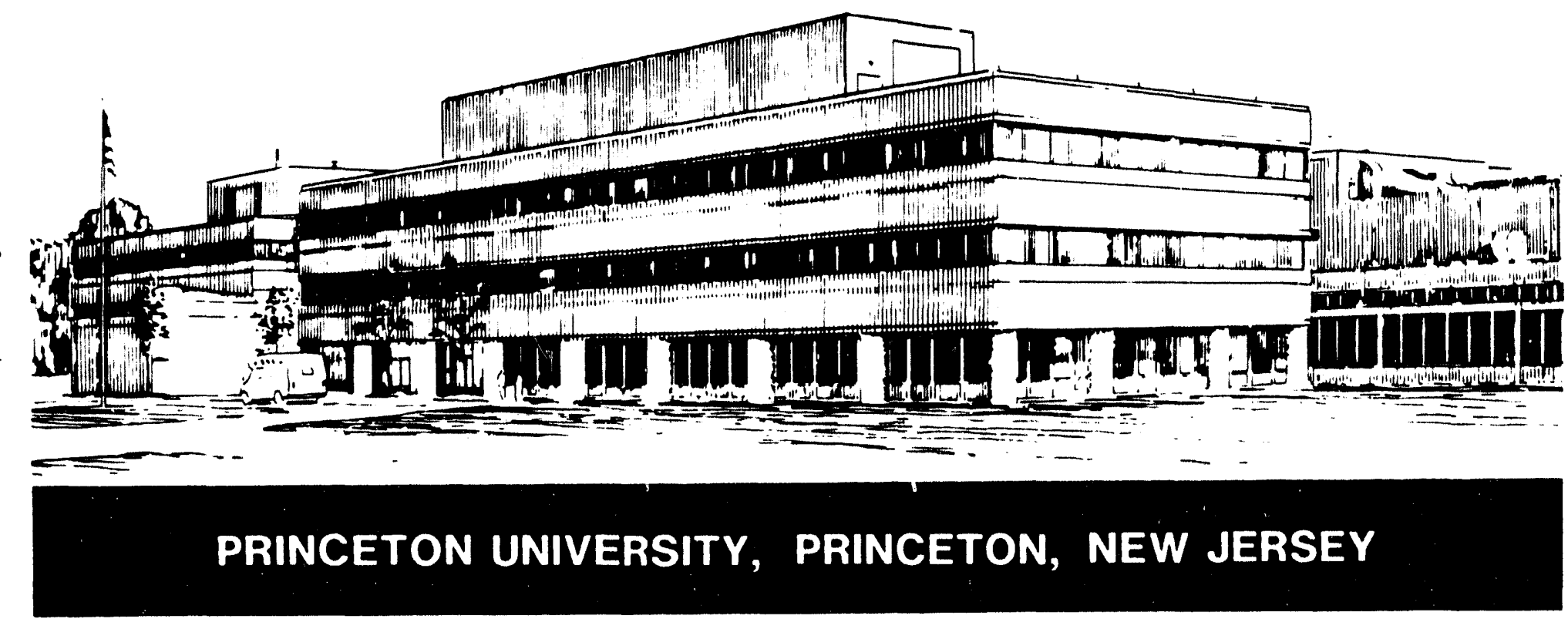




\section{NOTICE}

This report was prepared as an account of work sponsored by an agency of the United States Government. Neither the United States Government nor any agency thereof, nor any of their employees, makes any warranty, express or implied, or assumes any legal liability or responsibility for the accuracy, completeness, or usefulness of any information, apparatus, product, or process disclosed, or represents that its use would not infringe privately owned rights. Reference herein to any specific commercial produce, process, or service by trade name, trademark, manufacturer, or otherwise, does not necessarily constitute or imply its endorsement, recommendation, or favoring by the United States Government or any agency thereof. The views and opinions of authors expressed herein do not necessarily state or reflect those of the United States Government or any agency thereof.

\section{NOTICE}

This report has been reproduced from the best available copy.

Available in paper copy and microfiche.

Number of pages in this report: 63

DOE and DOE contractors can obtain copies of this report from:

Office of Scientific and Technical Information

P.O. Box 62

Oak Ridge, TN 37831;

(615) 576-8401.

This report is publicly available from the:

National Technical Information Service

Department of Commerce 5285 Port Royal Road

Springfield, Virginia 22161

(703) $487-4650$ 
PPPL 2930 (August 31, 1993)

\title{
A Standard DT Supershot Simulation
}

\author{
R. V. Budny \\ Princeton University \\ Plasma Physics Laboratory \\ P. O. Box 451, Princeton NJ, 08543
}

\begin{abstract}
A simulation of an anticipated TFTR DT supershot is described. The simulation is based on a reproducible, high performance, long duration DD supershot with a major radius of $2.45 \mathrm{~m}$. The TRANSP plasma analysis code is used to model fast ion (D, T, and alpha) parameters, including their distributions in energy and pitch angle. Values and fits are provided for comparing plasma modeling codes and for use in codes for analyzing MHD stability and collective alpha particle effects.
\end{abstract}




\section{Introduction}

Experiments with DT supershots are scheduled for TFTR starting in the fall of 1993. A large number of DT simulations have been performed using the TRANSP plasma analysis code for designing experiments and diagnostics, and for alpha physics studies. Examples based on discharges from 1986-1990 have been pı'blished. ${ }^{1}$ The purpose of this paper is to provide more detailed simulations based on a recent supershot. Distributions of the fast ions in energy and pitch angle are given.

One of the simulations discussed in Ref. 1 (based on 55851) had been selected as a standard example, and has been used for theoretical studies of TAE modes. ${ }^{2}$ The absence of significant MHD activiiy in that discharge made it appear especially suitable for DT experiments since the coherent MHD activity which is often observed in supershots may increase the alpha transport and prevent the accumulation of significant alpha pressures. MHD activity may also spoil the reproducibility, making it more difficult to study the alpha physics.

All the DT simulations discussed in Ref. 1 were based on plasrnas with $R_{0}=2.45 \mathrm{~m}$. During the 1992 experimental run, supershors with larger $R_{0}=2.52 \mathrm{~m}$ achieved record neutron emission rates. Because of this, the first DT supershot experiments planned for TFTR will have a major radius of $2.52 \mathrm{~m}$. Unfortunately, supershots with $\mathrm{R}_{0}>2.45 \mathrm{~m}$ usually exhibit a decrease in neutron yield and in profile peakedness during the NBI, which can prevent these supershots from maintaining stationary conditions. These decreases are expected to interfere with the accumulation of fast alphas, resulting in relatively low densities of fast alphas, and may make comparisons with steady-state theories more difficult. For this reason, the new DT standard supershor discussed below is still based on a supershot with $R_{0}=2.45 \mathrm{~m}$. Supershots with this radius are proposed for some of the DT experiments in TFTR, for example, the alpha heating experiment. ${ }^{3}$

The case described here resulted from an experiment conducted to optimize long duration, high performance supershots for reproducibility. ${ }^{4}$ The trade-off between performance and reproducibility led to a choice of supershots with slightly less beam power and neutron yield than 55851, but with higher reproducibility. These supershots also have lower central pressure and $\beta$, and thus have more margin to accommodate the higher pressure expected in DT due to differences in T-NBI, the additional alpha pressure, and the higher electron temperature from the alpha heating. 5

Many examples of these moderate, long duration, high performance supershots have been achieved. 4 They typically have "benign" fishbone activity during the flat-top phase. One 
example, 66887 . Was chosen as a new standard. Parameters during the stationary phase of $\mathrm{NBI}$ $(\sim 3.5-4.0 \mathrm{~s})$ are $\mathrm{P}_{\mathrm{B}}=24.4 \mathrm{MW}, \mathrm{I}_{\mathrm{p}}=1.65 \mathrm{MA}, \mathrm{B}_{\mathrm{TF}}=4.76 \mathrm{~T}, \mathrm{R}_{0}=2.45 \mathrm{~m}, \mathrm{a}=0.8 \mathrm{~m}, \varphi_{\psi}(0)=0.9$. and $q_{\psi}(a)=5$. The cotal and thermal energy confinement times are $0.14 \mathrm{~s}$ and 0.08 s respectively. Components of the volume-integrated stored energies at $3.75 \mathrm{~s}$ are given in Table 1 . The definition of toroidal beta used in TRANSP is the pressure divided by $8 \pi\left\langle\mathrm{B}_{z}{ }^{2}>\right.$ where $<\ldots>$ is the volume average. and $B_{2}$ is the vacuum toroidal field. The value of $8 \pi<B_{2}{ }^{2}>$ is $9.28 \mathrm{MJ} / \mathrm{m}^{3}$. The volume averages of components of toroidal beta are listed in Table II. The peak value of $\beta_{\text {norm }} \equiv$ $\left\langle\beta_{\text {total }}>/ I_{p} / a B_{T F}\right.$ is 1.85 . The values of the central $Z_{\mathrm{eff}}$ decreases to $\approx 2.3$ during the NBI phase. The impurities consist of carbon and small traces of metals. The contribution to the central $Z_{\text {elf }}$ from metals is less than $=0.02$. The average charge of the impurities in this discharge is $\approx 6.05$. The total particle continement time is modeled to be approximately $0.07 \mathrm{~s}$.

\section{TRANSP}

The TRANSP piasma analysis code has many modes of operation. Although its main use is for modeling tokamak discharges using measured parameters, it also can be used in predictive modes. The modeling modes provide information on the consistency of measured parameters and calculate parameters which are difficult to measure directly. Examples of the latter are the profiles of the plasma currents, the fast ion (NBI and ICH) density and pressure, and the particle and energy transport. Minimal assumptions and few adjustable parameters can be used for the TRANSP modeling. Assumptions that are typically used for modeling TFTR supershots are that the $Z_{\text {elf }}$ protiles are tlat, that the parallel resistivity, the magnetic field diffusion, and the fast ion orbits are neoclassical, and that the heat convection multipliers for the ions and electrons are $3 / 2$. The measured time-dependent profiles of $n_{e}, T_{e}, T_{i m p}$ (the impurity temperature) and $v_{\phi}$ (the toroidal rotation) are used. In various predictive modes, transport coefficients can be assumed and consequences such as profiles of temperatures and currents can be calculated.

Recently the number of non-impurity thermal ion species that can be modeled in TRANSP has been increased from 3 to 5 . One impurity species can, and generally is modeled. Fast ion parameters can be calculated using either Monte Carlo or Fokker-Planck techniques. Most of the results discussed below are calculated with the Monte Carlo option, but some results from the Fokker-Planck option are discussed and compared. With the Monte Carlo option, ${ }^{6}$ three fast species (beam ions and/or fusion products) can be modeled. The fast ions are treated as thermalized when they slow down to the average energy of the local thermal ion population $\left(\frac{3}{2} \mathrm{~T}_{1}\right)$. With the Fokker-Planck option, ${ }^{7}$ only two species (beam ions) are modeled. This option, which was written by $G$. Hammett. uses a bounce-averaging technique. ${ }^{8}$ He recently improved 
the thermalization model to give a more realistic simulation. For this he rewrote the FokkerPlanck equation as

$$
\frac{d f}{d t}=S_{\text {fast }}+C_{i}(f)+C_{e}(f)-\frac{f}{\tau_{c x}}-S_{\text {orbit }}-\frac{f \text { Maxwell }}{\tau_{\text {therm }}} H\left(4 T_{i}-E\right)
$$

with $f$ the distribution of either of the beam ions (excluding the thermal contribution). $S_{f a s t}$ is the fast ion source rate, $C_{i}$ is the collision operator with thermal ions, and $C_{e}$ is the collision operator with electrons. $S_{\text {orbit }}$ is the loss of particles into unconfined orbits.

The thermalization time $\tau_{\text {therm }}$ is chosen to be as short as possible while maintaining $f$ positive everywhere. The Heaviside function $\mathrm{H}\left(4 \mathrm{~T}_{i}-\mathrm{E}\right)$ guarantees that the only particles thermalized are those with $E<4 T_{i}$ or less if the loss cone extends to an energy less than $4 T_{i}$. This later case is unlikely, but might happen in pathological cases near the edge. The inclusion of the Heaveside function is necessary since only the isotropic $f_{\text {Maxwell }}$ is subtracted from $f$ in each time step. At high energies the pitch angle-scattering rate is very low, which implies that it takes a long time 10 isotropize. Without the Heaveside function, $\tau_{\text {therm }}$ would be very long. Furthermore, at very high energies $f$ is distorted by loss-cones and by collisions with electrons (which causes $f$ to have a slope above the critical energy of $T_{e}$, not $T_{i}$ ), so blindly subtracting off $f_{M a x w e l l}$ with a $T_{i}$ slope would result in negative values for $f$ unless $\tau_{\text {therm }}$ were very large.

This thermalization method is superior to that used by the Monte Carlo option since instantly turning the fast ions to thermal at $\frac{3}{2} \mathrm{~T}_{i}$ ignores the fact that it takes an ion-ion collision to isotropize the ions. However, the Monte Carlo option does a better job of handling other physics details as the Fokker-Planck option has no reabsorption of charge-exchanged ions and uses a small banana width approximation for the fast ions.

The alpha particles distributions are simulated only with the Monte Carlo option. The alpha births are performed using spatially 2D fusion reaction rate data (beam-beam + beamtarget + thermonucleari computed in the preceding timestep. The alpha particles are launched isotropically in the (rotating) plasma trame with the appropriate birth energy $\left(E_{(}\right)=3.5 \mathrm{MeV}$ ). This had previously been incorrectly coded in TRANSP, resulting in too many alphas being launched with pitch angles $\lambda\left(\equiv v_{p a r} / v\right)$ near -1 or +1 . The main effects of this were that the predictions of central alpha densities and $\beta_{\alpha}$ were about $25 \%$ too high. This has been corrected in July, 1993.

Effects of Doppler broadening of the alpha distributions from beam-target interactions have" not yet been incorporated in TRANSP. The alpha orbits and slowing-down, and their heating of the thermal plasma are calculated using the same Monte Carlo methods amployed in modeling the fast ions from NBI. The model takes into account non-zero orbit width effects and Larmor radius effects, but magnetic field ripple effects are not included. 
Ripple effects appear to be insignificant for $R_{0}=2.45 \mathrm{~m}$ plasmas. They are estimated to be $<5 \% .9$ Less than $10 \%$ of the alpha particles are expected to escape from the plasma via prompt first-orbit loss if the plasma current is higher than $I_{p}=1.5 \mathrm{MA} .{ }^{10}$ Measured DD fusion product losses agree with first-orbit and ripple loss model predictions in many cases. 10,11 Anomalous diffusion of the fast ions can be modeled in TRANSP. The anomalous loss of beam ions is relatively small for plasmas with $R_{0}=2.45 \mathrm{~m}$ when the current is not small $\left(I_{p}>\right.$ IMA). ${ }^{12,13} \mathrm{It}$ is assumed to be zero here.

The TFTR inner and RF limiters are modeled in TRANSP as toroidally symmetric circles. Trapped alphas are considered as lost to the limiters if their orbit guiding centers either come within a Larmor radius of these limiters, or if the guiding centers extend past a flux surface located outside the last closed flux surface with the extrapolated value of the square root of the normalized toroidal flux, $x$ equal to 1.3. The actual flux surfaces outside the last closed flux surface are unkıown to TRANSP. so only approximate orbits are used in this region. For this reason the extrapolation is not extended beyond $x=1.3$. The actual outer (RF) limiter is beyond this surface for most plasmas, thus TRANSP slightly overestimates the alpha orbit loss.

The alpha particles slow down and pitch-angle scatter on thermal plasma species (electrons, ions, and impurities). Collisional coupling between fast ion species (e.g., beam-beam and beam - alpha particle collisional effects) is not computed. The accumulation of thermalized alpha particles can be modeled with TRANSP using the increased number of thermal ion species (using D, T, He4, and an impurity species).

\section{DD modeling}

The time evolutions of several parameters of the DD discharge are shown in Figs. 1. Waveforms are shown in Fig. 1-a. The total and calculated components of the currents are shown in Fig. 1-b, and the calculated peakedness of various profiles are shown in Fig. 1-c. Examples of several TRANSP symmetrized profiles versus major radius are shown in Fig. 2. Figure 2-a gives the temperature profiles. The temperature of the impurity ions is symmetrized from measured protiles of the carbon impurity. The temperature of the thermal $D$ is calculated from this impurity temperature. "ine TRANSP modeling for the DD discharge agrees well with measurements, so this DT simulation should be a good estimation of the DT parameters to be expected. Details of the discharge are given in Ref. 4.

The ideal MHD high-n stability has been analyzed by S. Sabbagh using the EQGRUM and STBAL codes. A plot of the pressure gradient and of the ballooning-unstable region is 
shown in Fig. 3. These are plotted versus the square root of the nomalized poloidal flux. This plot indicates that $p^{\prime}$ could increase $>30 \%$ before reaching the high-n stability limit. Higher performance supershots are computed to have $p^{\prime}$ very close to the unstable region. An example (for 55851 ) is shown in Ref. 1.

\section{DT Simulations}

TFTR has iwelve NBI sources, six aimed in the co direction and the outer six in the counter direction. $D$ or $T$ can be injected in any corrbination of these sources. For the DT simulations discussed here, the NBI is assumed to consist of 13MW D-NBI from 5 sources and 11.4MW T-NBI from another 5 sources. The injection of both the $D$ and $T$ are chosen to be nearly balanced (co versus counter). The voltages of the full energy components are chosen to be those of 66887, approximately $105 \mathrm{keV}$. The half and third energy fractions are chosen to be approximately those of 66887 also.

The neutron emissivity rates predicted by the Monte Carlo run are shown in Figs. 4-a. The thermonuclear fraction is $10 \%$ of the total. This fraction is predicted to be higher (up to $-30 \%$ ) for supershots with higher central densities. The simulation yields peak values of the

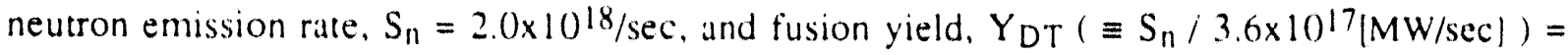
$5.6 \mathrm{MW}$. The normalized fusion yield is $\mathrm{QDT}\left(\equiv \mathrm{Y}_{\mathrm{DT}} / \mathrm{PB}_{\mathrm{B}}\right)=0.23$. The total and beam-target neutron emission rates predicted with the Fokker-Planck option, shown in Figs. 4-b, are 35\% higher. This option typically gives neutron rates that are $-10.21 \%$ higher than those from the Monte Carlo option.

The time evolutions of the alpha heating and the alpha power lost to the limiter are shown in Fig. 5. The limiter loss is computed to be $\sim 8 \%$ of the alphat heating rate. A cross section through the plasma showing tlux surfaces and the location of the limiters is given in Fig. 6-in. Surershots generally have flux surfaces that are approximately circular, with $x$ close in value to r/a. A ploc of $r / a$ versus $x$ is in Fig. $0-b$.

Profites of the scattering times and slowing down times for the fast particles at birth are shown in Fig 7. Protiles of the average energles of the fast ions are shown in Fig. 8. Profiles of the electron healing are shown in Fig. 9

The electron temperature will be effected by the alpha heating, by any intrinsic isotopic scaling differences between DD and DT, and by differences in the D and T NBI deposition and heating. Methods for separating these effects are discussed in Ret. [3]. For the simulations discussed here, the electron energy conductivity $\chi_{0}$ is assumed to be identical to that calculated 
for the DD discharge. This models the case where there is no intrinsic isotopic scaling differences between DD and DT, and where there is no change in confinement with the increase in heating due to the alpha particles. The intrinsic isotopic scaling from D to DT supershots is unknown. The energy transport in supershots is insensitive to changes in the NBI power, but it is not known if this will be the case with alpha heating.

The net effect of this assumption of identical $\chi_{e}$ for DD and DT on the central $T_{e}$ is that it is predicted to increase $-10 \%$ in DT. Profiles of the total pressure and electron temperature of the DD discharge and of the DT simulation are compared in Fig. 10. Figure 10-c shows that $p^{\prime}$ is expected to increase $20 \%$ in the inner third of the DT supershot relative to the DD supershot. This increase is due to the increased electron energy, beam energy, and the additional alpha pressure, listed in Table 1 . The simulation yields the volume averages of the beta coroidal components shown in Table II. The value of $\beta_{\text {norm }}$ is 1.99 .

The ideal MHD stability of the DD discharge and of the DT simulation has been analyzed by J. Manickam using the PEST package. Both are calculated to be unstable to an internal $\mathrm{m}=\mathrm{n}=1$ mode. Such a mode would be expected since the DD discharge exhibited fishbone activity during the steady state phase of NBI.

The peakedness of some of the DT profiles are shown in Fig. 11. The neutron production rates, the fast alpha distribution, and $\beta_{\alpha}$ are very peaked, relative 10 other profiles. TRANSP symmetrized profiles are shown in Figs. 12 for comparison with the DD calse shown in Fig. 2. The thermal $D$ and $T$ densities differ considerably due 10 the different recycling, which was assumed to be dominantly D. The profiles of components of $\beta_{\text {tor }}$ are shown in Fig. 13

Various parameters can be derived from the profiles calculated by TRANSP. The Alfven speed and frequency profiles are plotted in Figs. 14. They are detined as,

$$
\begin{aligned}
& v_{\text {Alfvén }}=\frac{B_{T F}}{\sqrt{4 \pi m_{H}\left(2 n_{D}+3 n_{T}+2.5 n_{b u a m}+4 n_{(L}+12 n_{1 m p)}\right)}} \\
& \omega_{\text {Allven }}=\frac{v_{\text {Alfvén }}}{2 q_{\psi} R}
\end{aligned}
$$

The trajectory in tume of $\left\langle\beta_{\alpha}\right\rangle$ versus the ratio valpha $(0) / v_{\text {Alfven }}(0)$ of the birth alpha speed to the Alfvén speed at $x=0$ is shown in Figs. 15. This ratio achieves its peak value during the stationary phase, and then rapidly decreases after the NBI as the density decreases. TAE modes are expected to be excited during this ramp-down phase. 1

Values of the thermal $\eta_{e}$ and $\eta_{10}$, are plotted in Figs. 16. They are defined as: 


$$
\begin{aligned}
& \eta_{e} \equiv \frac{d \ln T_{e} / d r}{d \ln n_{e} / d r} \\
& \eta_{i e} \equiv \frac{d \ln T_{i} / d r}{d \ln n_{e} / d r}
\end{aligned}
$$

\section{Distributions}

Both Monte Carlo and Fokker-Planck methods were used to generate the distribution functions.

$$
f \equiv \frac{d n}{d E d \lambda}
$$

of fast ions in the laboratory frame. The independent variables are $x$, pitch angle $\lambda$, and energy $E$. Plots of integrals of the distributions over $E$ or $\lambda$ from the Monte Carlo run are given in Figs. 17. 19.

Fits to the pitch angle distributions are shown in Figs. 20. The alpha distributions are peaked at pitch angles $\lambda=-1$ and +1 since the ions with $\lambda-0$ have larger excursions into regions of large $x$ with higher probability of being lost. The distributions are also skewed toward positive pitch angles, especially for alphas at large $x$. This is caused by preferential losses of counterstreaming ions. One consequence of this is that the profiles of the average rotation of fast ions are peaked with co-rotation at large $x$, as shown in Fig. 21. A simulation was pertormed with the total plasma current increased to 8MA to compare the $\lambda$ distributions. The alpha distributions for this extrapolation are much flatter due to smaller banana widths. Results are shown in Figs 22.

There is considerable notse in the distributions due to the Monte Carlo sampling. The noise was reduced by sampling $+(000$ beam ions and 4000 alpha particles. Also the sampling was averaged over a time range of $200 \mathrm{msec}$. The Fokker-Planck runs do not have sampling noise. Plots of integrals of the distributions over $E$ or $\lambda$ are given in Figs. 23-24. The $D$ and $T$ distributions are similar to those in Figs. 17-18, except in the low energy regions due 10 the different thermalization models used. Also they are smoother.

Plots for the pitch-angle integrated distributions and for the thermal Maxwellian distributions (fMaxwell $\sim \sqrt{\mathrm{E}} \exp \mid-\mathrm{E} / \mathrm{T}$ ) ) at the plasma center are shown in Figs 25. The Maxwellian components of the $D$ and $T$ distributions integrate to the central thermal densities, $2.0 \times 10^{19} / \mathrm{m}^{3}$ and $1.5 \times 10^{19} / \mathrm{m}^{3}$ respectively. Although the thermal alpha density was not modeled in the TRANSP runs discussed here, the alpha thermalization rate is predicted. The central alpha 
thermalization rate is very small $\left(<10^{17} / \mathrm{m}^{3} / \mathrm{sec}\right)$ up to $3.75 \mathrm{sec}$, and increases rapidly after that time. Profiles of the time integral of this rate are shown in Fig. 26. The time-integral of the central rate to $3.75 \mathrm{sec}$ is $6 \times 10^{15} / \mathrm{m}^{3}$. This value was used to normalize the Maxwellian distribution shown in Fig. 25-c. Corresponding results from the Fokker-Planck run are shown in Fig. 27. These distributions differ from those in Figs. 25-a and 25-b in the region of 20-40keV due to the different thermalization treatment.

Plots and fits to the pitch-angle integrated distributions at the plasma center, normalized as

$$
F \equiv \frac{f}{\sqrt{E}}
$$

are given in Figs. 28. In the approximation $T_{i} \sim 0$, the relatively flat middle region below the birth energy is predicted to decrease as

$$
F \sim\left|E^{\mid .5}+E_{\mathrm{crit}} 1.5\right|^{-1}
$$

with $E_{\text {crit }}=$ the critical energy. ${ }^{14}$ The values of $E_{c r i t}$ in steady state are predicted to be $\sim 20 T_{e}$ for $D$ beam ions and $40 \mathrm{~T}_{\mathrm{e}}$ for alphas (using $\ln \left(\Lambda_{\mathrm{e}}\right)=17$ and $\ln \left(\Lambda_{\mathrm{ion}}\right)=23$ ). The values for these in the center are 205 and $409 \mathrm{keV}$ respectively. The fits to the distributions yield the cutoff energies shown in Table III. These are lower than the values given above. The beam ion distributions are complicated by the high values of $T_{1}$ and by the presence of the half and third NBI energy components.

An effective temperature $T_{\text {eff }}$ can be deduced by fitting $\ln (F)$ above the creation energies, $E_{0}$. ${ }^{15}$ This temperature is a weighted average of $T_{1}$ and $T_{e}$, depending on $E_{\text {crit }}$. Plots and fits are shown in Figs. 29. Fit parameters are shown in Table III.

The distribution for the alphas evolves considerably during the discharge, even during the relatively stationary phase of the last $0.5 \mathrm{sec}$ of NBI. Early in the NBI the distribution versus energy is hollow, peaked near the birth energy. The fits for the central $\ln (F)$ versus energy at several times, $3.6 \mathrm{sec}$. just arter the start of the stationary phase, and $4 .()$ sec, just before the termination of the NBI are compared with the value at $3.75 \mathrm{sec}$ in Fig. 30. The distributions become more Maxwellian at late times. 


\section{Fits to profiles}

Values of parameters and fits are given below for use in codes to calculate effects such as the MriD stability, and TAE and KBM modes. Figures 31 give various profiles versus $x$. Examples of fits are given in the plots. Some of the profiles are fitted well by a sum of a Gaussian and a power of $\left(1-x^{2}\right)$. A summary of simple fits to the cenural values $(x<0.5)$ of several of the profiles using either a Gaussian or a power of $\left(1-x^{2}\right)$ are given in the Table IV.

Many plasma analysis codes use the normalized poloidal flux $P$ or the square root of the normalized poloidal flux as the independent spacial variable. Figure 6 -b shows the relation of $P, \vec{P}$. and $r / a$ to $x$. Figures 32 give selected parameters versus $P$. These fits are being used in NOV.A.K calculations.

Profile values are given in Appendices I and II. In TRANSP, some parameters are computed on zone centers and some are computed on zone boundaries. For simplicity, all the values in Figs. $31-32$ and in the Appendices are given at zone centers.

\section{Summary}

TRANSP results for simulations of a TFTR DT supershot are given. They are based on a DD supershot which was chosen since it is reproducible, has a high neutron vield, a long duration of stationary conditions, and appears to have a sufficient margin of stability to accommodate the increased pressure expected in DT. The simulation yields peak values of $\beta_{\text {norm }}$ $=1.99$, fusion yield, $Y_{D T}=5.6 \mathrm{MW}$, and normalized fusion yield QDT $=0.23$. The alpha loss 10 limiters is predicted to be small $(<8 \%)$.

Parameters and fits are given during the relatively stationary phase. Monte Carlo and Fokker-Planck options are used for calculating beam ion parameters and the Monte Carlo option is used for calculating fast alpha parameters. The Monte Carlo option has a more complete model of the physies, except for the thermalization, and generally gives lower fuston rates. Distributions versus position, energy and pltch angle are given. The $D$ and $T$ beam ion distributions are relatively constant during the steady-state phase of the discharge. The alpha distributions evolve during this phase since the slowing down times are long. The alpha distributions in pitch angle are peaked at forward and backward pitch angles. 


\section{Acknowledgments}

I wish to thank C. Z. Cheng, G. Hammett, S. Kishore, D. McCune, D. Mikkelsen, S. Sabbagh, and S. Zweben for helpful comments, and M. G. Bell, C. Bush, K. Hill, D. Jassby, L. Johnson, H. Park, D. Mansfield, A. Ramsey, G. Taylor, J. Schivel, and E. Synakowski for measurements. This work was supported by the U. S. Department of Energy Contract No. DEAC02-76-CHO-3073. 


\section{Tables}

Table I - Components of the stored energy for the DD and DT supershot

\begin{tabular}{|l|l|l|}
\hline & $D D(66887 \mathrm{~A} 08)$ & $D T(66887 \mathrm{Pl0})$ \\
\hline$U_{\text {total }}$ & $3.42 \mathrm{MJ}$ & $3.69 \mathrm{MJ}$ \\
\hline$U_{\text {prp }}$ & $0.70 \mathrm{MJ}$ & $0.80 \mathrm{MJ}$ \\
\hline$U_{\text {parr }}$ & $0.91 \mathrm{MJ}$ & $1.08 \mathrm{MJ}$ \\
\hline$U_{\mathrm{e}}$ & $0.91 \mathrm{MJ}$ & $0.93 \mathrm{MJ}$ \\
\hline$U_{\text {ion }}$ & $0.89 \mathrm{MJ}$ & $0.88 \mathrm{MJ}$ \\
\hline
\end{tabular}

Table II - Components of volume averaged beta for the DD and DT supershot

\begin{tabular}{|l|l|l|}
\hline & $D D(66887 \mathrm{~A} 08)$ & $\mathrm{DT}(66887 \mathrm{P} 10)$ \\
\hline$\left\langle\beta_{\text {total }}\right\rangle$ & $0.783 \%$ & $0.842 \%$ \\
\hline$\left\langle\beta_{\text {beam }}\right\rangle$ & $0.370 \%$ & $0.395 \%$ \\
\hline$\left\langle\beta_{\mathrm{e}}\right\rangle$ & $0.208 \%$ & $0.213 \%$ \\
\hline$\left\langle\beta_{\text {ion }}\right\rangle$ & $0.205 \%$ & $0.202 \%$ \\
\hline$\left\langle\beta_{\alpha}\right\rangle$ & 0 & $0.034 \%$ \\
\hline
\end{tabular}

Table III - Fits to the fast ion distributions

\begin{tabular}{|l|l|l|l|}
\hline fast ion & fit to $F$ & fit to $\ln (F), E<E_{0}$ & fit to $\ln (F), E>E_{0}$ \\
\hline & $E_{\text {crit }}(\mathrm{keV})$ & $T_{\text {eff }}(\mathrm{keV})$ & $T_{\text {eff }}(\mathrm{keV})$ \\
\hline $\mathrm{D}$ & 71 & 90 & 14 \\
\hline T & 10() & 110 & 12 \\
\hline alpha & 750 & 1300 & 65 \\
\hline
\end{tabular}


Table IV - Simple fits to central values of selected parameters

\begin{tabular}{|l|l|l|l|l|}
\hline \multicolumn{1}{|c|}{ Parameter } & \multicolumn{2}{c|}{$\begin{array}{c}\text { Gaussian fit } \\
\mathrm{a}^{*} \exp \left\{-(\mathrm{x} / \mathrm{b})^{2}\right\}\end{array}$} & \multicolumn{2}{c|}{$\begin{array}{c}\text { Power fit } \\
\mathrm{a}^{*}\left(1-\mathrm{x}^{2}\right)^{\mathrm{b}}\end{array}$} \\
\hline & $\mathrm{a}$ & $\mathrm{b}$ & $\mathrm{a}$ & $\mathrm{b}$ \\
\hline$\beta$ & 0.040 & 0.41 & 0.040 & 5.6 \\
\hline$\beta_{\alpha}$ & 0.0026 & 0.33 & 0.0025 & 8.3 \\
\hline$n_{\alpha}$ & $1.8 \times 10^{17} / \mathrm{m}^{3}$ & 0.36 & $1.8 \times 10^{17} / \mathrm{m}^{3}$ & 7.3 \\
\hline
\end{tabular}




\section{References}

[1] R. Budny, M. G. Bell, H. Biglari, et al., Nucl. Fusion 29 (1992) 429.

(2) C. Z. Cheng, Phys. Fluids B, 1991. C. Z. Cheng, et al., LAEA conference, Wurzburg, Germany (1992).

See also Fourth Workshop on TFTR alpha physics, PPPL February 1993.

(3) TFTR DT-XP-9

[4] R. Budny, et al., "Long Duration High Performance Supershors", in preparation.

[5] R. Budny, M. G. Bell, J. D. Strachan, et al., July, 1993 EPS, Lisbon.

[6] R. Goldston, R. J. McCune, D. C. Towner, et al., J. Comput. Phys, 43 (1981) 61.

171 J. D. Strachan, P. L. Colestock, S. L. Davis, et al., Nuclear Fusion 21 (1981) 67.

[8] G. W. Hammett, "Fast lon Studies of Ion Cyclotron Heating in the PLT Tokamak," Ph. D. Dissertation Princeton, 1986, (University Microfilms No. GAX86-12694).

19] R. Boivin, et al., Nuclear Fusion 33 (1993), 449.

[10] S. J. Zweben, et al., IAEA conference, Wurzburg, Germany (1992).

(11) S. J. Zweben, et al., Nucl. Fusion. (1990).

[12] W. Heidebrink, G. Sadler, et al, submitted to Nucl. Fusion.

(13) S. J. McCaulley, R. V. Budny, D. McCune and J. D. Strachan, PPPL repon

114] D. Jassby, Nucl. Fusion 17, 309 (1977).

115] C. L. Fiore, S. S. Medley, G. W. Hammett, et al., Nucl. Fusion 28, 1315 (1988). 


\section{Figure Captions}

Fig. 1 a) Waveforms of 66887 for the applied NBI power, chordal density, density peakedness, major radius, current, $q_{\psi}(a)$, total and perpendicular stored energy, and total neutron emission; b) the ohmic, bootstrap, and beam-driven components of the plasma current computed with TRANSP, c) peakedness of various profiles computed with TRANSP.

Fig. 2 TRANSP symmetrized profiles versus major radius of a) $T_{e}$ measured from electron cyclotron emission, $T_{1 \text { mp }}$ measured from charge-exchange recombination spectroscopy, and TD corrected for impurity -hydrogenic differences, b) $n_{e}$ measured by interferometry, and $\mathrm{nD}_{\mathrm{D}} \mathrm{n}_{\text {bcam }}$, and $\mathrm{n}_{\text {imp calculated by TRANSP. }}$

Fig. 3 Gradient of the total pressure computed by TRANSP and the instability region for ideal MHD high- $n$ ballooning instability.

Fig. 4 Time evolutions of the total neutron emissivity and its components from beam thermal, beam-beam and thermonuclear DT fusions predicted by the a) Monte Carlo, and b) Fokker-Planck options.

Fig. 5 Time evolutions of the alpha heating powers to electrons and ions, and the loss of alpha power to the limiters or by excursion past $x=1.3$.

Fig. 6 a) Toroidal slice through TFTR showing the circle which is the approximate location of the limiters and the MHD equilibrium flux surfaces calculated by TRANSP and parameterized by the square-root of normalized toroidal flux $x=0.2,0.4,0.6,0.8,1$ (the last closed flux surface), and 1.3, which is used as the cutoff for alpha orbits; b) profile of $r / a$, the normalized poloidal flux $P$, and the square-root of $P$ versus $x$.

Fig. 7 Profiles versus the square-root of the normalized coroidal flux parameter $x$ of the fast ion a) slowing down, and b) scattering times at their birth energies.

Fig. 8 Profiles of the average energies of the fast a) $D$ beam ions, b) $T$ beam ions, and $c$ ) alpha particles versus $x$. Profiles at several times are shown. The fast $D$ and $T$ ion profiles are relatively constant compared with those of the alphas.

Fig. 9 Stacked profiles of the electron heating from beam ions, ion-electron coupling, and alpha heating.

Fig.10 Comparison of the DD and equivalent DT profiles of $T_{e}$, total pressure, and the gradient of the total pressure versus $x$.

Fig. 11 Peakedness of various profiles including the DT neutron emission, the fast alphas, $\beta_{\alpha}$, and the total pressure.

Fig. 12 Profiles versus major radius of a) temperatures, and bi densities

Fig.13 Profiles of $\beta_{\text {toroidal }}$ and the alpha component $\beta_{\alpha}$.

Fig. 14 Profiles of the Alfven speed and frequency. 
Fig. 15 The trajectory of $\left\langle\beta_{\alpha}\right\rangle$ versus the ratio $v_{\alpha}(0) / v_{\text {Alfvern }}(0)$.

Fig. 16 Profiles of $\eta_{e}$ and $\eta_{i e .}$

Fig.17 Integrals over a-b) pitch angie, and c-d) energy of the fast $D$ beam ion distribution computed with the Monte Carlo option.

Fig. 18 Integrals over $a-b$ ) pitch angle, and $c$-d) of the fast $T$ beam ion distribution computed with the Monte Carlo option.

Fig.19 Integrals over a-b) pitch angle, and c-d) of the fast alpha distribution computed with the Monte Carlo option.

Fig.20 Fits to the distributions in pitch angle (integrated over E). from the Monte Carlo run of the fast a) $D$ beam ions, b) $T$ beam ions, and c) alpha particles.

Fig. 21 Profiles of the fast ion toroidal rotations.

Fig.22 Integrals of the distribution functions computed with the Monte Carlo option of the fast alpha particles in the hypothetical case of $I_{p}=8 \mathrm{MA}$.

Fig.23 Integrals over $a$-b) pitch angle, and $c$-d) energy of the fast $D$ beam ion distribution computed with the Fokker-Planck option.

Fig.24 Integrals over $a-b)$ pitch angle, and $c$-d) energy of the fast $T$ beam ion distribution computed with the Fokker-Planck option.

Fig.25 Integrals over pitch angle of the central distribution $f$, the thermal distribution fMaxwell, and their sum versus $E$ from the Monte Carlo run of the fast a) $D$ ions, b) $T$ ions, and $c$ )

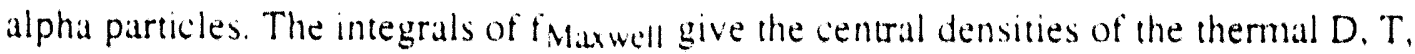
and of the alpha ash estimated from the alpha thermalization rate.

Fig.26 Profiles of the time-integrated alpha thermalization rate.

Fig.27 Integral over pitch angle of the central distribution $f$, the thermal distribution fMaxwell, and their sum versus $E$ from the Fokker Planck run of the fast a) $D$ ions, and b) $T$ ions.

Fig. 28 Profiles and fits to $F \equiv f / \sqrt{E}$ at $x=()$ from the Monte Carlo run of the fast a) $D$ beam ions, b) T beam ions, and c) alpha particles.

Fig 29 Profiles and fies $10 \ln (1 / \sqrt{E})$ an $x=0$ from the Monte Carlo run of the fast a) $D$ beam ions, b) T beam ions, and c) alpha particles.

Fig.3() Comparisons of In $(i / v \vec{E}$ ) for alpha particles al $x=()$ for different umes.

Fig 31 Protiles and tits of selected parameters versus $x$

Fig 32 Protiles and hits of selected parameters versus the nomalized polondal thux. 


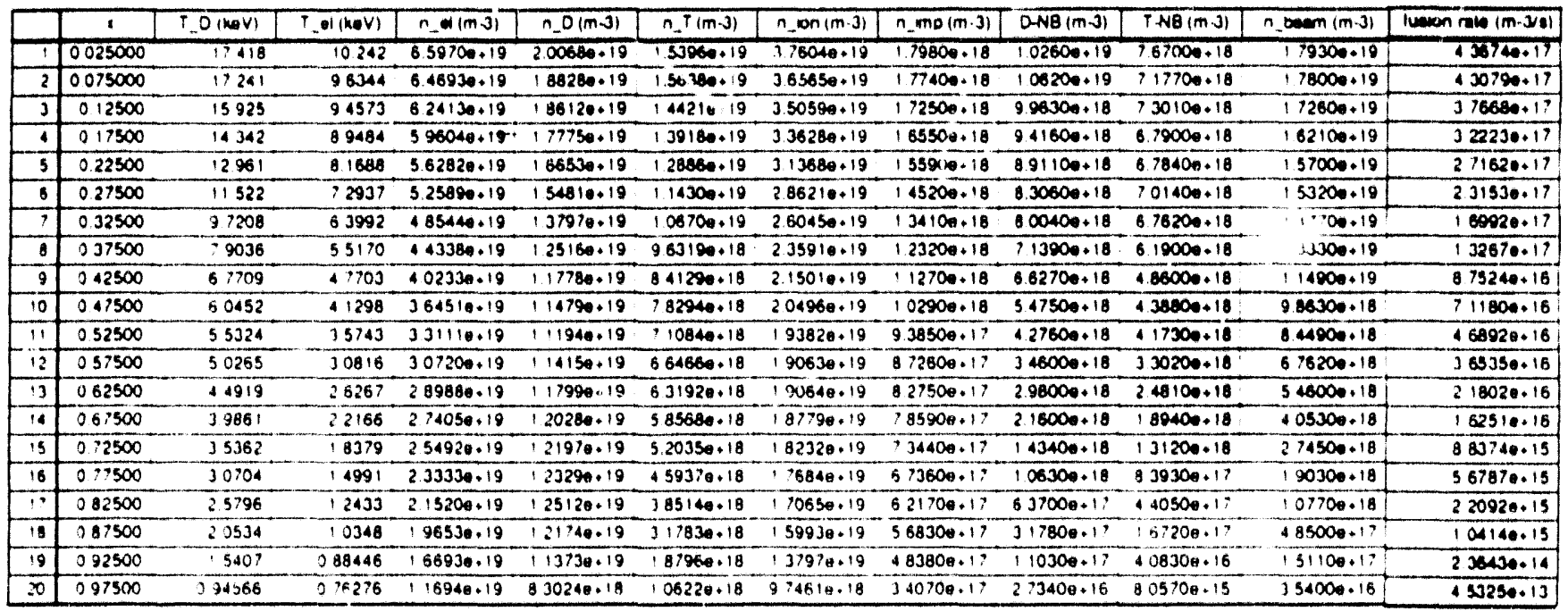

\begin{tabular}{|c|c|c|c|c|c|c|c|c|c|c|c|c|}
\hline & n_alona im 3 ! & 9 & $101(\mathrm{M} / \mathrm{m} 2)$ & B, $001(W)$ & Dota alona & beta $10 t$ & $P_{1} 10 t|\mathrm{~Pa}|$ & $P, n\left|P_{a}\right|$ & $P_{\text {. boum }}\left|P_{\mathbf{a}}\right|$ & tia & $P$ (nom dol fun) & $0 \times 0.5$ \\
\hline 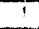 & $65500+1 ?$ & 0.86065 & 31330 & 0.083141 & 00026070 & 0040859 & 394820.05 & $213780+05$ & $181040+05$ & 0051619 & 6.358028 & $00761: 6$ \\
\hline 2 & $33400+1$ & 09097 & 29068 & 0.15737 & 00024350 & 0039583 & 386640.05 & $200746+05$ & 185900.05 & 010326 & 0022585 & 015028 \\
\hline 1 & $34200+17$ & 09342 & 28921 & 0.30893 & 00020010 & 0032765 & $31898 \theta \cdot 05$ & $1.62746+05$ & 156240.05 & 020639 & 0087242 & 029537 \\
\hline 5 & 112900.17 & 096276 & 27283 & 037703 & 00016650 & 0028863 & $280630+05$ & $138880+05$ & $: 11750.05$ & 925772 & 0.13440 & 036661 \\
\hline 6 & $9+4300 \cdot 16$ & .0245 & 23503 & 042812 & 00013420 & 0025148 & $244970+05$ & 114200.05 & $30760+05$ & 030892 & 018949 & $0 \$ 3530$ \\
\hline$\therefore$ & $\div 6800 \cdot 15$ & .1019 & 20772 & 046865 & 000098740 & 0020901 & 203780.05 & 90497 & 113290005 & 0.36001 & 025025 & 050025 \\
\hline 9 & $19500+16$ & 3377 & $\$ 110$ & 050702 & 000051050 & 0014008 & $15899 \theta+05$ & 54091 & 81797 & 246163 & 238157 & $0.1 \%$ \\
\hline 10 & $129,00+16$ & $484^{\circ}$ & 1668 & 051431 & 000035670 & 2011313 & j984e.05 & $4190 \%$ & 55931 & 05120 & 244866 & 066982 \\
\hline$\because 1$ & $23200 \mathrm{H} \cdot 16$ & .5502 & 099049 & 551680 & $0000244: 0$ & $20090: 81$ & 9740 ? & 36194 & 51213 & 056220 & 351535 & $0 \because 8 B$ \\
\hline 12 & $53000 \cdot 16$ & 9509 & 0.75409 & 051131 & 200015280 & 2007190 & 5914 & $305: 9$ & 38596 & 251200 & 558089 & $0752: 5$ \\
\hline 13 & .05700 .15 & 20935 & 254608 & 049926 & 200010180 & 1005606 & $55: 29$ & 25917 & 29262 & 356158 & 64412 & 080250 \\
\hline is & $593600 \cdot 15$ & $2363:$ & $2 \sqrt{65} 52$ & 248678 & 53630005 & 0045560 & 44052 & 2175 & 33346 & 1095 & 0.0502 & 083960 \\
\hline-15 & $39180 e \cdot 15$ & 25694 & 239996 & 04737 & +2210005 & $10036: 10$ & $34: 5 ?$ & 10.5 & 15332 & 95996 & 2,6256 & 087325 \\
\hline 16 & 220000.15 & 30393 & 026660 & 045689 & $253: 00$ os & 00025235 & 23933 & 1323 & 9095 & 380865 & 081680 & $0903^{\circ}$ \\
\hline 3 & $50904+4$ & 39373 & 0.6442 & 242348 & 89410000 & $200: 465$ & 084 & 95313 & 23435 & 2705 & 991498 & 295654 \\
\hline 9 & $200+14$ & +475 & $015: 22$ & 040805 & $5 B 020006$ & $200.20 B O$ & $5: 5^{\circ} 4$ & $5 \% 9$. & 98630 & 95279 & 295901 & 099929 \\
\hline$\infty$ & $50+4)=1$ & 50479 & 0.3925 & 239520 & $\$ 00600106$ & $2003312^{\circ}$ & $31: 3$ & 2904 & $204+5$ & 10000 & 2000 & 1000 \\
\hline
\end{tabular}




\begin{tabular}{|c|c|c|c|c|c|c|c|c|c|c|c|c|}
\hline & 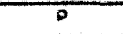 & Y.OWv & Tol(nev) & $n \_1(\operatorname{mon} 3)$ & $n .0(1 / m)$ & $n_{\sim}(i m 3)$ & $n m p(/ m) !$ & $n . \operatorname{lon}(1 \mathrm{~m}) 1$ & n b m $1 / m j$ & n ulne $(/ \mathrm{ms})$ & $a$ & is $($ Wumz \\
\hline & 000014460 & 7418 & 10242 & 659700.19 & 20060019 & $153060 \cdot 19$ & 214000018 & $376040+19$ & 172060.18 & $165600+17$ & 086013 & $3 \longdiv { 3 3 0 }$ \\
\hline 2 & 0014210 & 17241 & 96344 & 646030.19 & 188280.19 & 156380.19 & $200000 \cdot 18$ & $365650 \cdot 19$ & $171700+19$ & $153260+1\}$ & 090977 & 2006 \\
\hline 3 & 0036200 & 15925 & 94573 & $624130+19$ & $186120+19$ & $144210+19$ & 202859.16 & $350590 \cdot 19$ & 168210019 & $145640,1 ?$ & 092553 & $28 B 12$ \\
\hline 1 & 006499 & 14342 & 094 & 590040.19 & $17790+19$ & $139180+19$ & $193500+10$ & $336280+19$ & $15930 \cdot \cdot 19$ & $130000+1:$ & 093427 & 28921 \\
\hline 5 & 0.1085 & 12961 & 1680 & $362820 \cdot 18$ & $163530+19$ & $128860+19$ & 182880.18 & 313680.19 & 154500.19 & 112030.17 & 036276 & 29283 \\
\hline 5 & 018203 & 11322 & 12937 & $5.25090 \cdot 19$ & $154810+19$ & $114300+10$ & $170040+18$ & $286210+10$ & 151410.19 & $9+2520+16$ & 10245 & $: 1503$ \\
\hline$\therefore$ & $02200 \%$ & 97200 & 61992 & $6454 n+19$ & $137970+19$ & $10670 n+19$ & $1576 / 0.18$ & 260450.19 & 143100.10 & 117320.16 & 1019 & 2002 \\
\hline A & 0.2828 & 9036 & 39170 & $443380+19$ & $125160 \cdot 19$ & 963190.18 & 14280.18 & $235910+19$ & 133460.19 & 302310.16 & 12125 & $65 \%$ \\
\hline 10 & $0+1530$ & 50452 & 41298 & $364510+19$ & 1.1990 .19 & 182940.18 & 118740.18 & 20496019 & 900130.10 & $32000+16$ & 14647 & 668 \\
\hline $1 !$ & 048232 & 55324 & 3574.3 & 331110.19 & $=1194 *+19$ & $=10840 \cdot 18$ & 107910,18 & $193820+19$ & $82430 m+10$ & $2.32000+16$ & 10502 & 900049 \\
\hline 2 & 254855 & 50265 & 10816 & $307200+19$ & $14150+19$ & $664 b 6 a+14$ & $100150+18$ & 130630.19 & $\$ 57670.10$ & $1.53540+16$ & 18509 & $2 \times 409$ \\
\hline 3 & 361301 & 44919 & 25267 & $289860+19$ & 11900.19 & $631920 \cdot 18$ & $34529+1$ & 100040.19 & $513590+10$ & 100720.16 & 20935 & ISABOA \\
\hline 4 & 267493 & $398 B$ & 22166 & 270050.19 & $1.0280+19$ & $5856 B 0,18$ & Q9385a+1: & 18790.19 & 110420.10 & 803400,15 & 23637 & 4525 \\
\hline 5 & $0+3097$ & 15362 & 18379 & $254920 \cdot 19$ & 21970.19 & 320350.18 & 931500.1 ? & 182320.19 & $305700+18$ & $300010+15$ & 25694 & 039896 \\
\hline 16 & 078989 & 30704 & 14991 & $233330+19$ & $2329 a+19$ & $4593 / 6+18$ & $961260+1$ & 1 BSA40+19 & $180400+18$ & 219640.15 & 10393 & 226660 \\
\hline 10 & 004241 & $25: 96$ & 2433 & 215200.19 & $25120+19$ & $385140+18$ &, 02140.11 & 1.0650 .19 & $90013 n \cdot: 1$ & 111030.15 & 14575 & 02029 \\
\hline 9 & $293 / 0_{9}$ & 15407 & 308446 & $166936+19$ & $13 / 3 \theta \cdot 19$ & 181968.18 & \$41/10n+1? & 137970.19 & $111 B B_{+}+1$ & $35899 \theta+14$ & 141.5 & 7922 \\
\hline 0 & 297954 & 294566 & 2,6275 & $\because 16944.19$ & $\$ 10240.18$ & $10622 \theta \cdot 1 \theta$ & 381564.15 & TAS10.18 & $29900 \cdot 16$ & $196920 \cdot 14$ & $504 \%$ & 0139.6 \\
\hline
\end{tabular}

\begin{tabular}{|c|c|c|c|c|c|c|c|c|c|c|c|}
\hline & $\$ 001: W$ & buta alches & Dola 101 & $P_{1} \mid 0 t_{i} P_{n !}$ & $p \operatorname{lo}\left|P_{4}\right|$ & $P_{\text {buam }} \mid P_{a_{1}}$ & Altwen hoq (1) & Altren vel imis! & $1+1.41$ & 010 & $+\infty$ \\
\hline & 200314 & 00026083 & 0040859 & 394620.05 & $21378+05$ & 19104005 & 749740.05 & $74950+9$ & 0025000 & $3 \longdiv { 2 5 6 }$ & $0 \$ 1320$ \\
\hline 3 & 015737 & 00024350 & 0039543 & $386640 \times 05$ & $200746+05$ & $185000 \cdot 05$ & $1 \times 3210+06$ & $=80990.10$ & 0015000 & 051725 & 2001 \\
\hline 3 & 023260 & 00022485 & 0036546 & 355220,03 & 104154005 & 17029.05 & 131350006 & .11000 .0 & 012500 & 12013 & 23000 \\
\hline+ & 230893 & 00020001 & 0032365 & 318960005 & $62740 \mathrm{ws}$ & $156240+05$ & $335780 \cdot 06$ & $9157 \times 10$ & 01500 & SABA & 2235 \\
\hline 5 & 23703 & 00016644 & 0028863 & 250530.105 & - Juabea ws & 141.50 .05 & 1412640.06 & $04328 A \cdot 10$ & 122500 & 16682 & 127 \\
\hline$\Rightarrow$ & 242012 & $000+3410$ & 0025148 & 244970005 & $=14200005$ & - $1096+0.05$ & 139806.06 & $025920 \cdot 10$ & $02: 500$ & 6335 & $\therefore 355$ \\
\hline 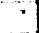 & 46865 & 00098832 & 002000 & $20570=05$ & $\infty 049$ : & $110 e^{294} \cdot 05$ & 13319006 & $2005=10$ & 032500 & 16348 & 2? 39 \\
\hline 1 & 24911 & $9000 ? 231 ?$ & 2016045 & 548440.05 & 59084 & $35:-6$ & $3200050.0 \%$ & $701: 50 \cdot 10$ & 31500 & 1953 & 5917 \\
\hline 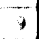 & 5090 & 200051141 & 0014008 & 35890.05 & 54091 & 919 & $110000+000$ & $19160 \mathrm{~m}+1$ & 42500 & 1504 & 1546 \\
\hline 0 & 35143 & $35001569^{\circ}$ & 5014313 & ToHAe ous & 4190 ? & $5593:$ & 301990.06 & $131360+1:$ & $34 / 500$ & 5017 & 21192 \\
\hline$\because$ & 51580 & 900024416 & $00090:$ : & $910^{\circ}$ & 16194 & 5121 & 20020,16 & 139001 & 352500 & $1.3 y$ & $\therefore 32^{2}$ \\
\hline$\therefore$ & $65: 3$ & $3000+52+0$ & $300 \cdot 79 n$ & $5914^{\circ}$ & $105 \%$ & $145 \%$ & Z GetHenh & 1 that & $\therefore \sin 0$ & $\therefore 47$ & 1301 \\
\hline ' & $4992 \%$ & 30009 & $3005,80 n^{\circ}$ & $55 \%$ & 2519 & $2+5 x$ & $\because 5 A=\ldots+10$ & $34 b 24+\cdots$ & 160500 & lolin: & $\therefore 1$ \\
\hline+ & 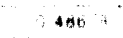 & 53200 & $30+550$ & 4tho. & $\therefore+13$ & $204 n$ & 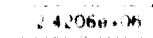 & 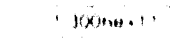 & 36.500 & $\therefore 5 \mathrm{H}:$ & $34 \%$ \\
\hline 5 & 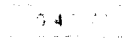 & $+2 \cdots+4$ & anols:ll & 145 & -925 & $\left.\left\{x_{i}\right)\right\}$ & . $395500+14$ & $\therefore b_{6}+$ & $\because 320$ & $\therefore h^{\circ}$ & $S A$ \\
\hline$\Rightarrow$ & 45004 & $\therefore 515: 40$ & 10025,36 & and & $+1,1$ & Wo: & $\therefore$ th:ans & $4630 \mathrm{~m}+$ & $\cdots_{*}, \cdots$ & $\therefore 30 ?$ & $=554$ \\
\hline$\because$ & 44034 & $(10 \mathrm{BBH}) \mathrm{s}$ & 2001 ins & 10264 & $\because 356$. & +11. & $20970, \ldots$ & $559 \div 0.1$ & 42,500 & $2 M$ & $\therefore 511$ \\
\hline 1 & 42148 & Tharees & 90011465 & $138 \cdot 5$ & B5) 3 & 341 & $\because \forall B$ H. h & HOAAH. & 3.500 & 296.4 & 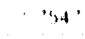 \\
\hline 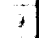 & ACH & 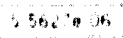 & Do 200 & $n \cdot 4$ & $5: 31 ;$ & and 30 & $\therefore 25$ bow & dbe ' 4.1 & 73500 & +148 & 351 \\
\hline$\therefore$ & $3+20$ & $1.12 \% \pi$ & $000132^{\circ}$ & 111 & $M$ & 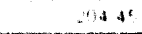 & 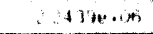 & $\therefore 45,00$, & 1500 & $26_{2}: 35$ & 1.10 \\
\hline
\end{tabular}


Fia. i-a
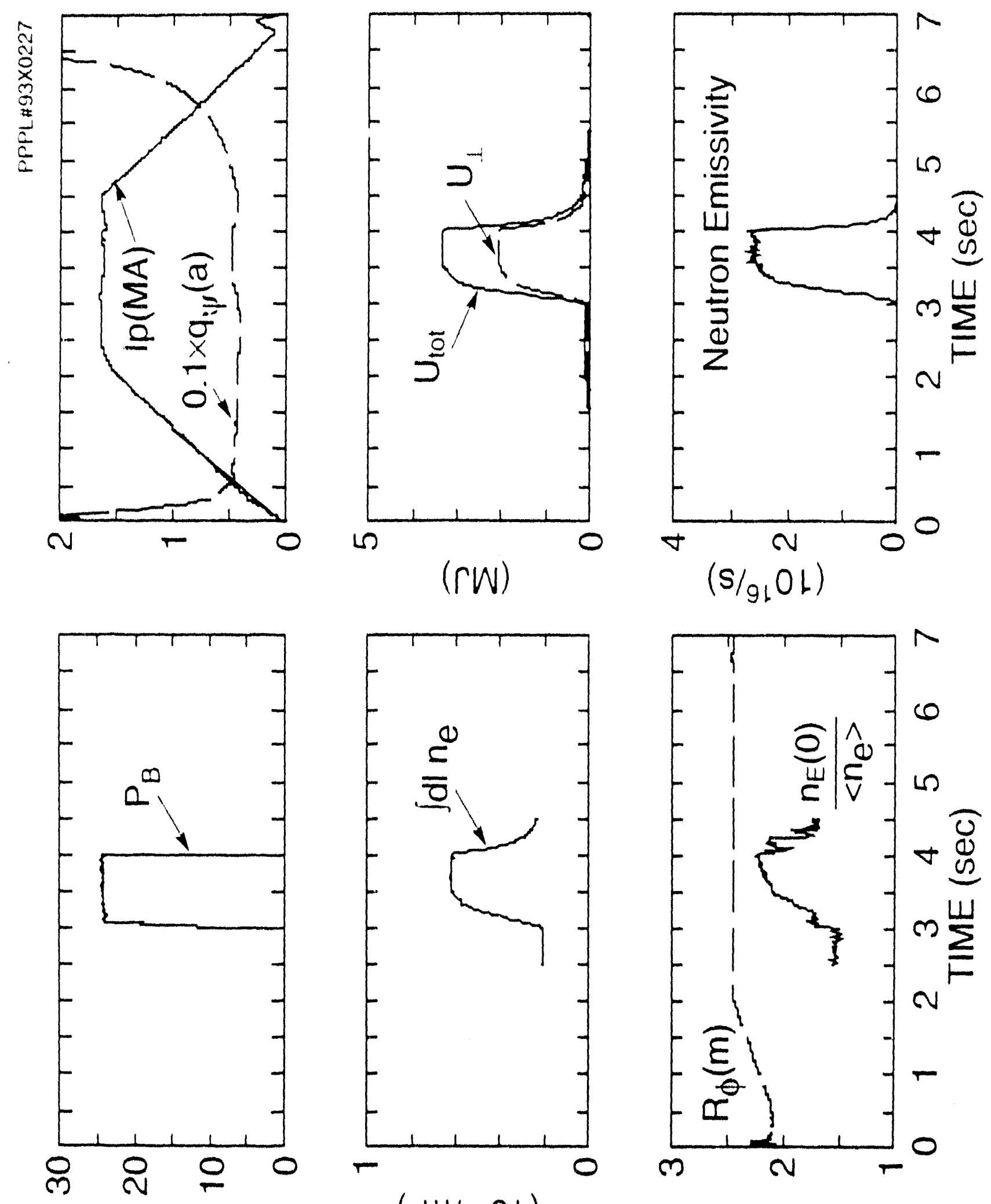

(MW)
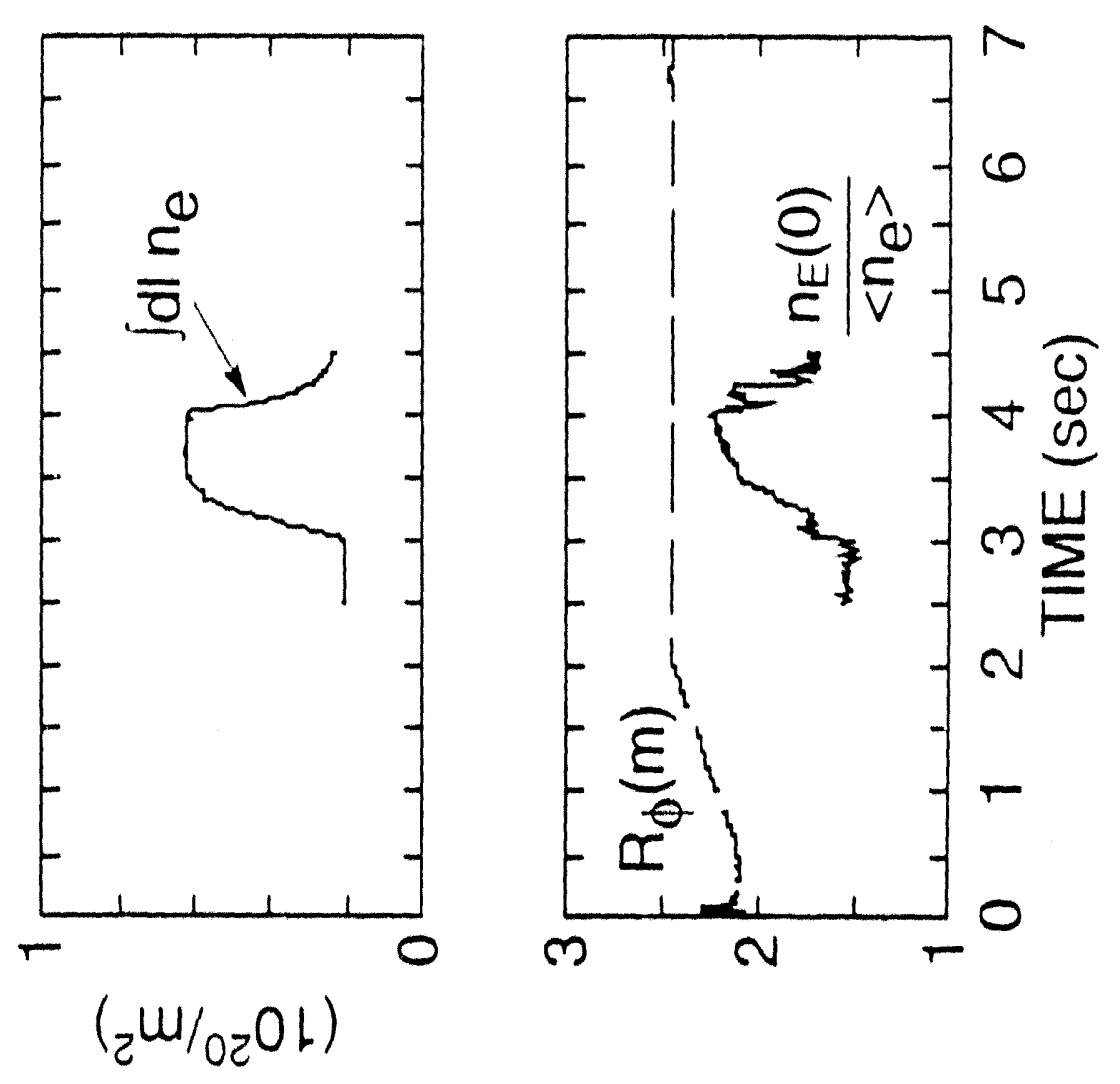


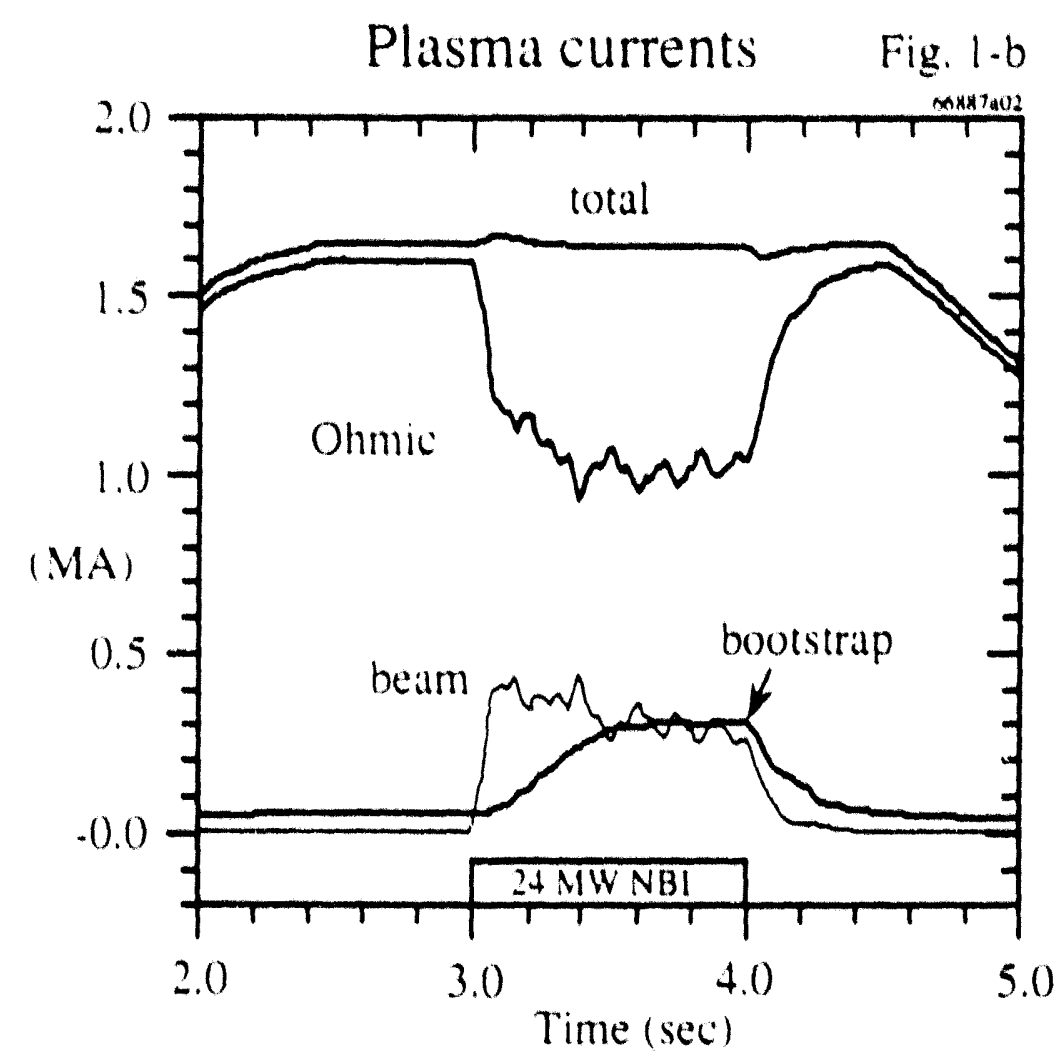

Profile peakedness Fig. 1-c

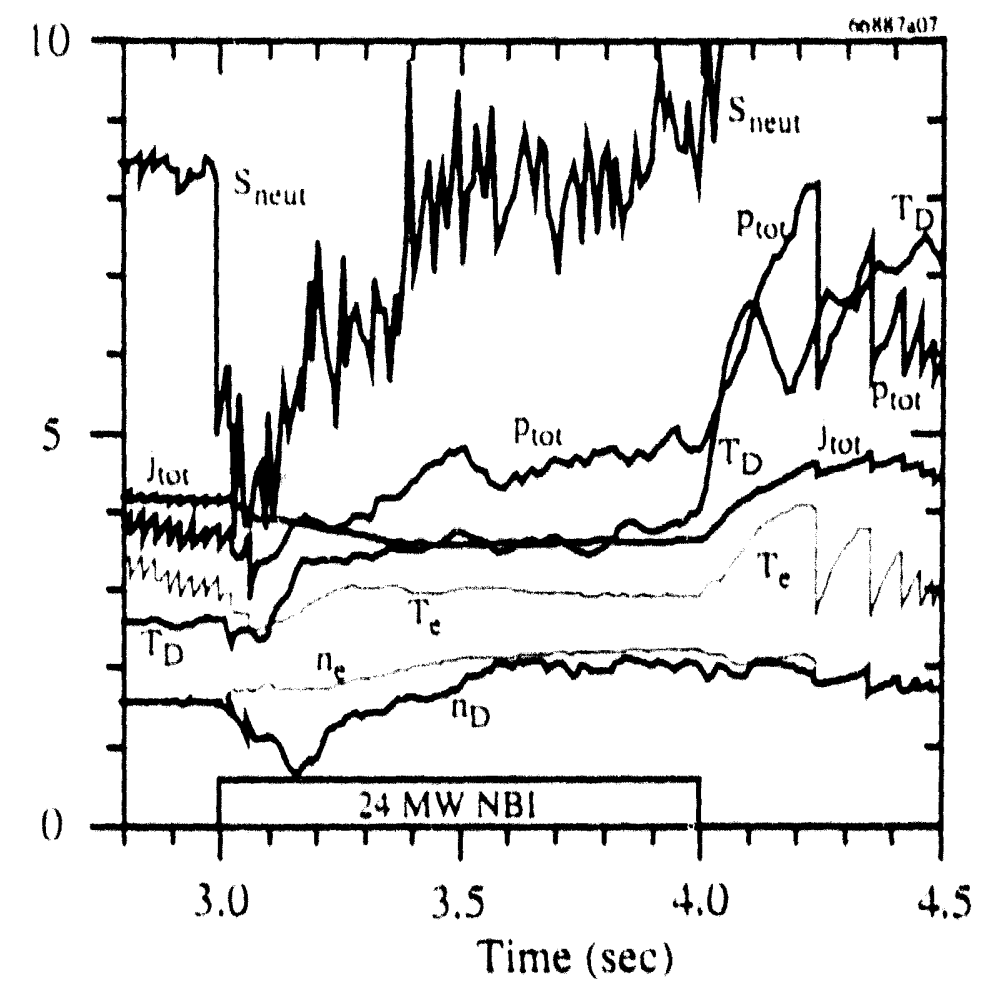


Temperature profiles Fig. 2-a
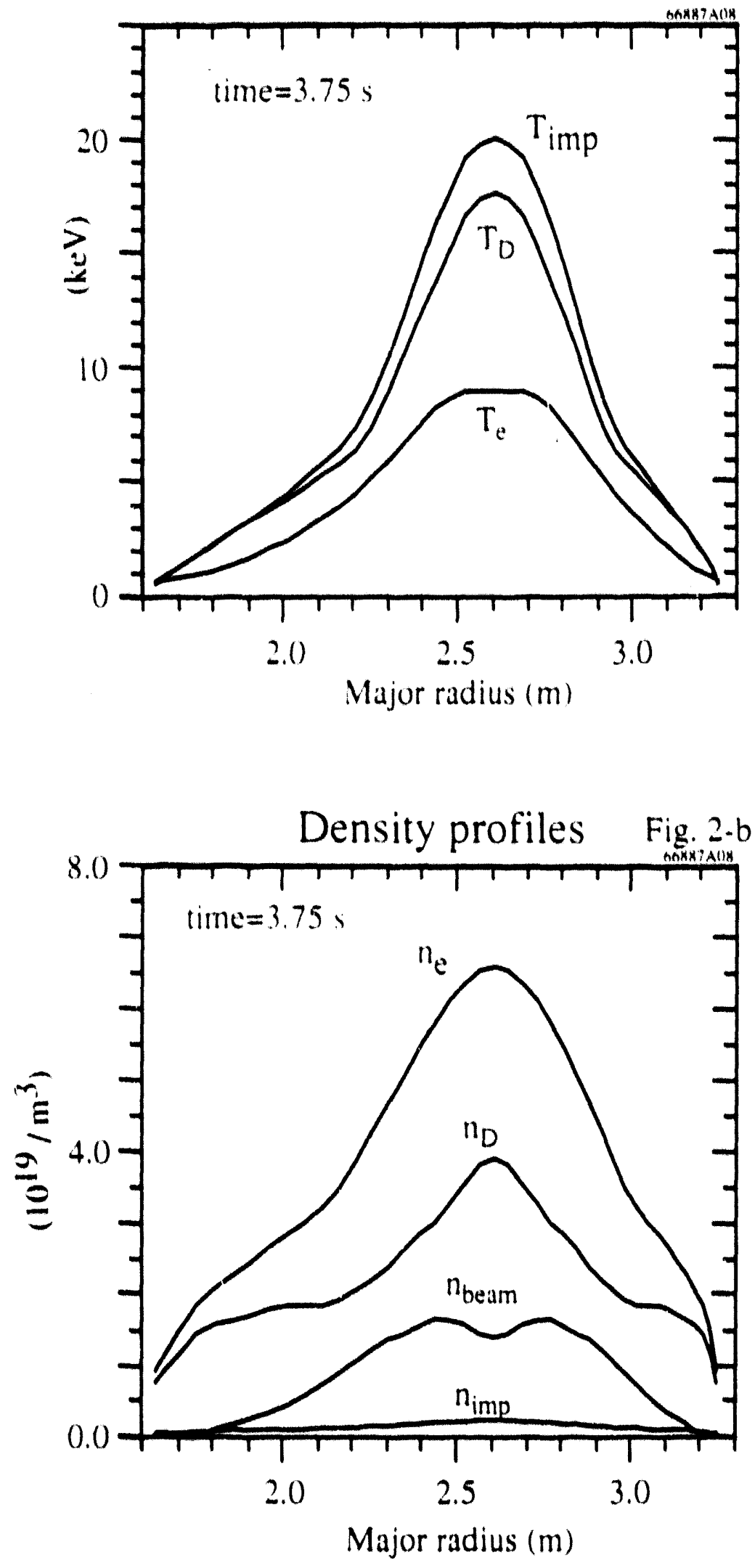


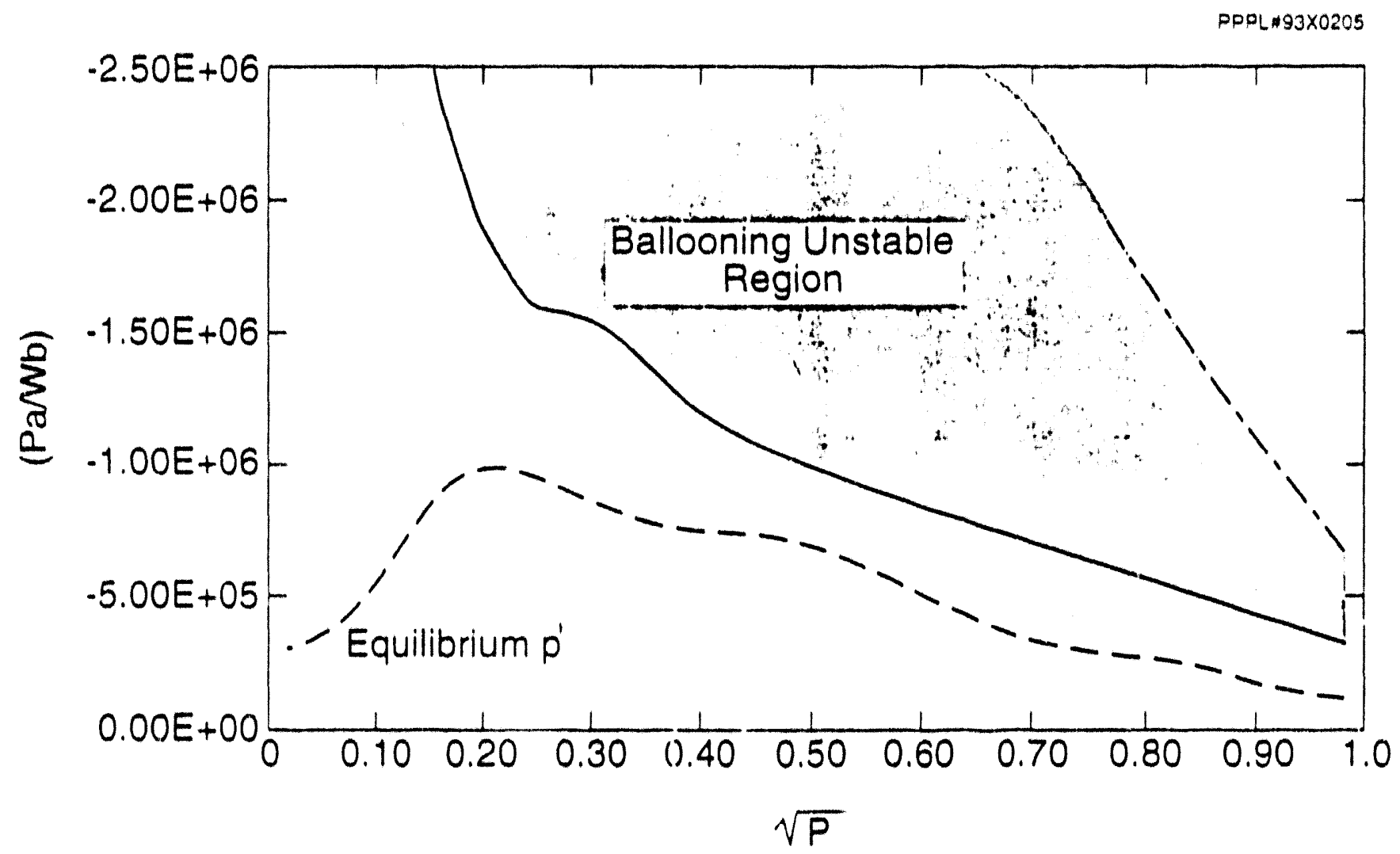




\section{Neutron emission components}

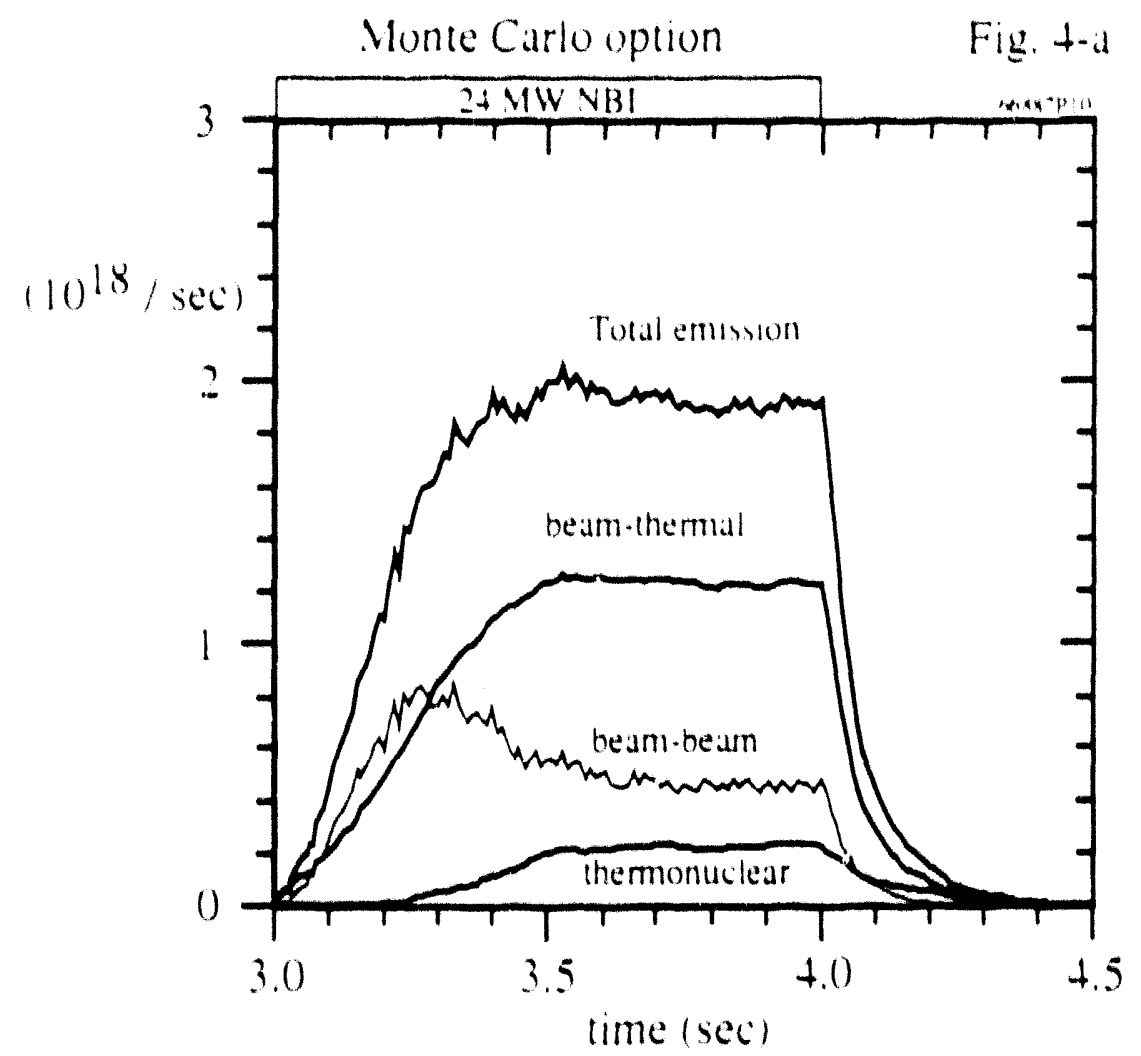

Fokker Planck option

Fig. 4-b

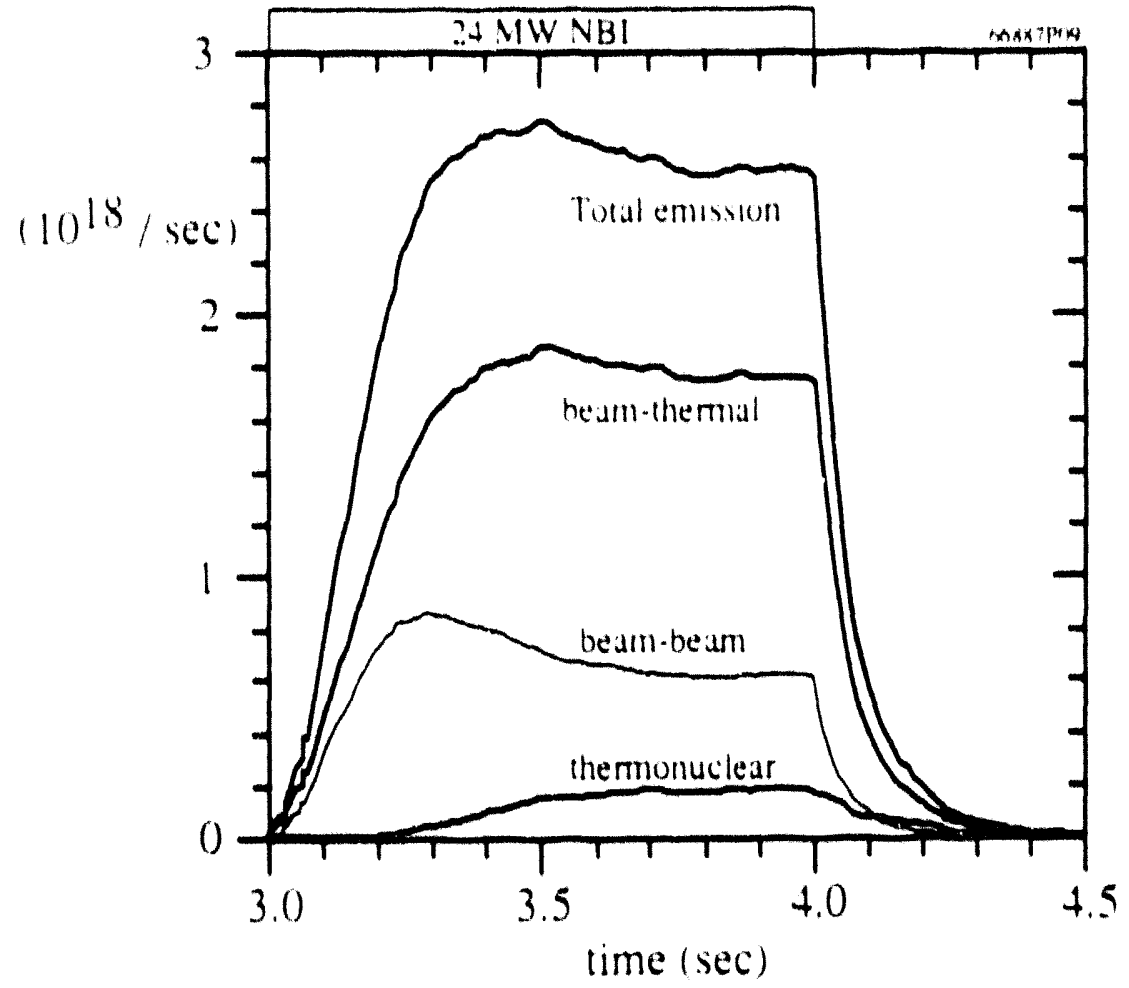




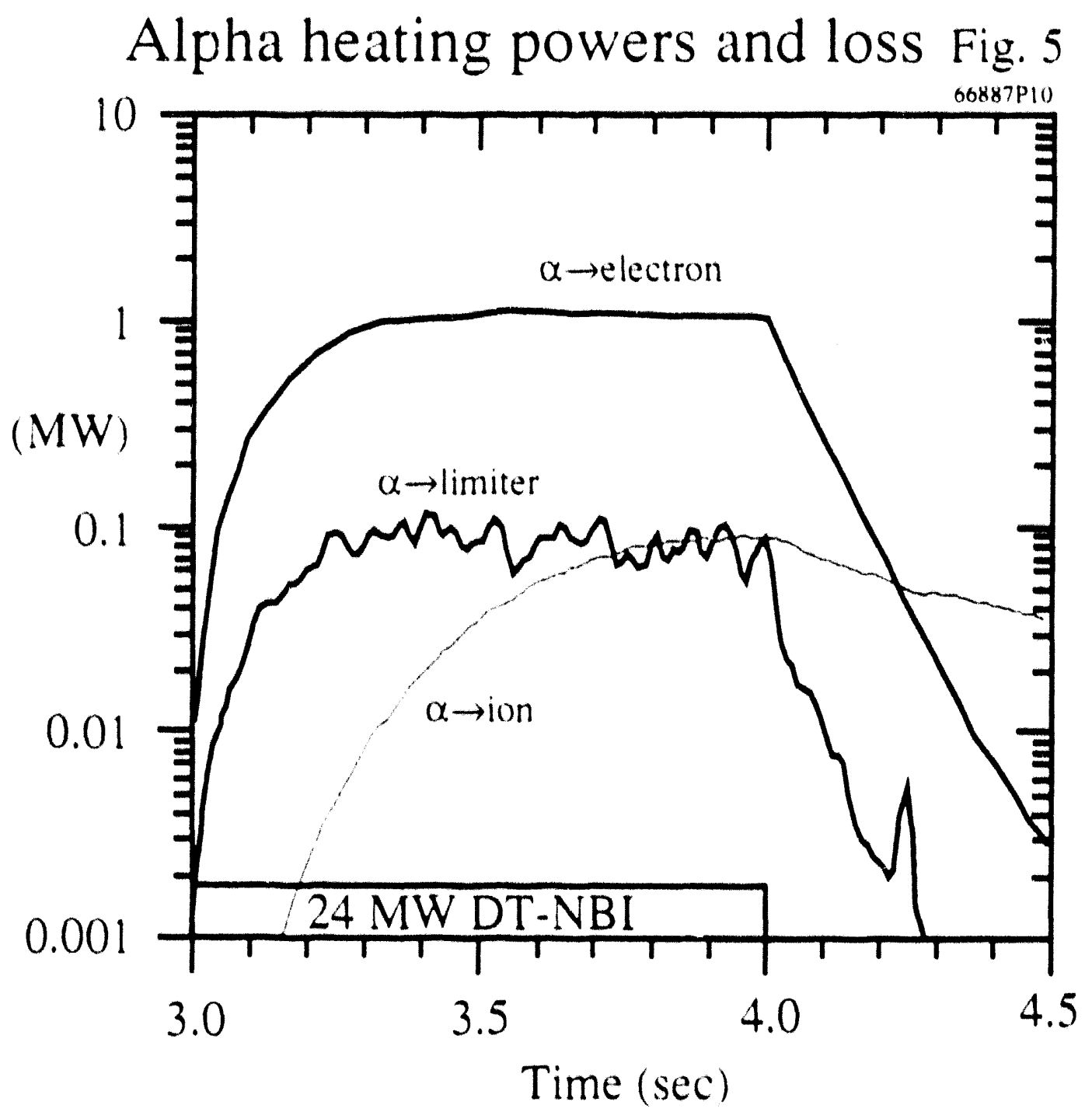


Flux surfaces

Fig. 6-a

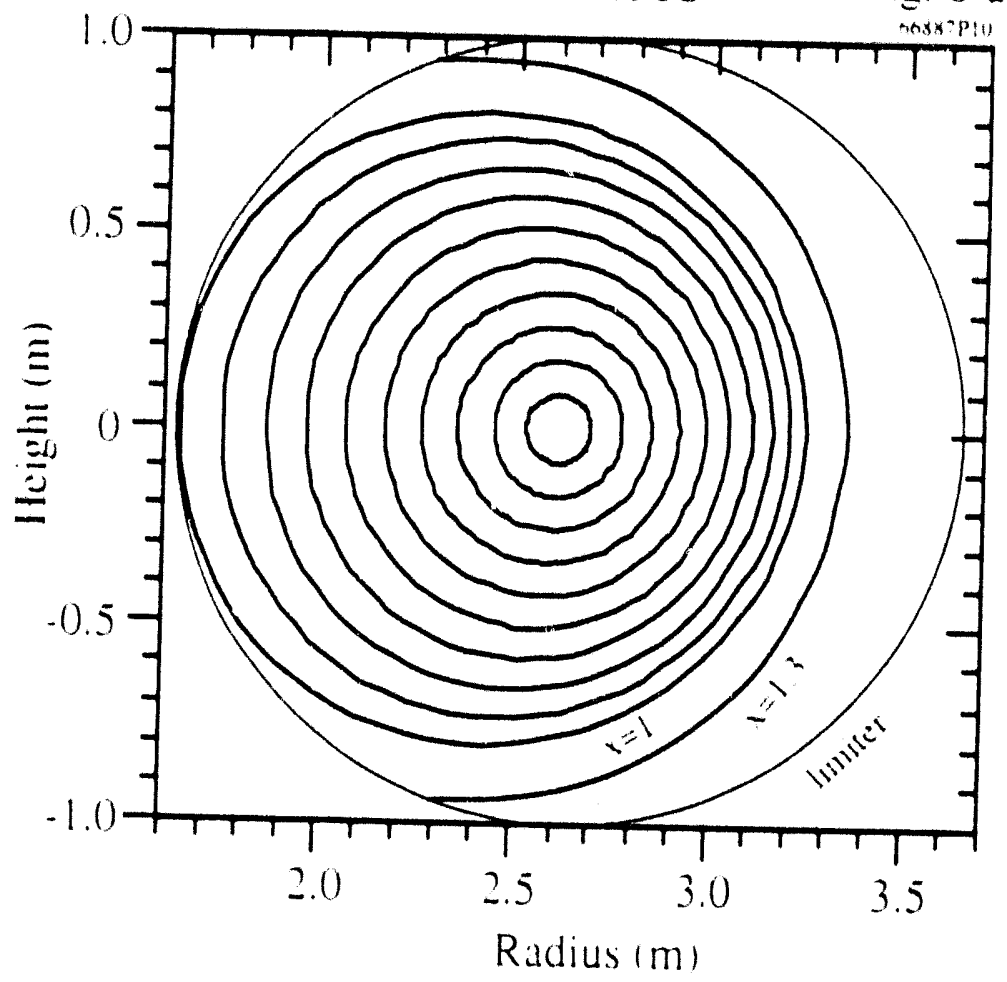

Radial variables Fig. 6-b

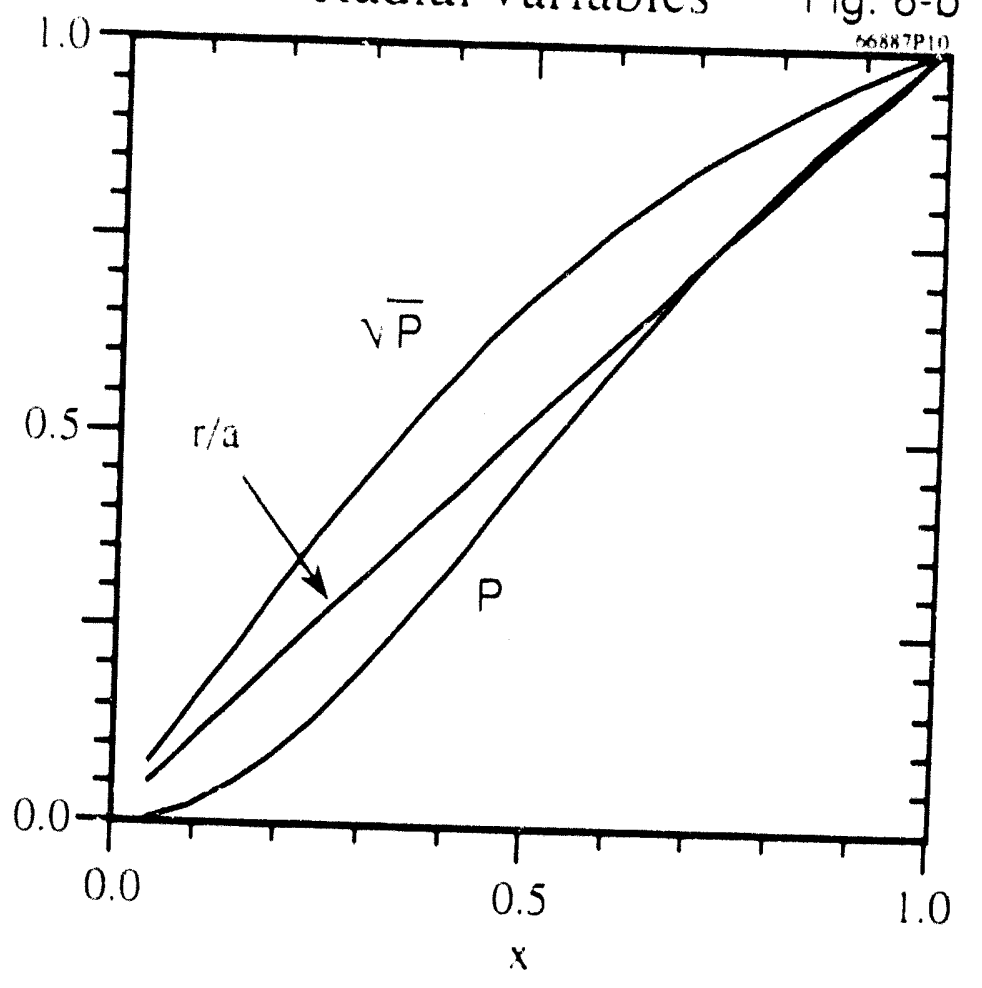



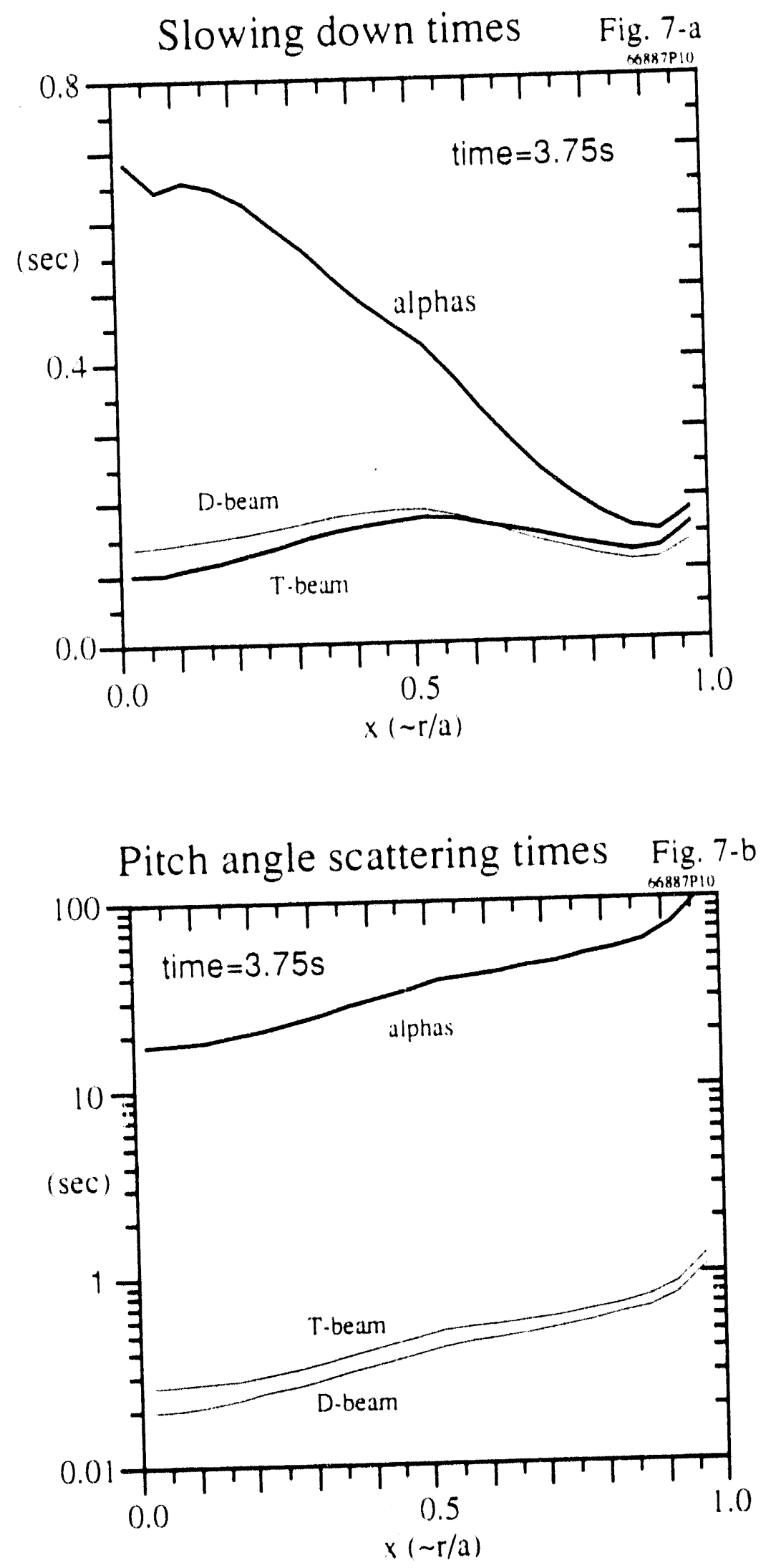

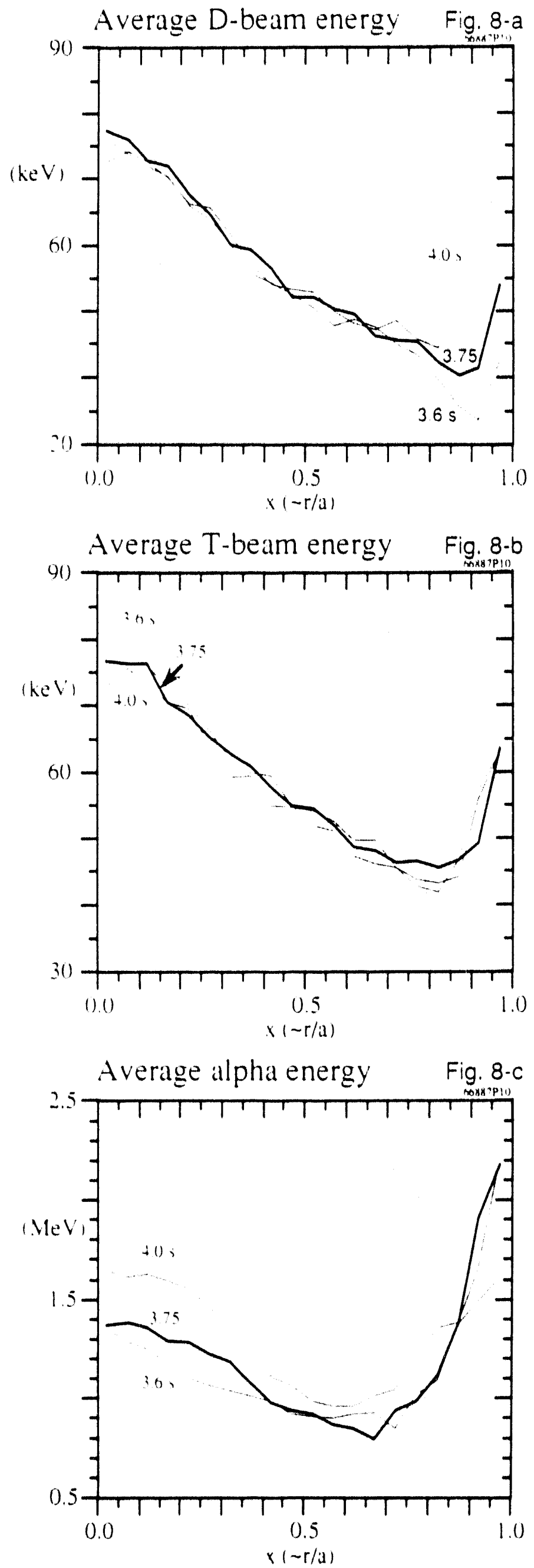
Electron heating profiles Fig. 9

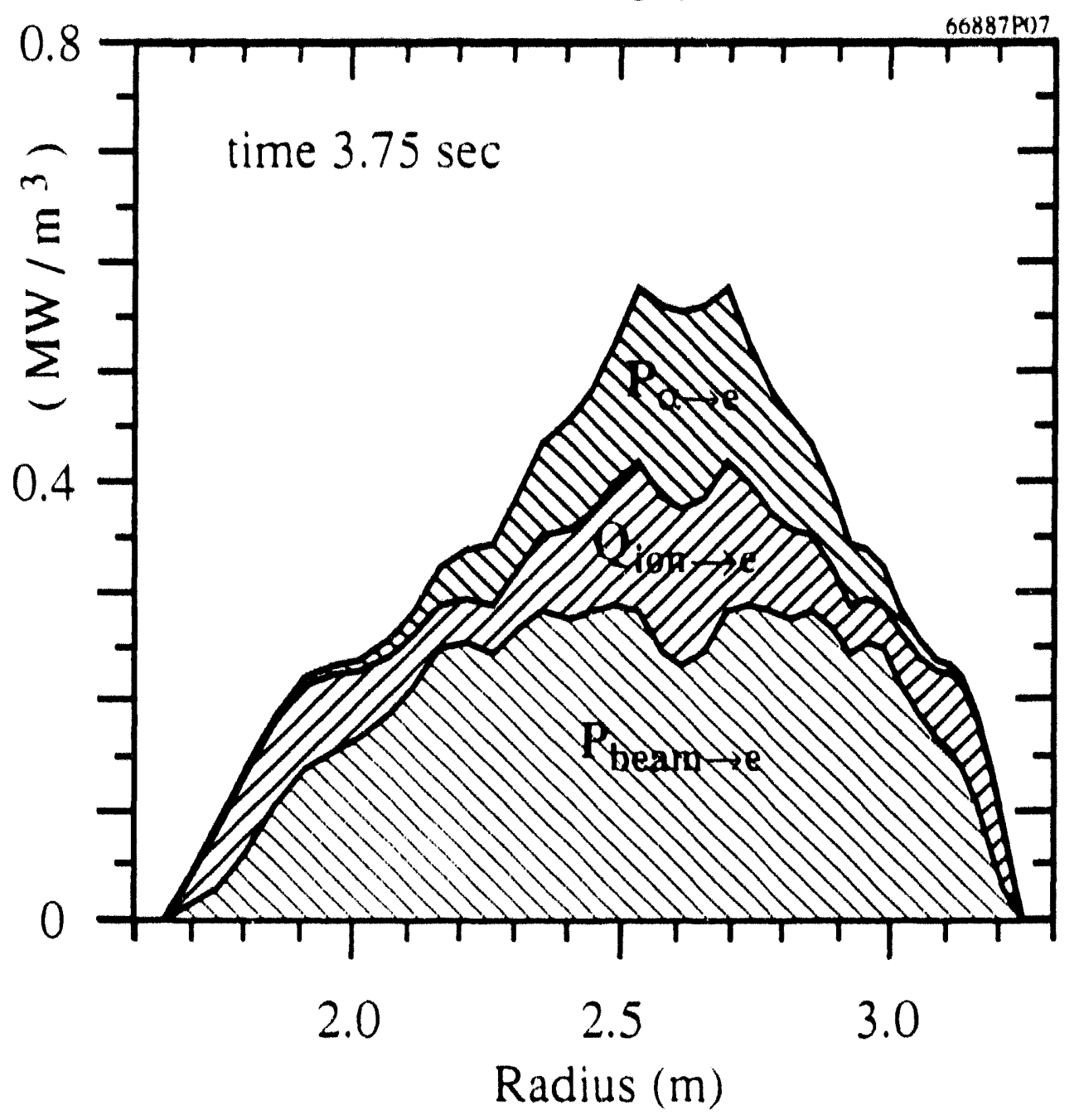


Electron temperature Fig. (10.d

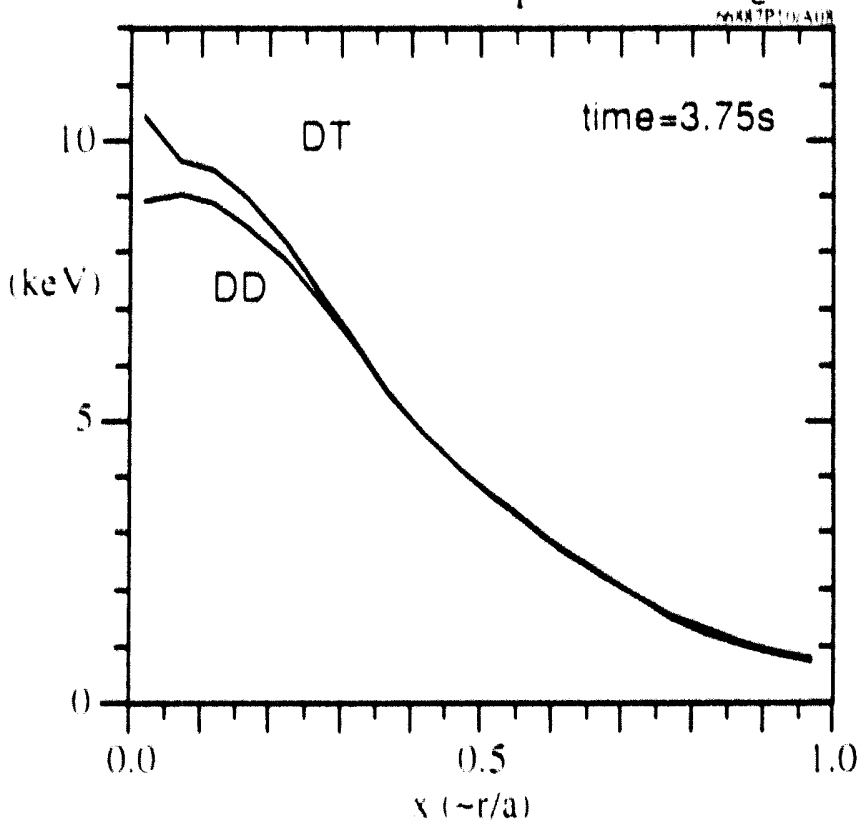

Total pressure

Fig. 10.b
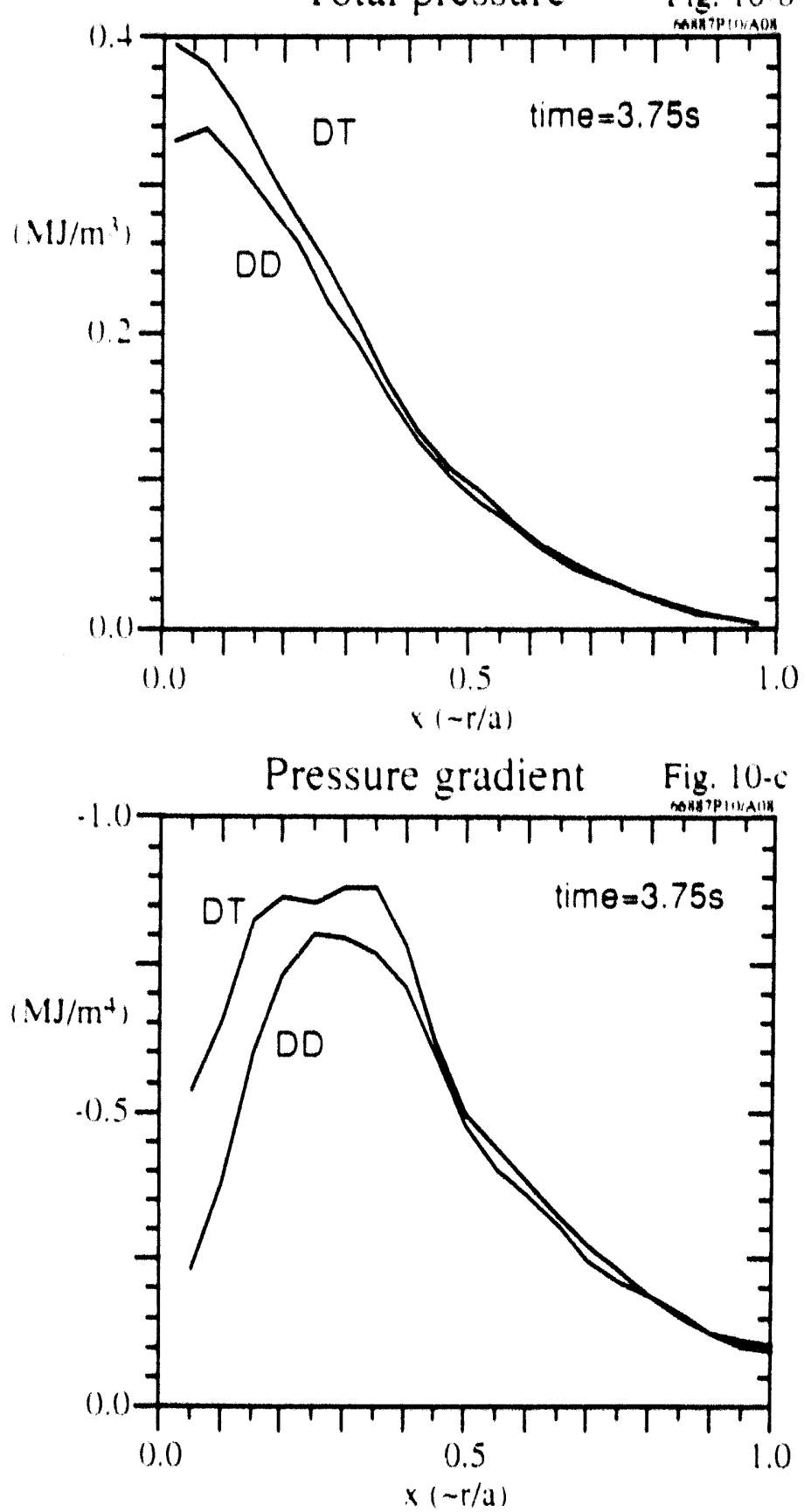
Profile peakedness Fig. 11

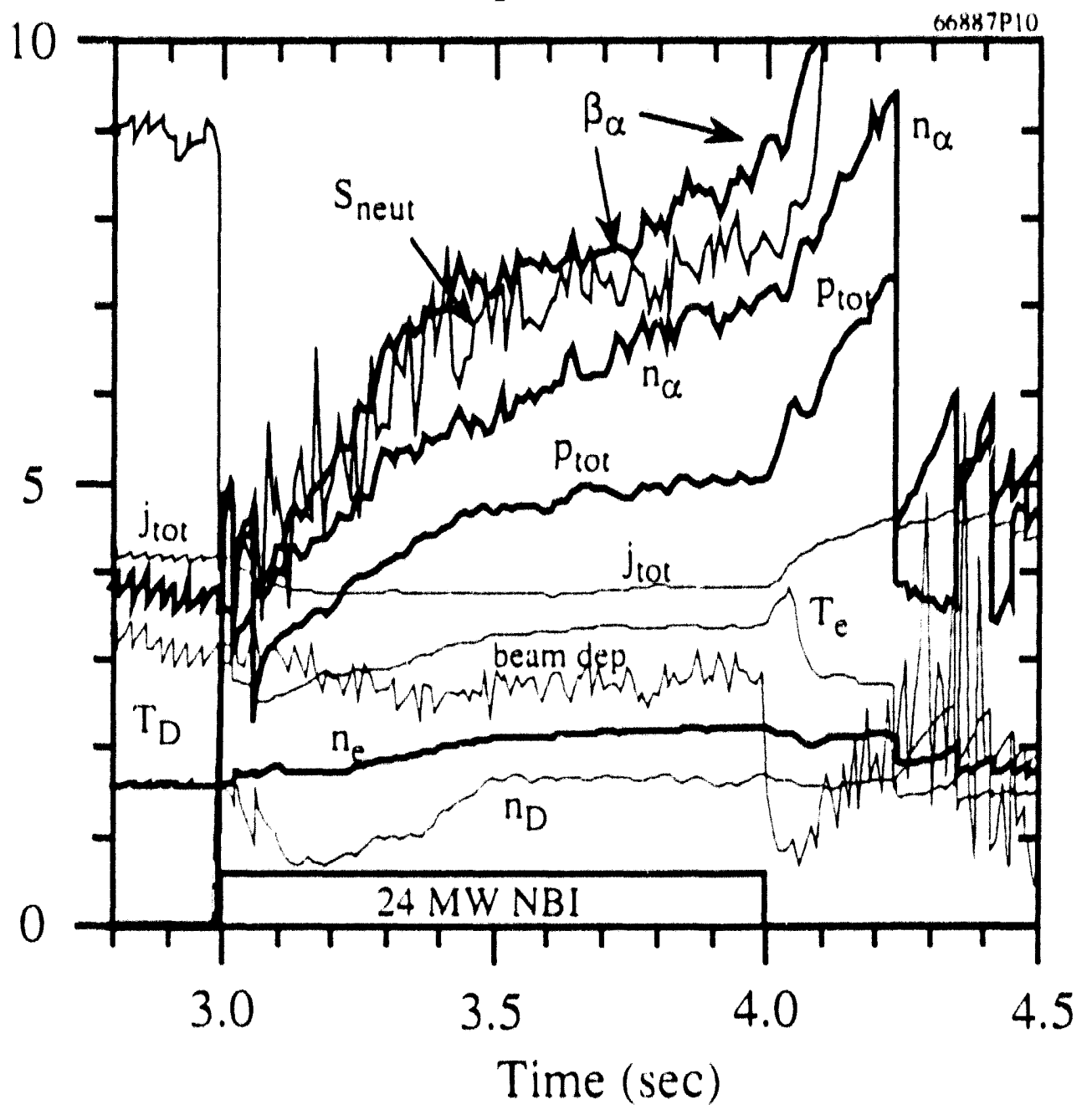



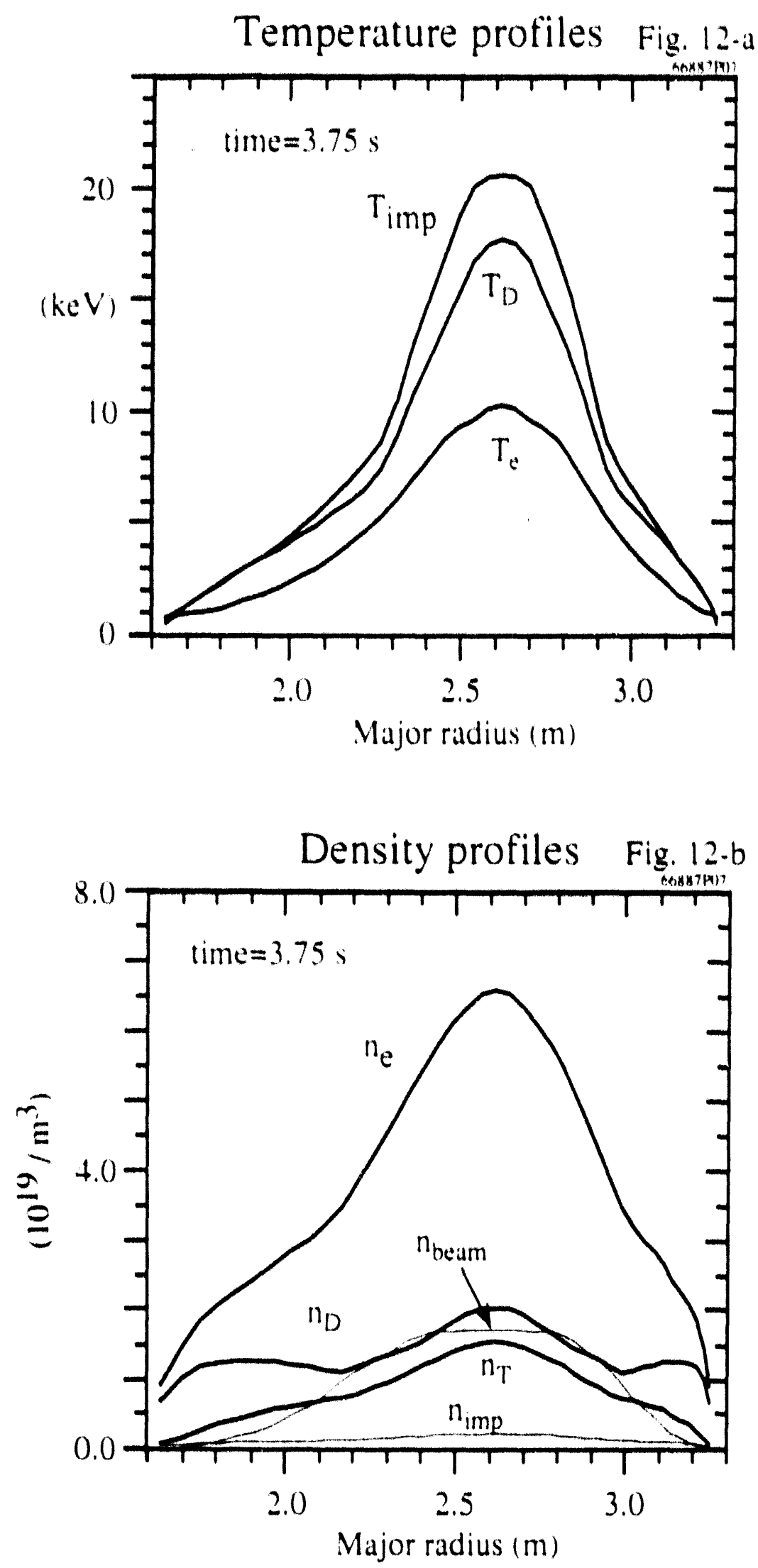
Toroidal $\beta$ profiles Fig. 13
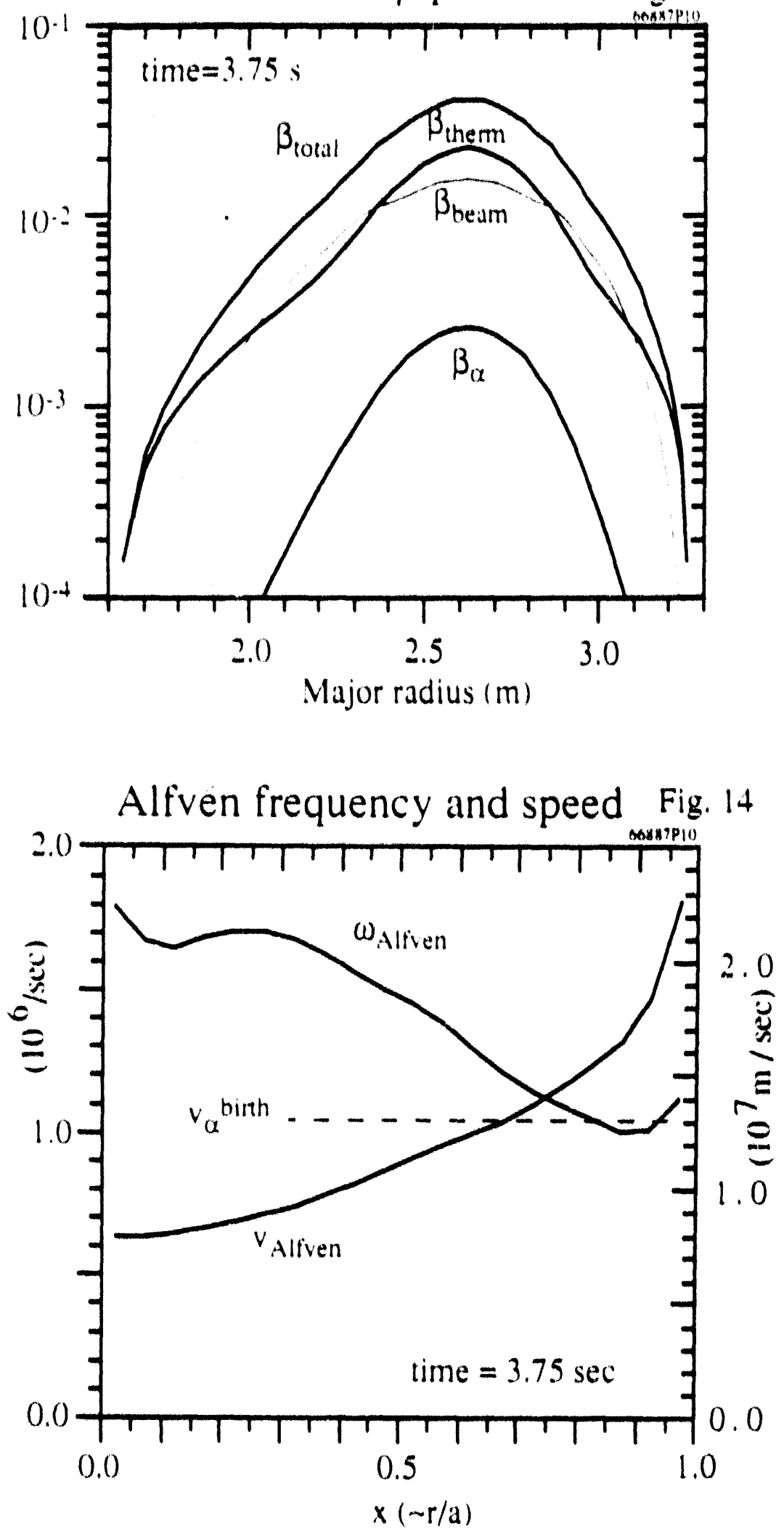
TAE trajectory

Fig. 15

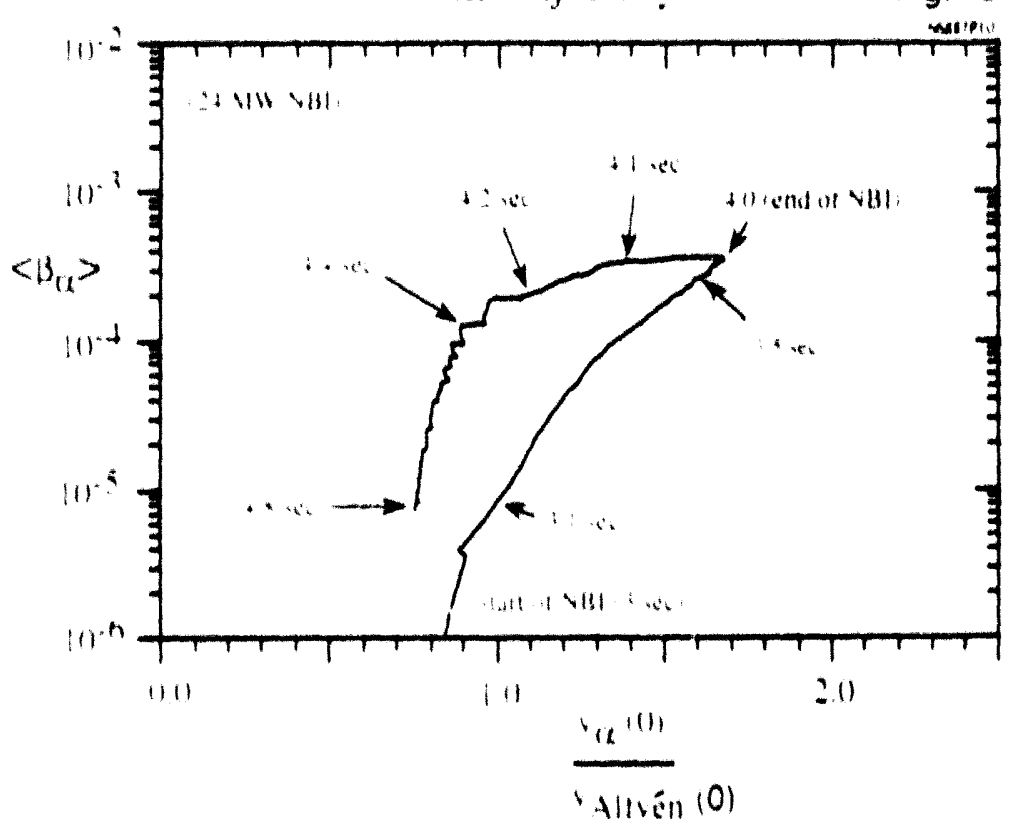

Profiles of $\eta_{\mathrm{e}}$ and $\eta_{\text {ie }}$ Fig. 16

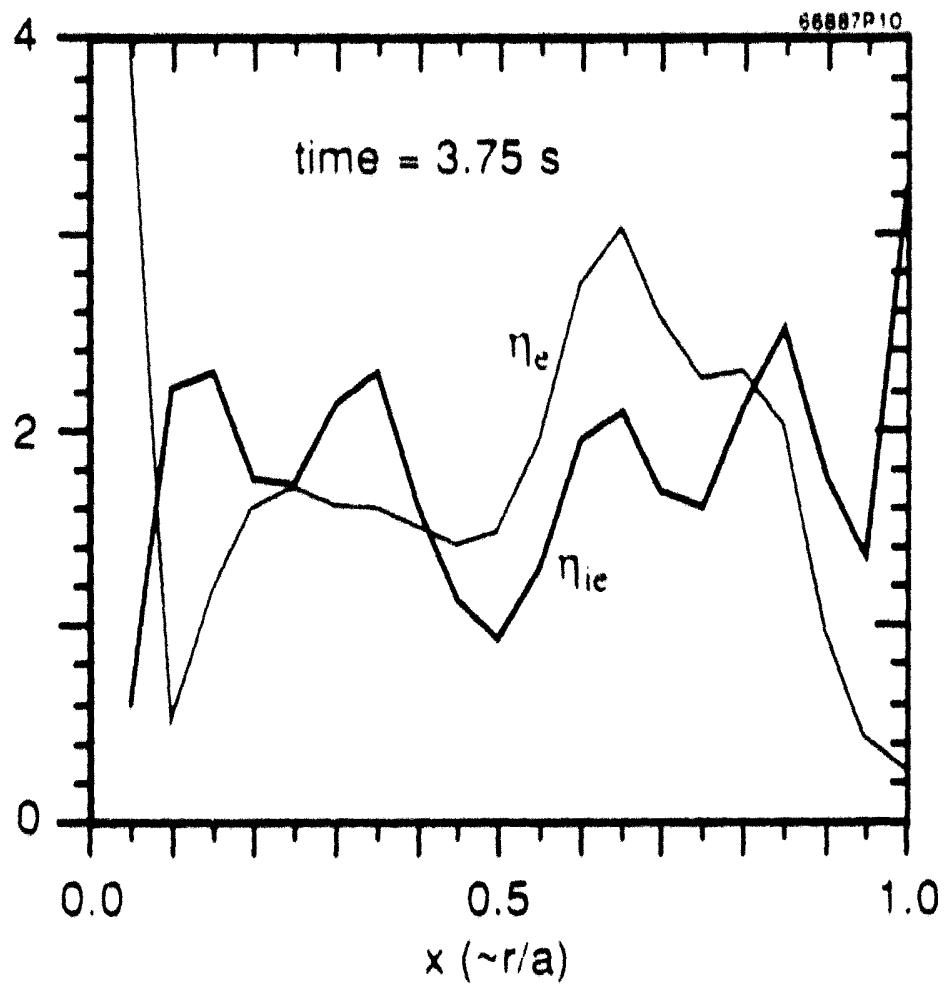




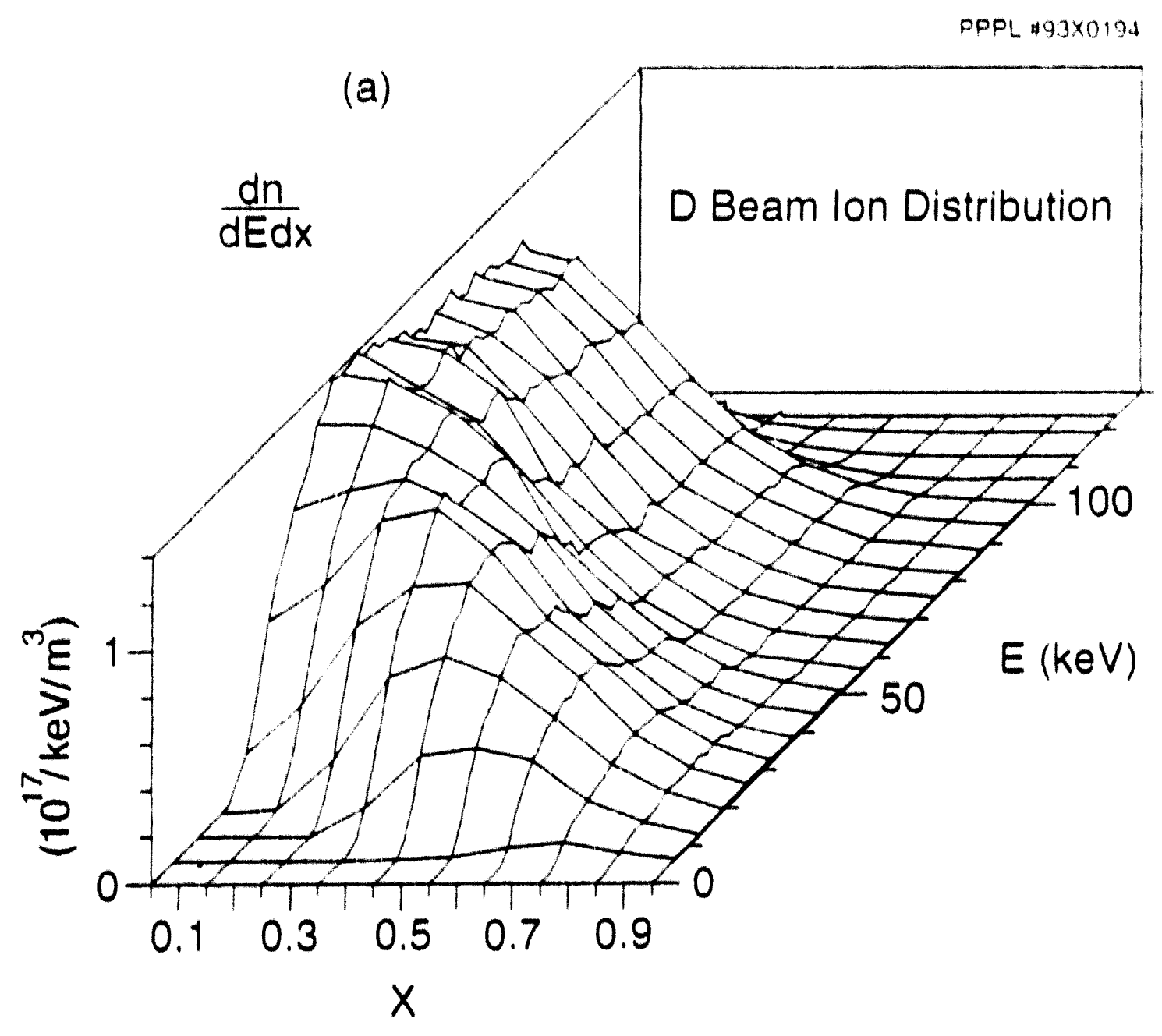

Fig. 1:1

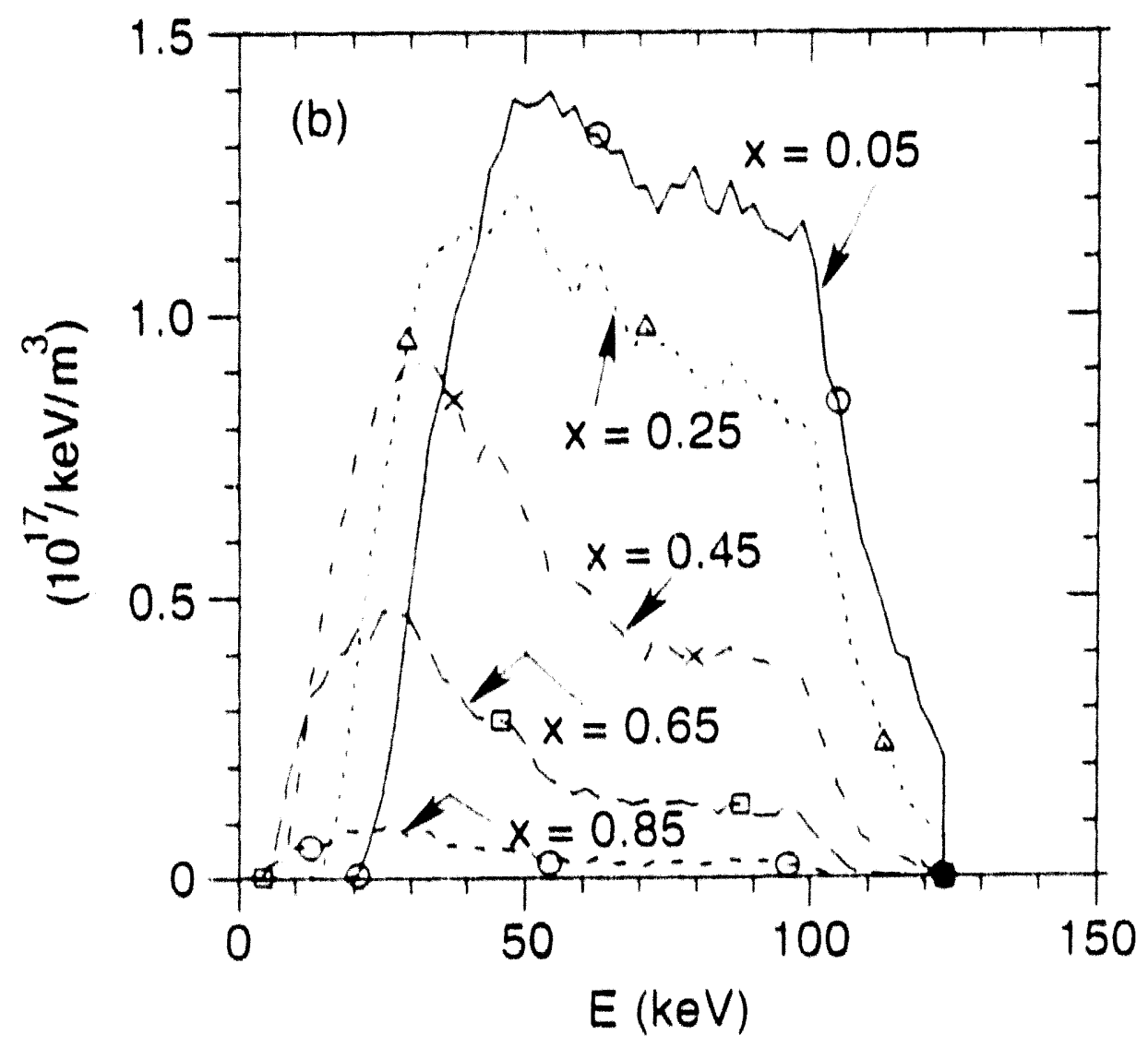


PPDL $\$ 93,20135$
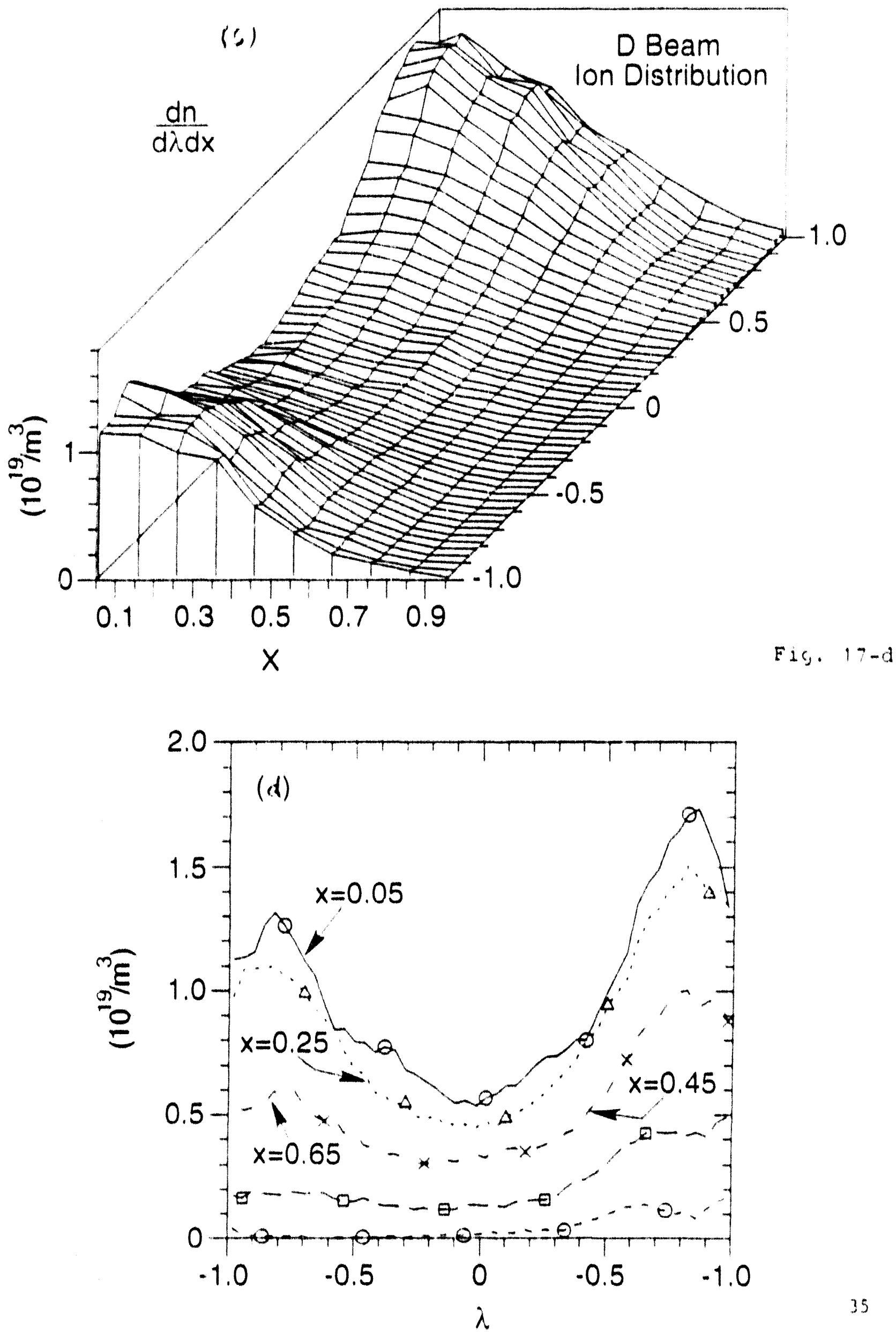


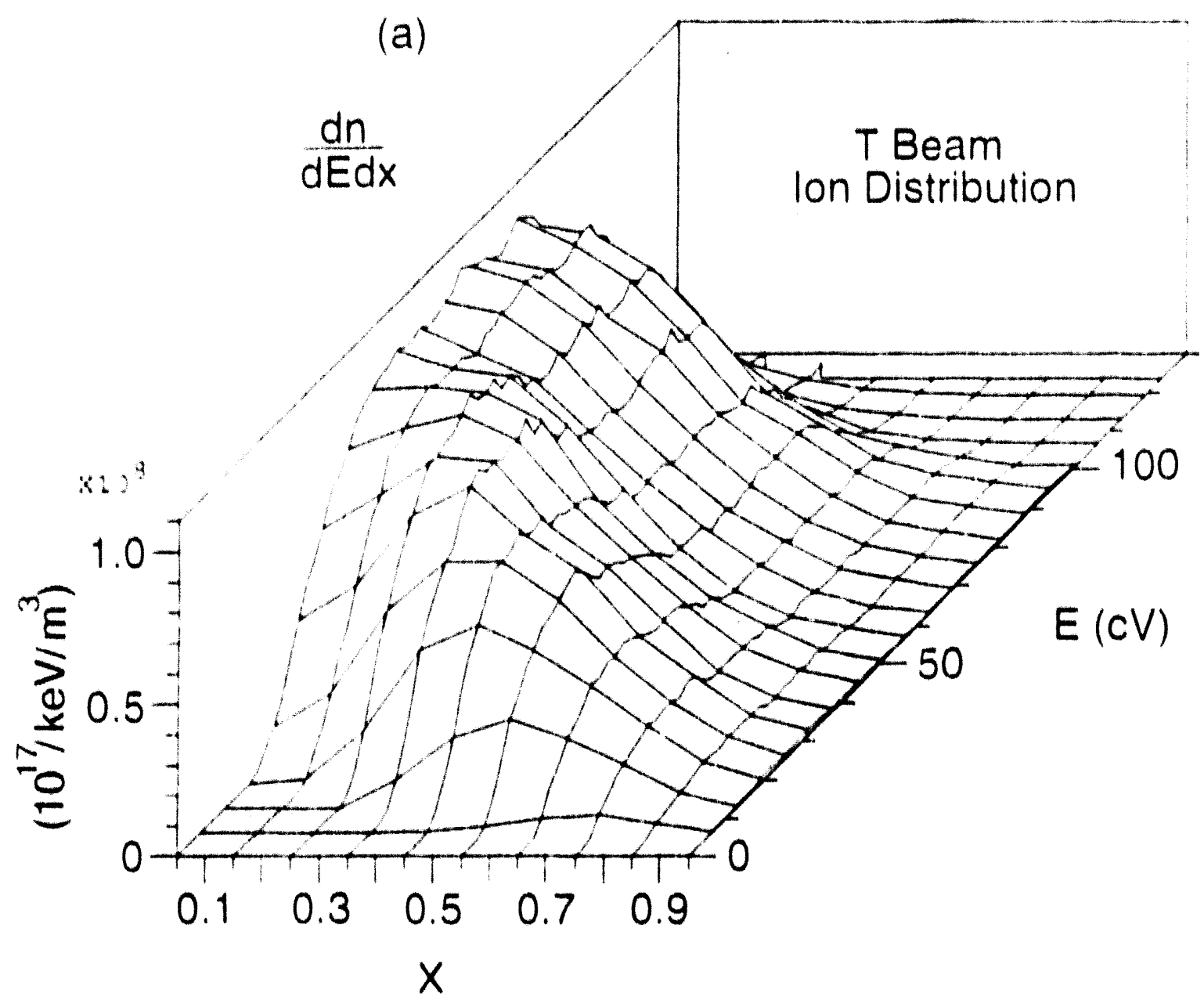

id. 18-b

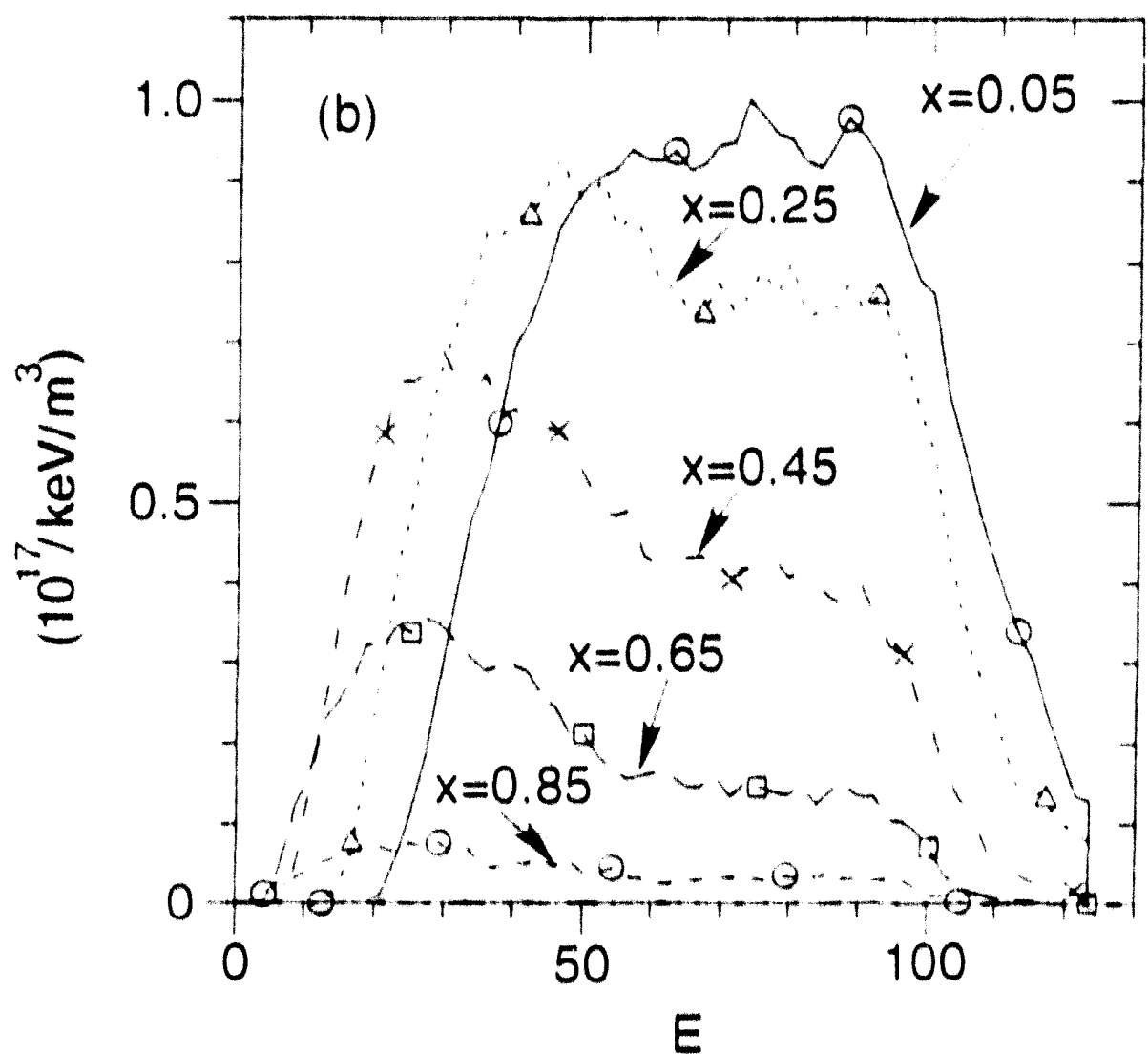



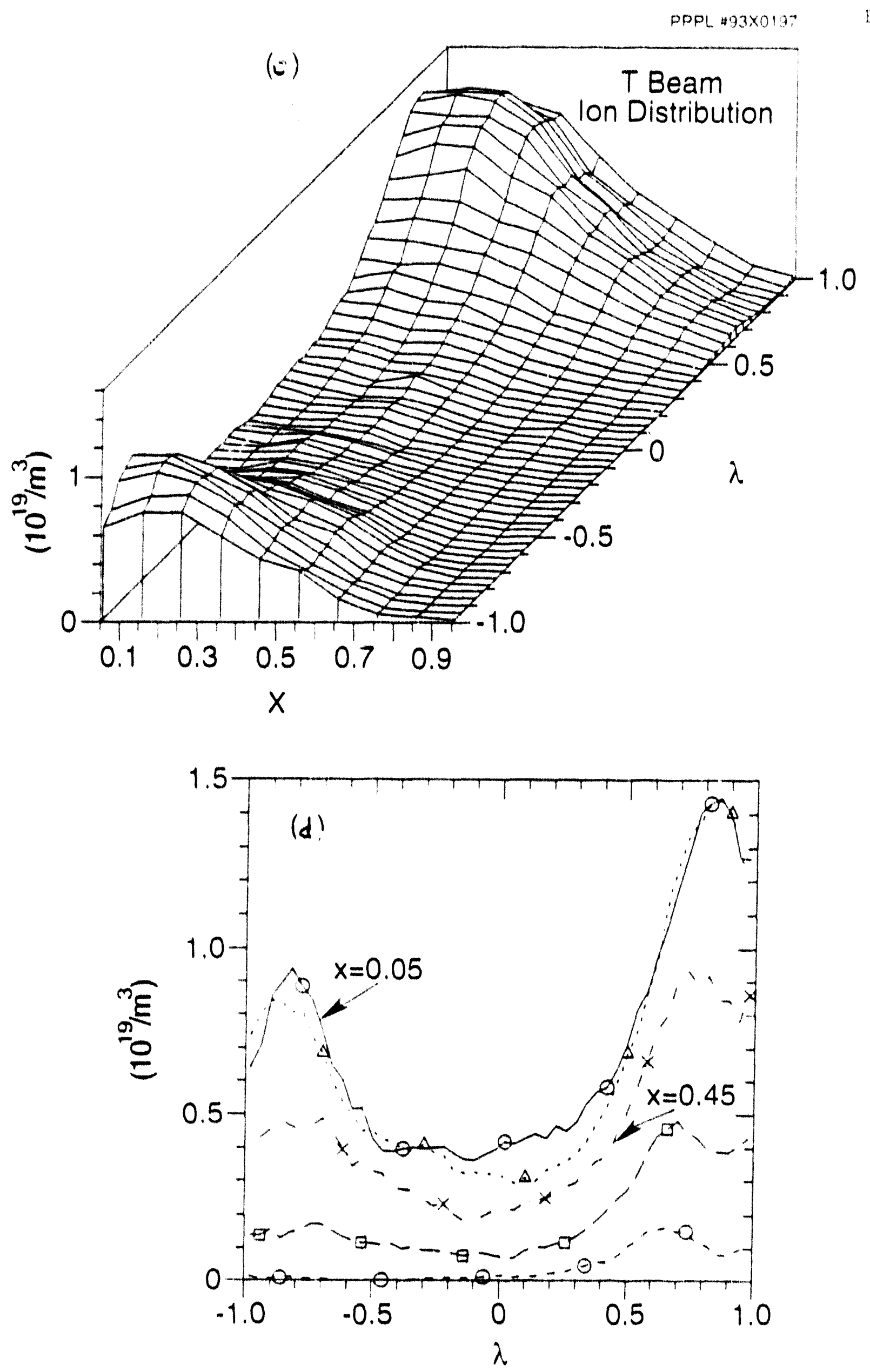
PPPL $493 \times 18$ :"10

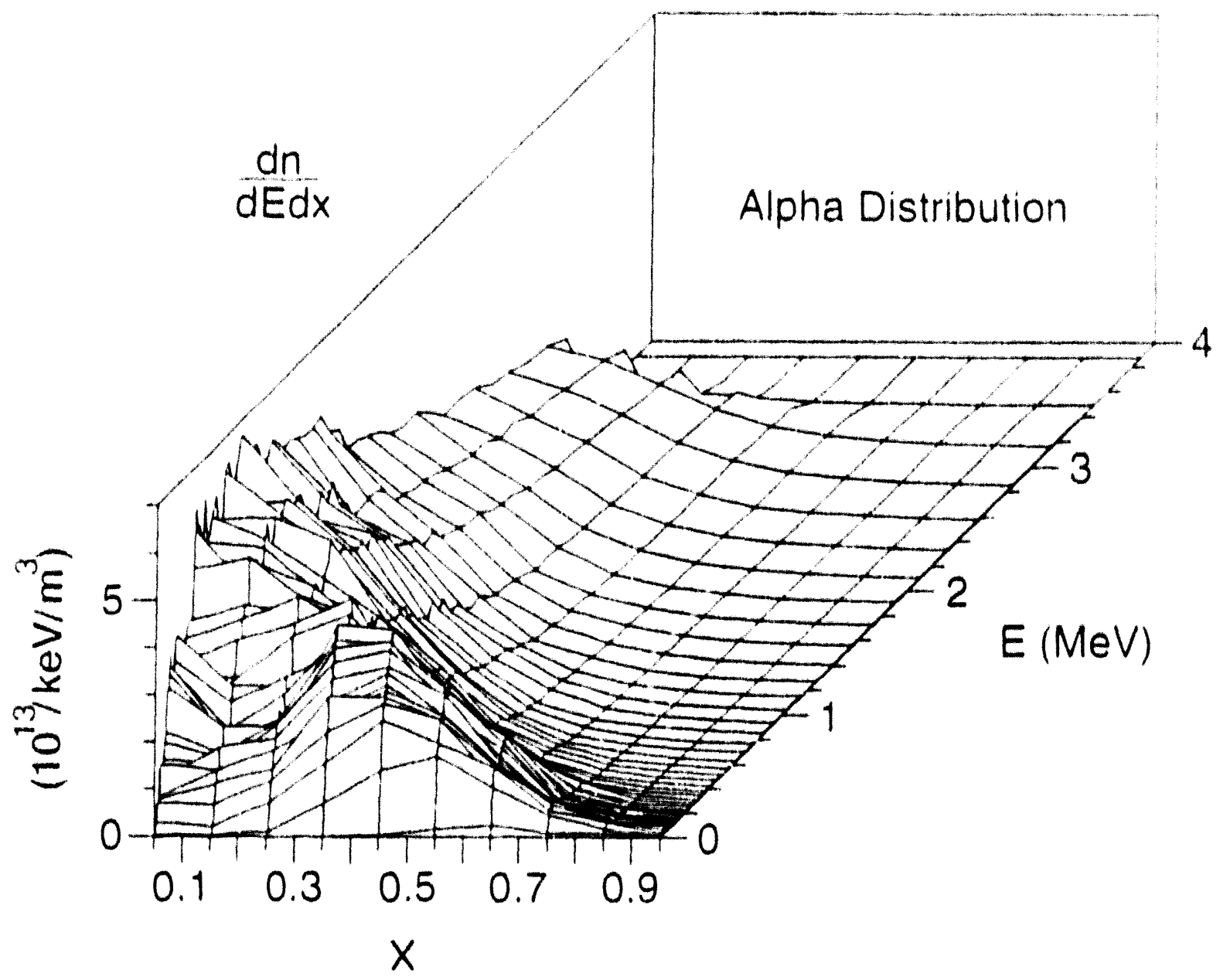

$r 1+19-b$

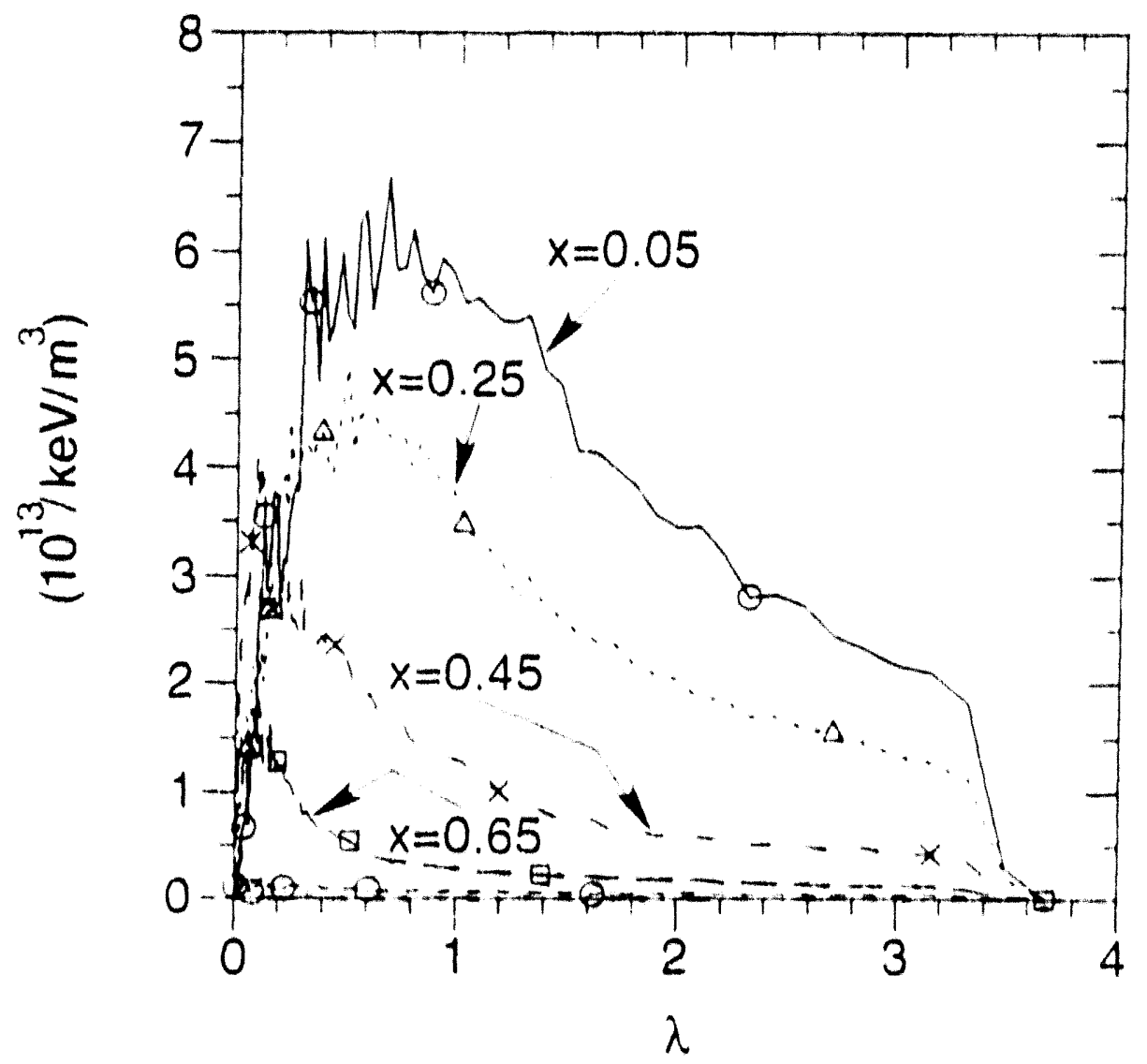



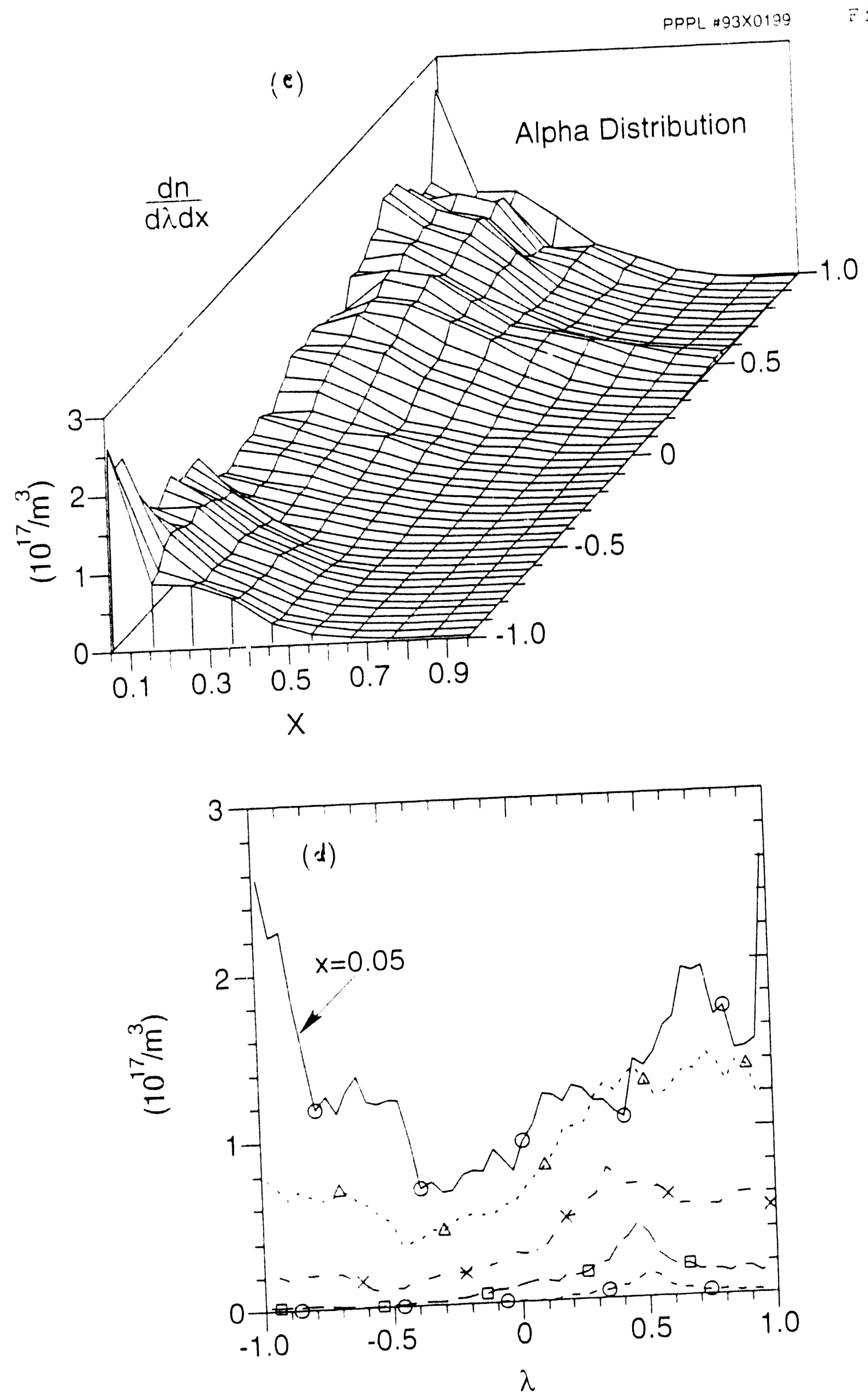

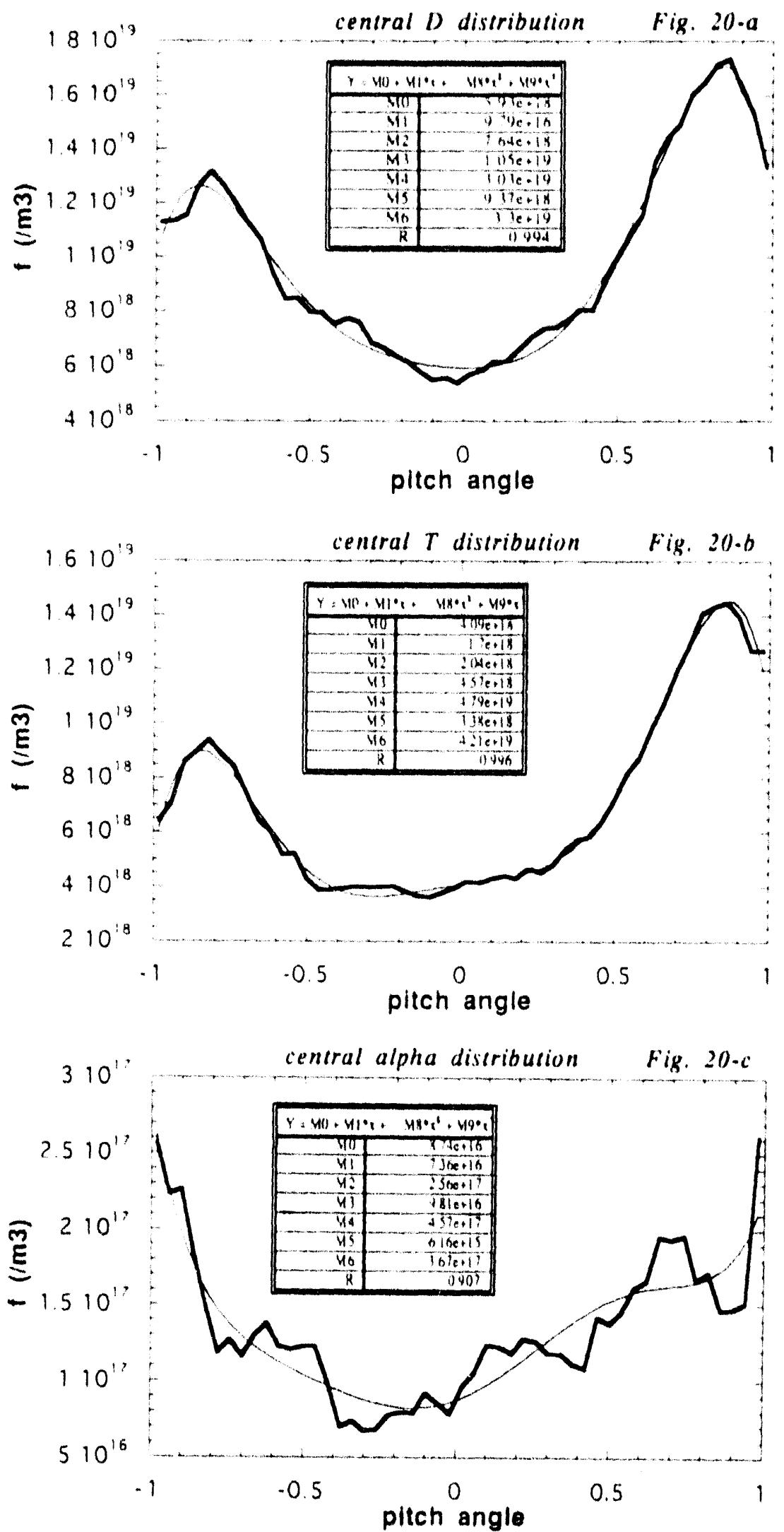
Rotation frequency profiles Fig. 21

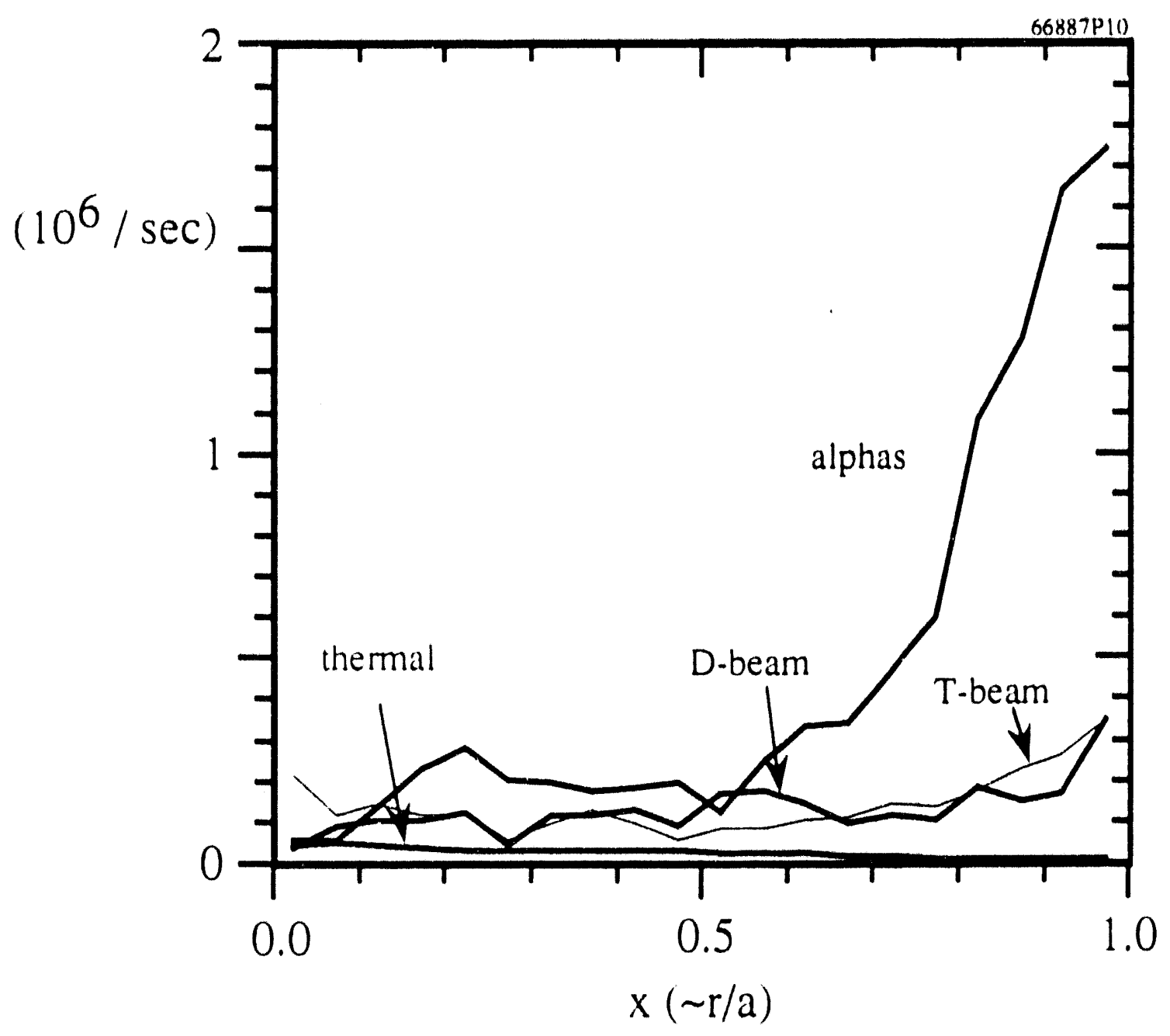


Fig. 22

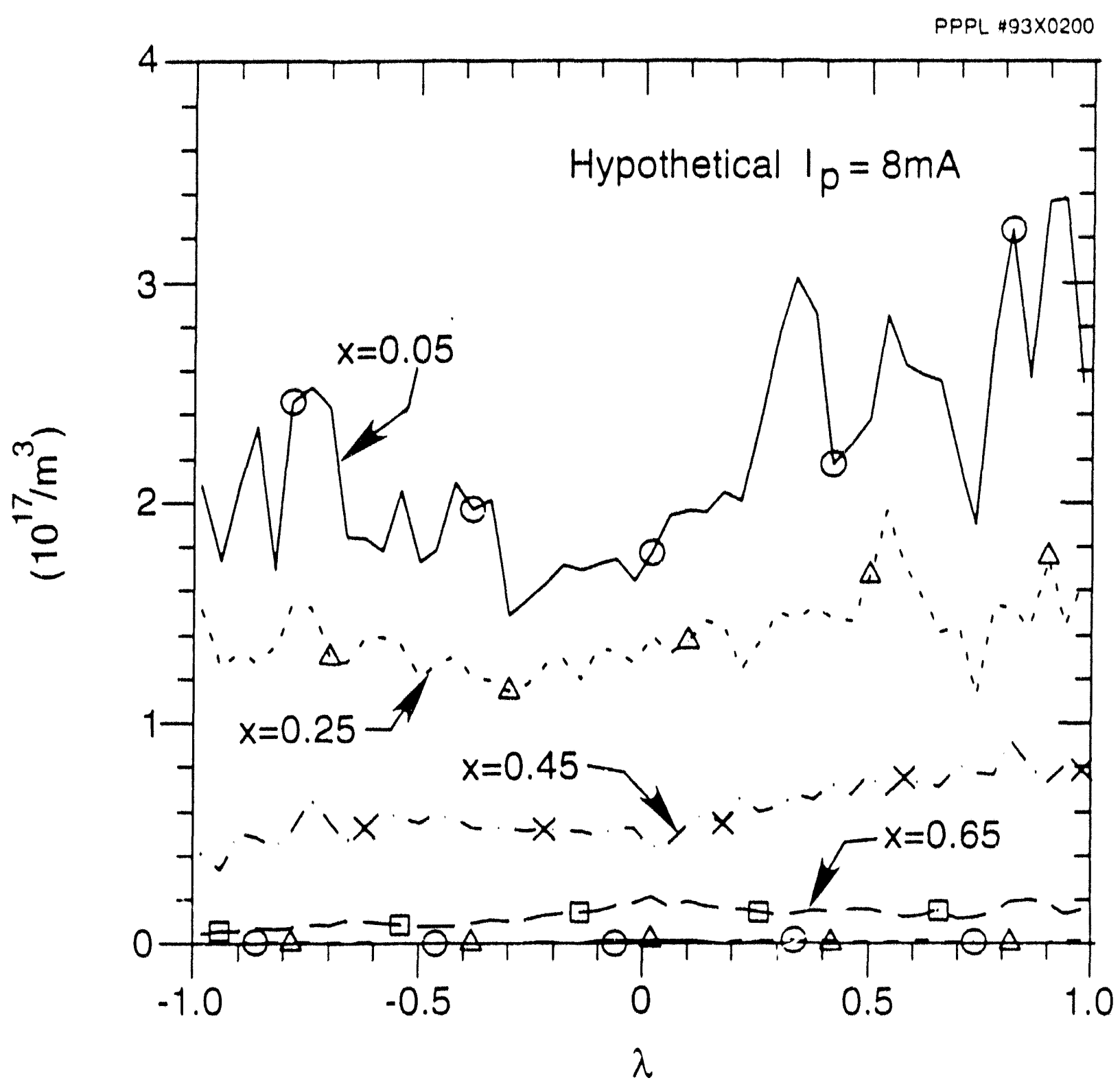



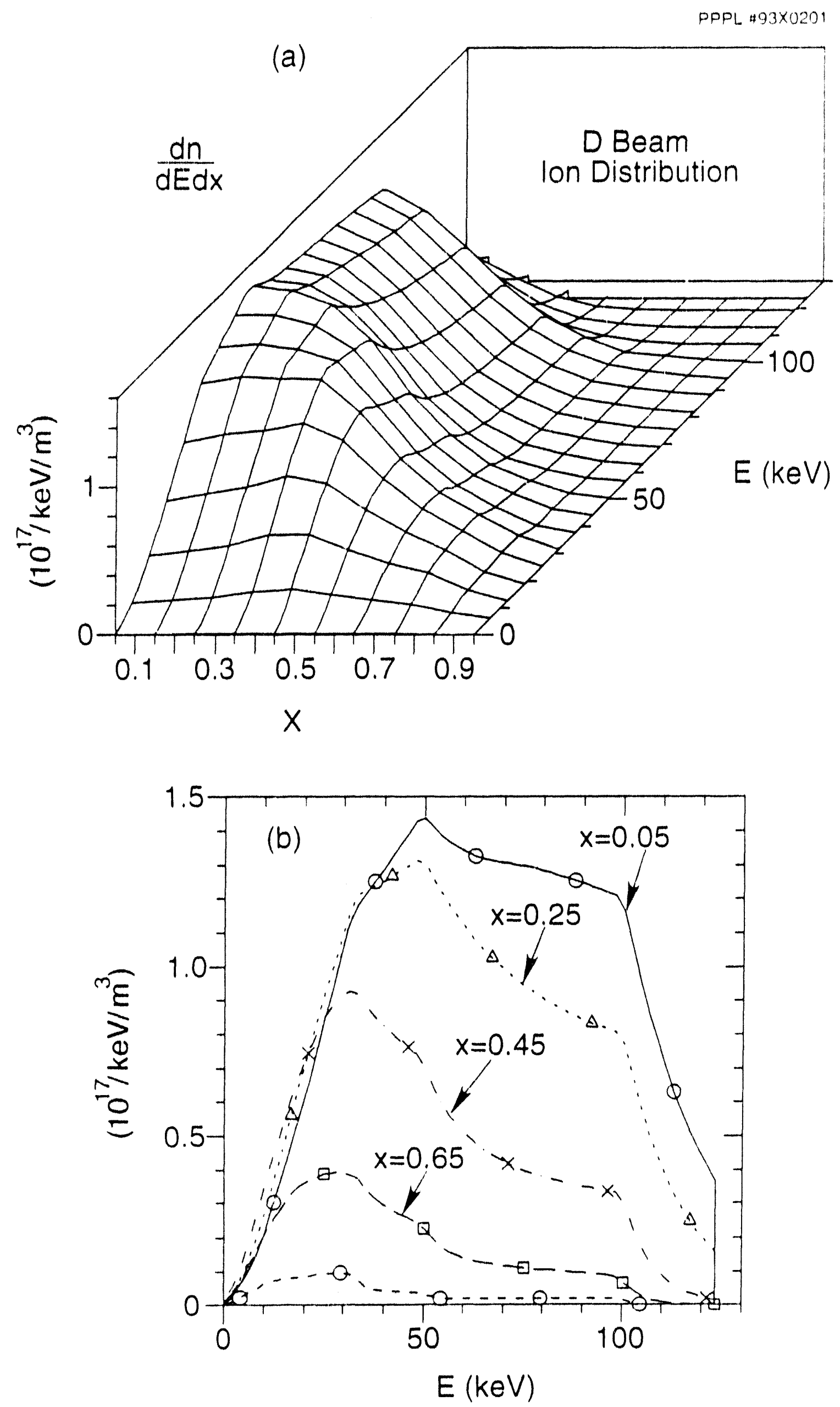
PPPL $\$ 93 \times 0202 \quad$ Fig. 23
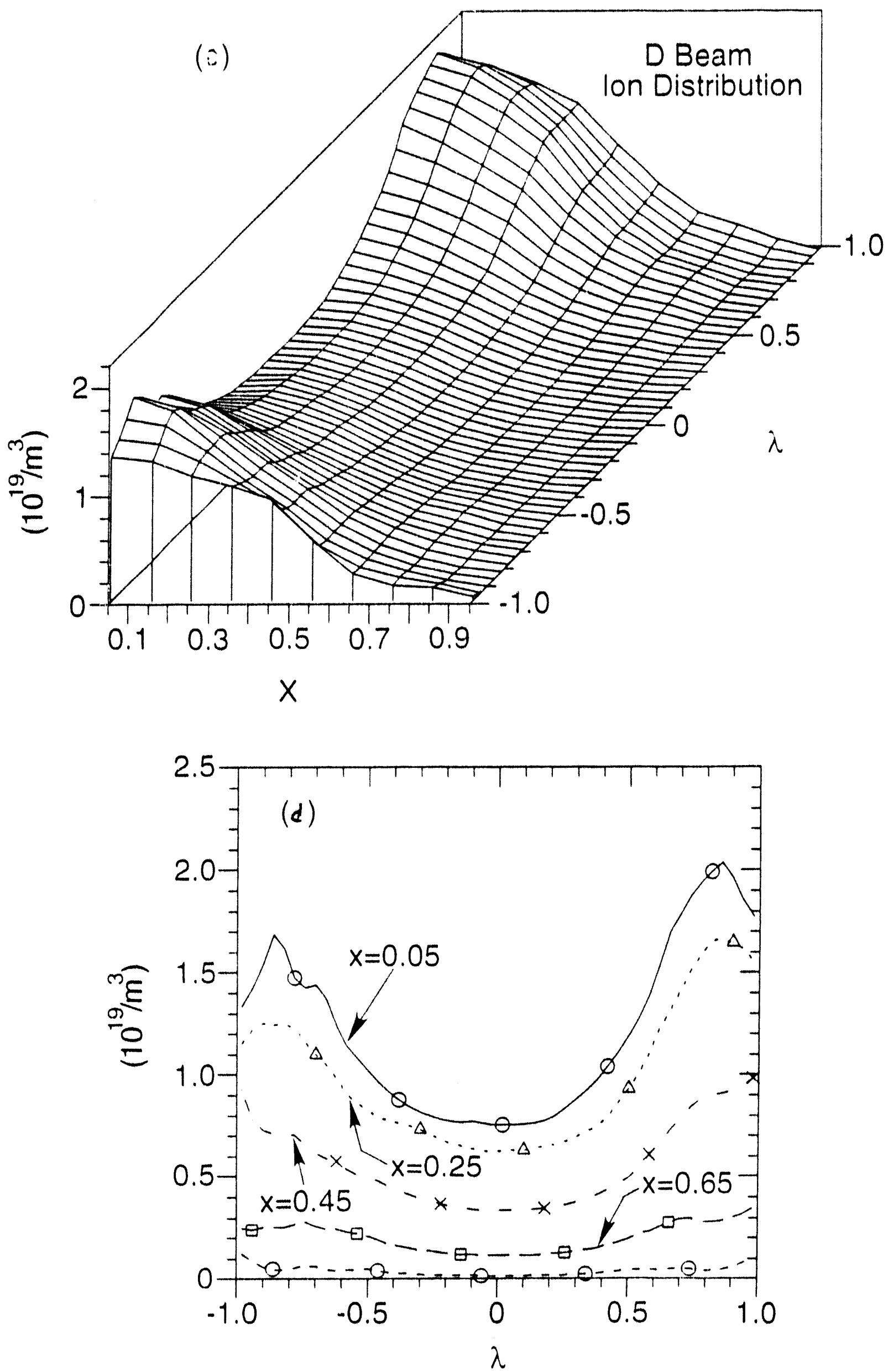

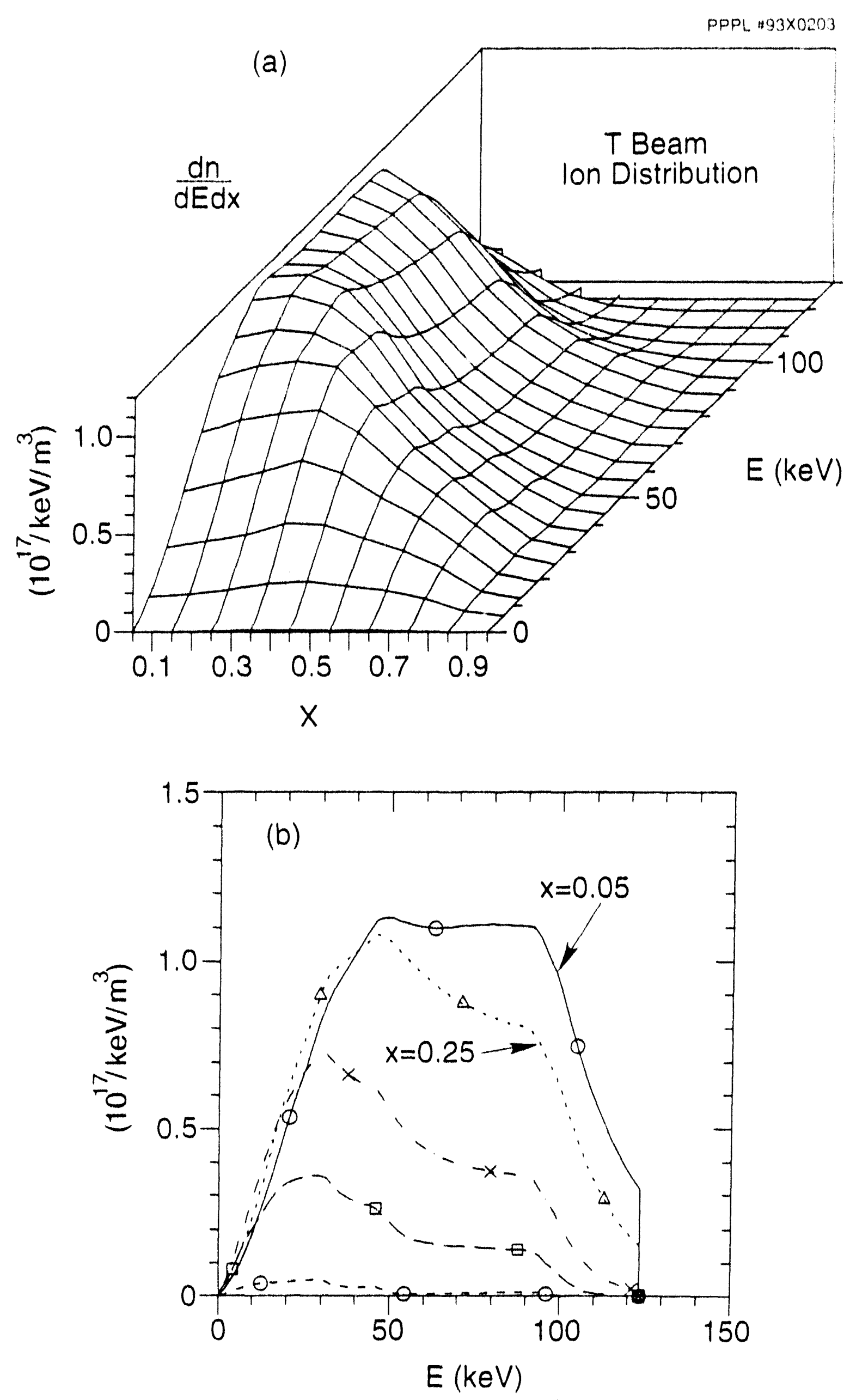

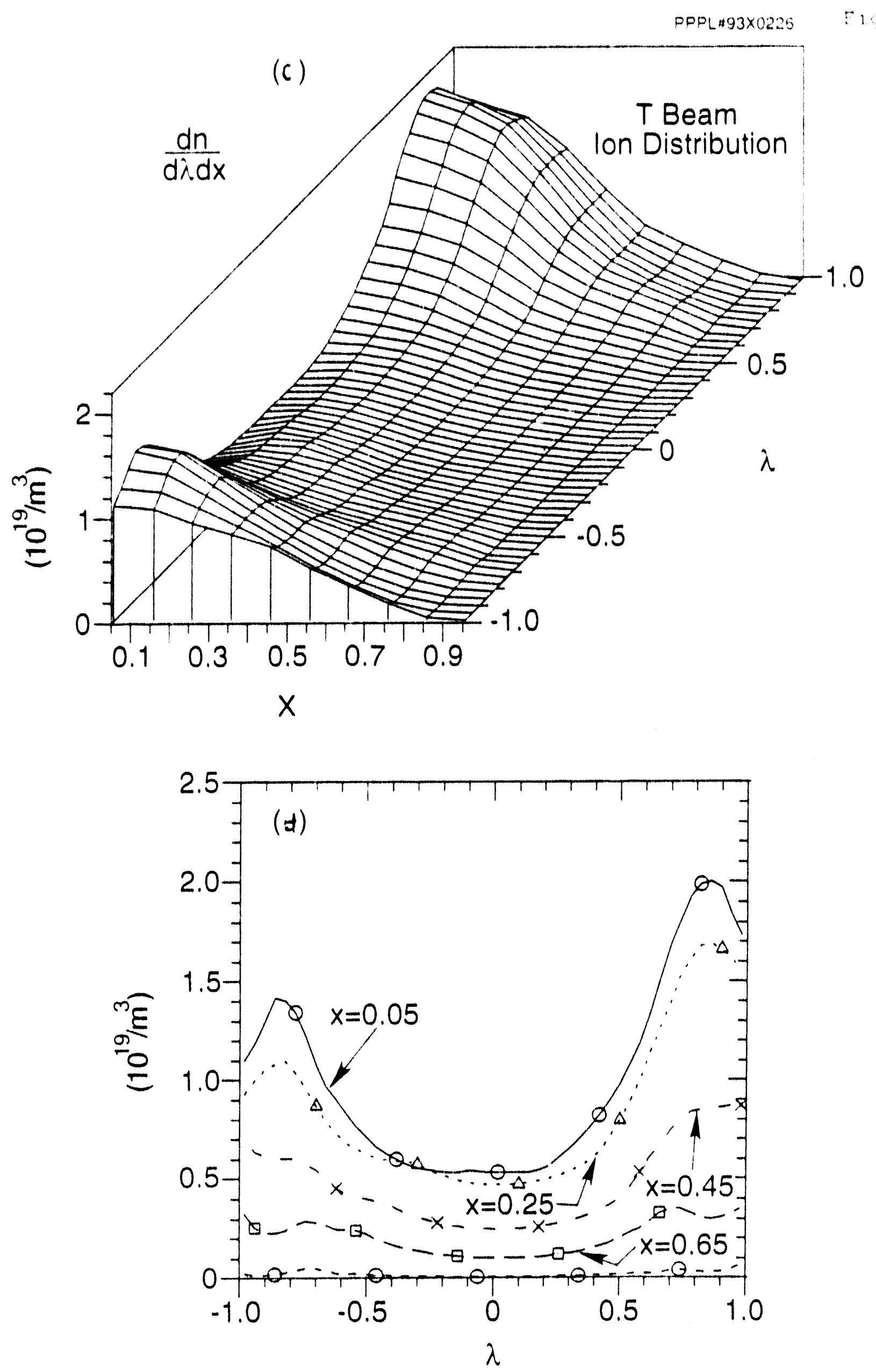

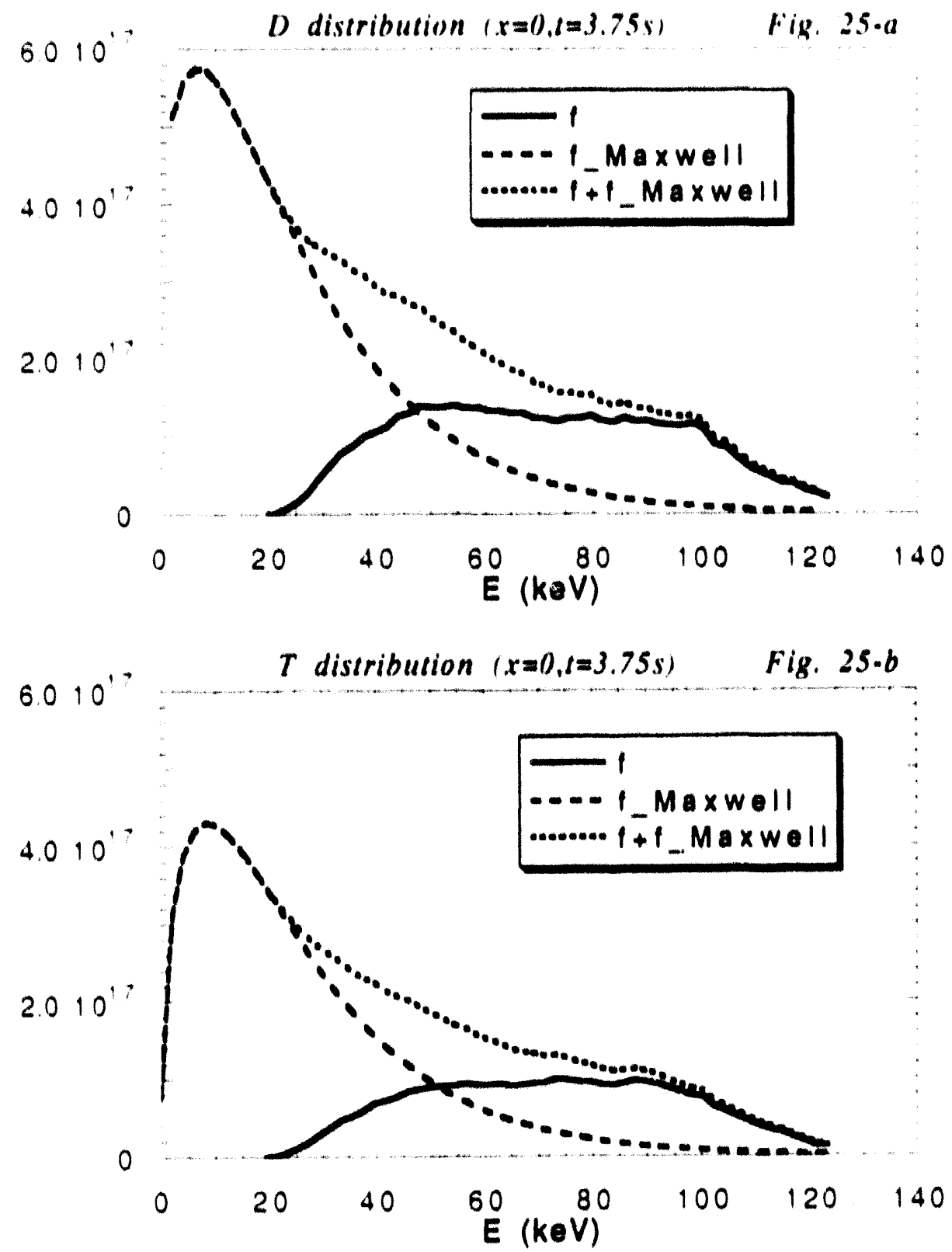

alpha distribution $(x=0, t=3.75 s) \quad$ Fig. $25 \cdot c$

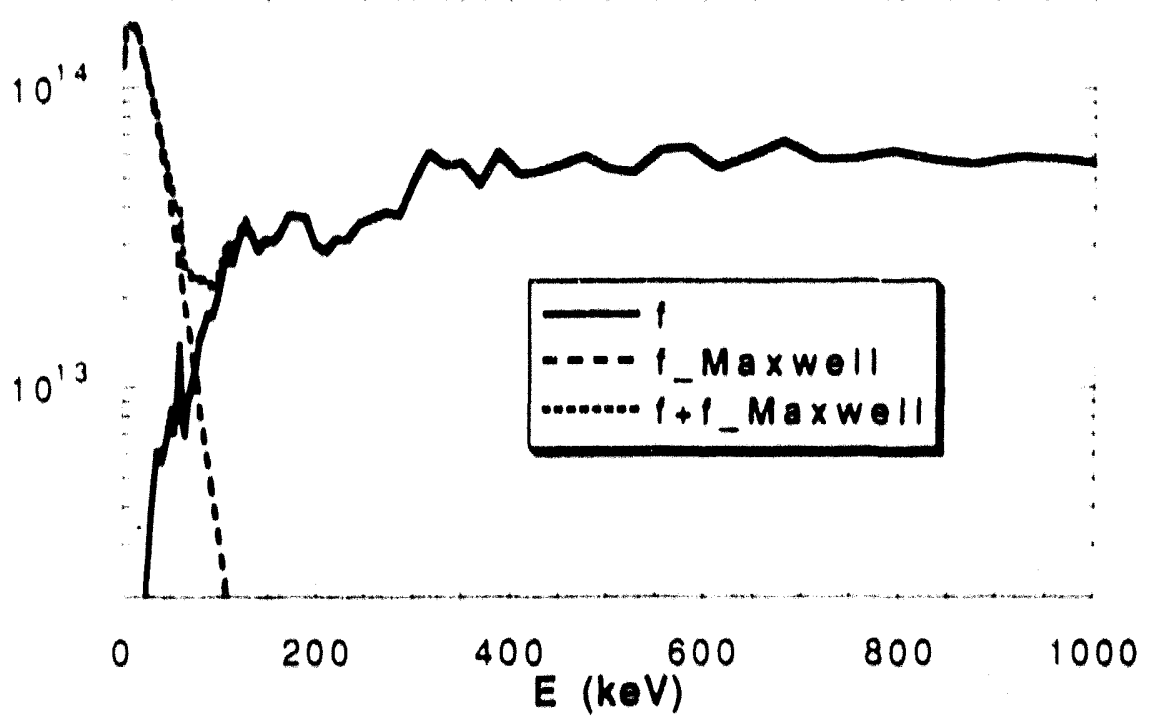




\section{Profiles of the time-integrated alpha thermalization rate}

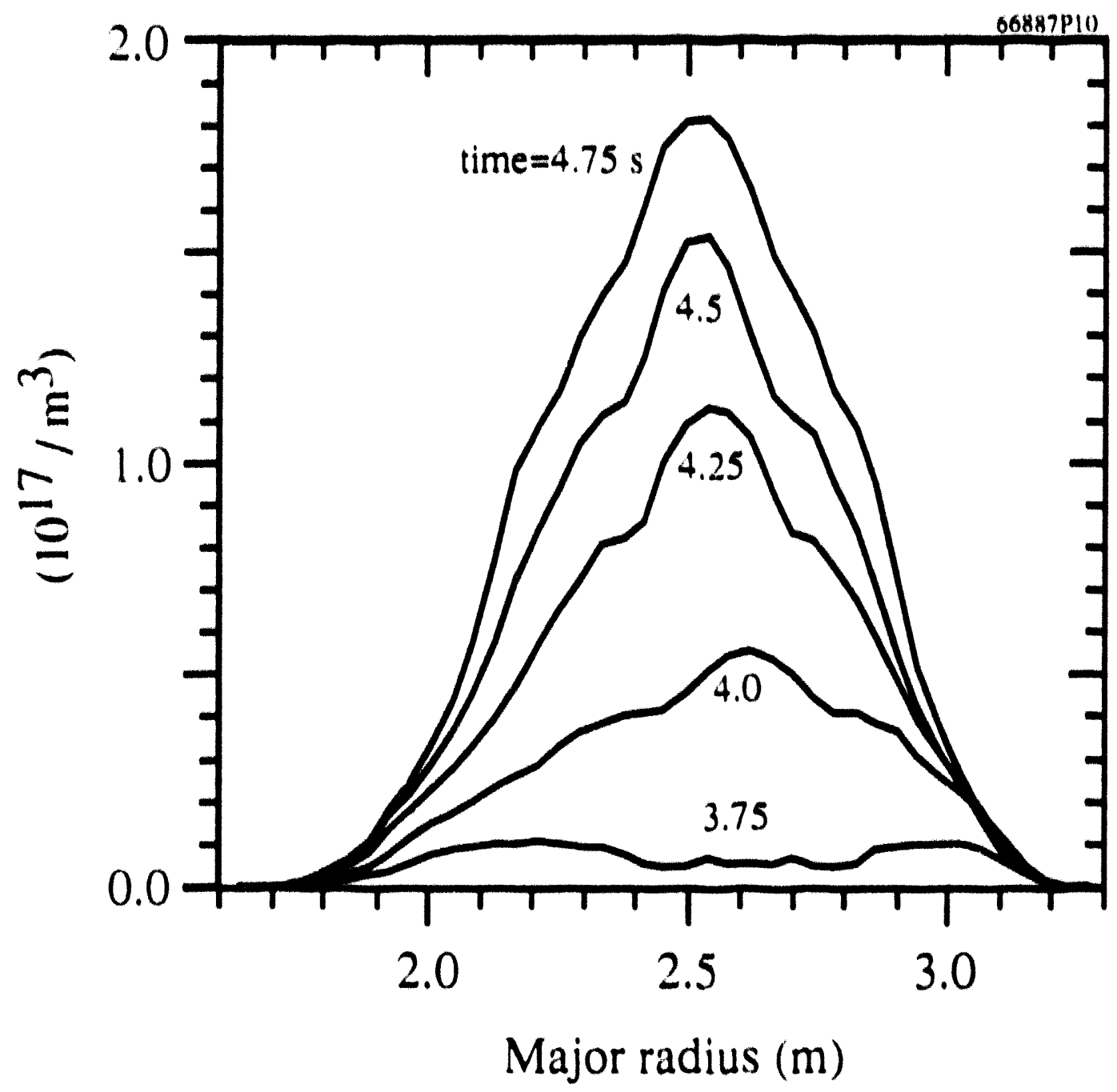




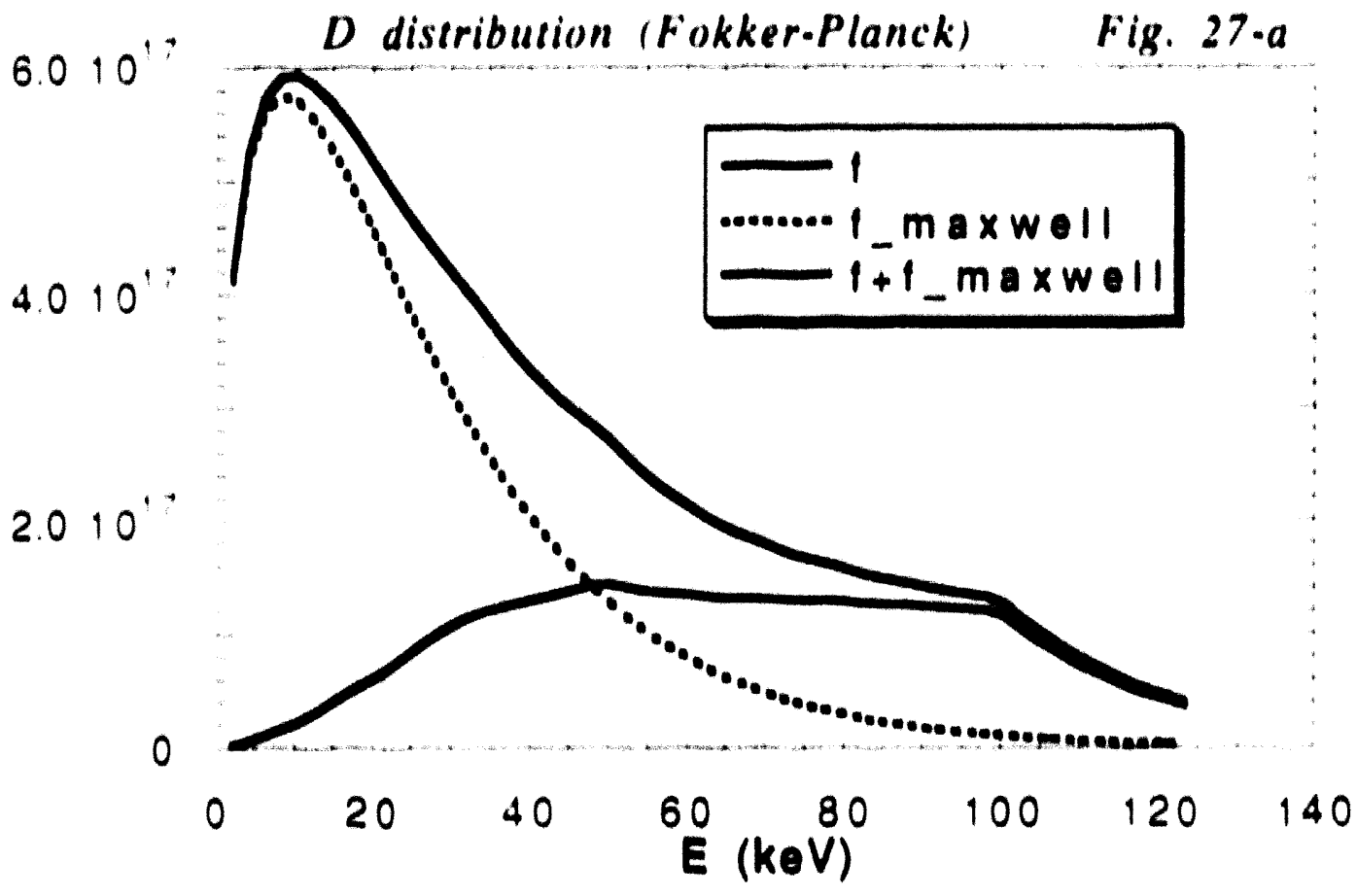

$6010^{\circ} \quad T$ distribution (Fokker.Planck) Fig. 27.6

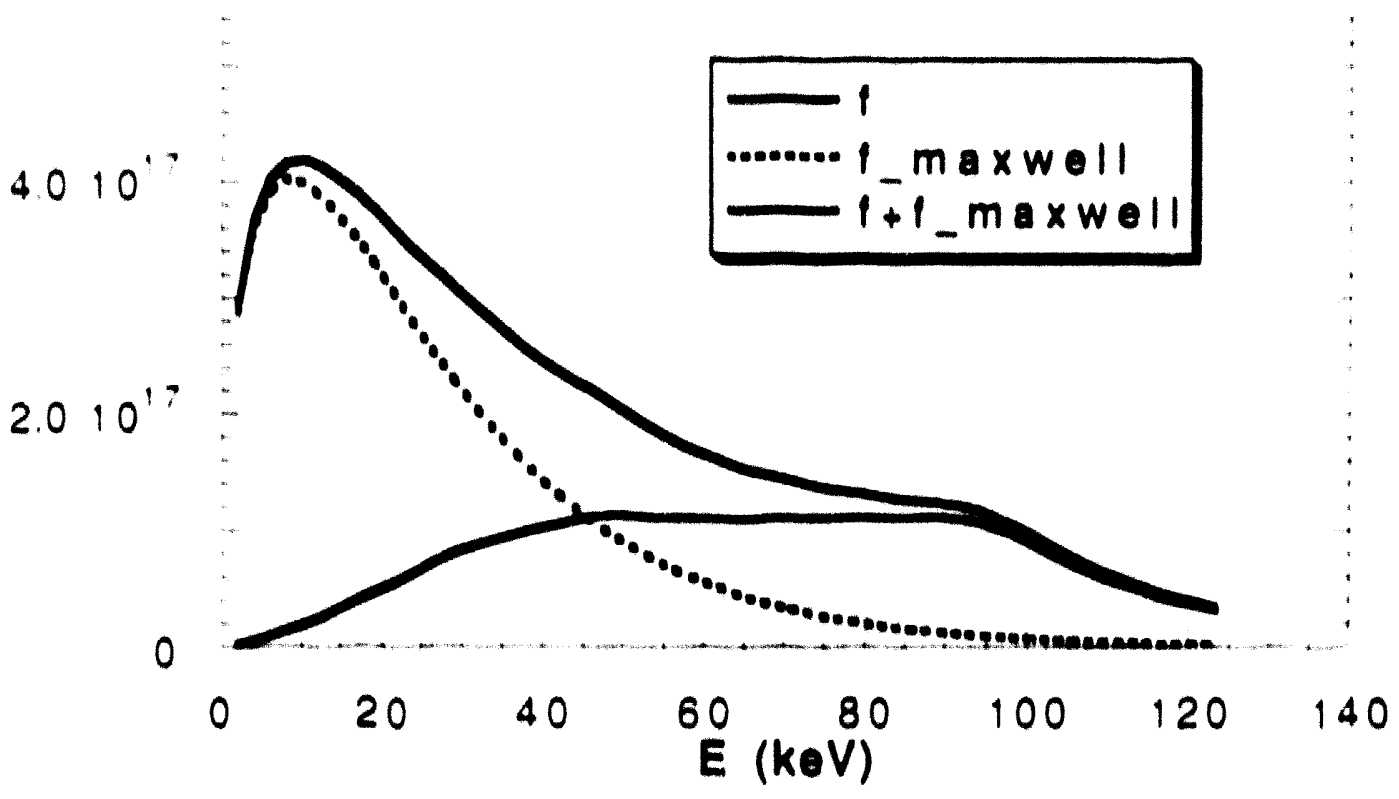




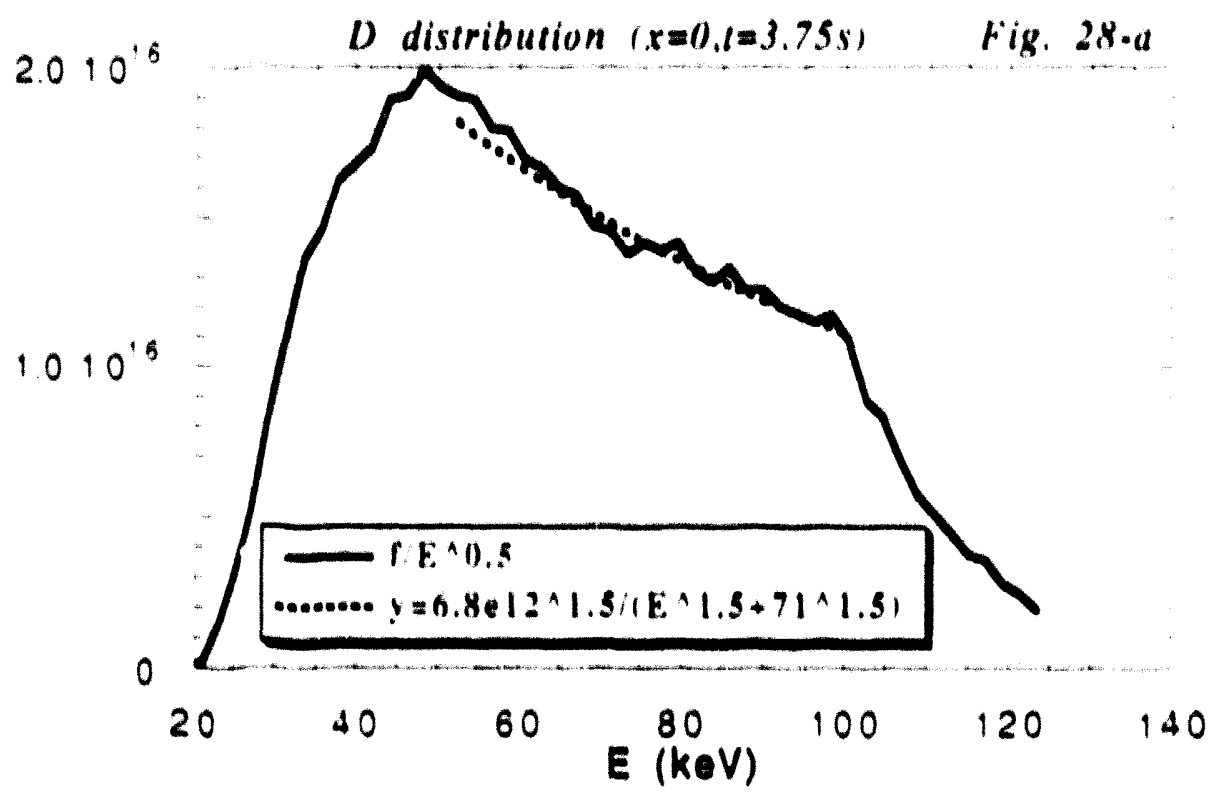

$1.510^{16}$

$T$ distribution $(x=0,1=3.75 \mathrm{~s})$

Fig. 28.b

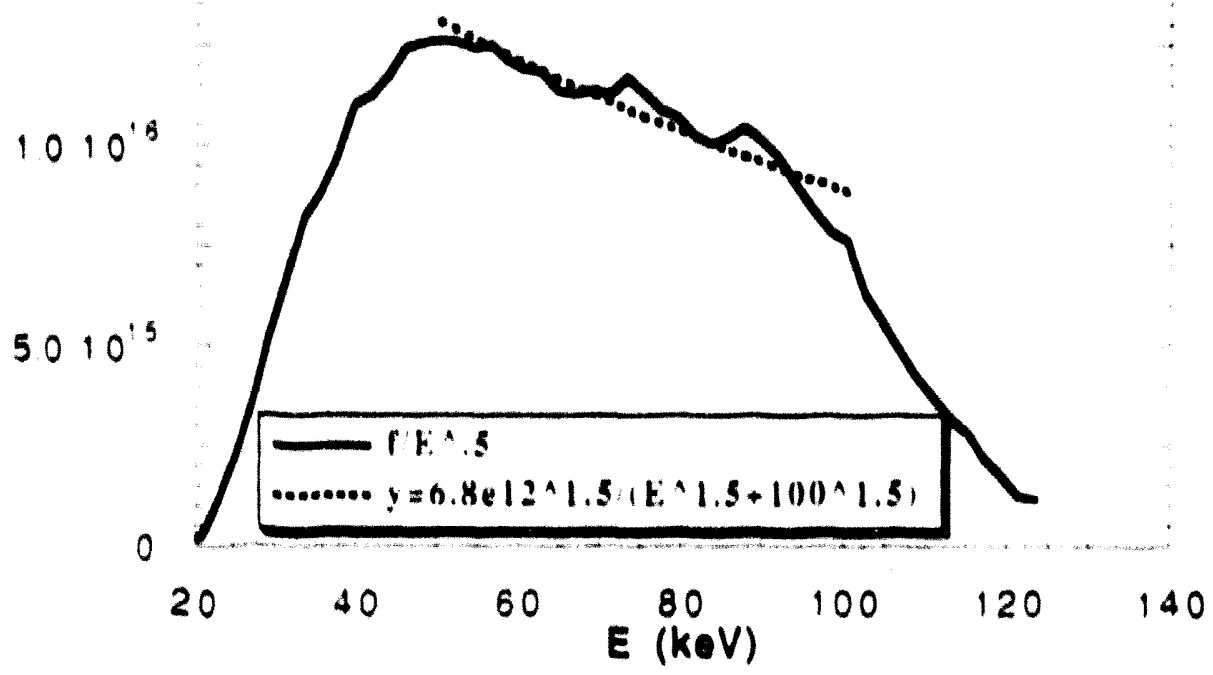

$4010^{\prime 2}$

alpha distribution $(x=1), 1=3.75 \mathrm{~s})$

Fig. $28 \cdot c$

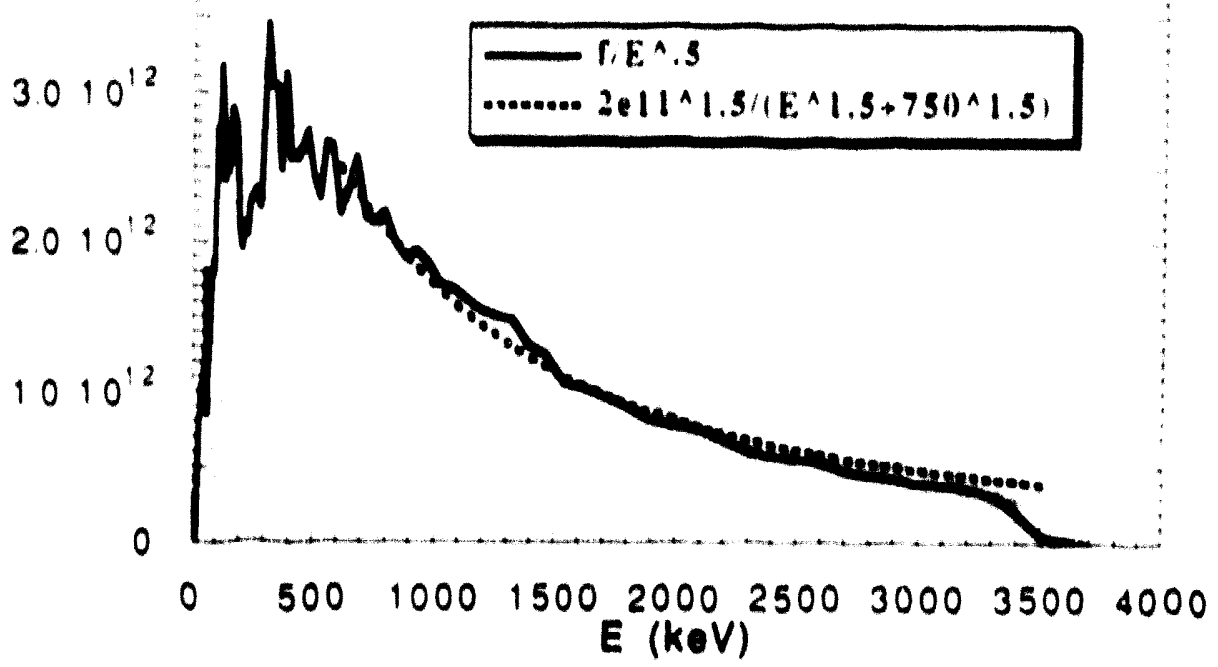



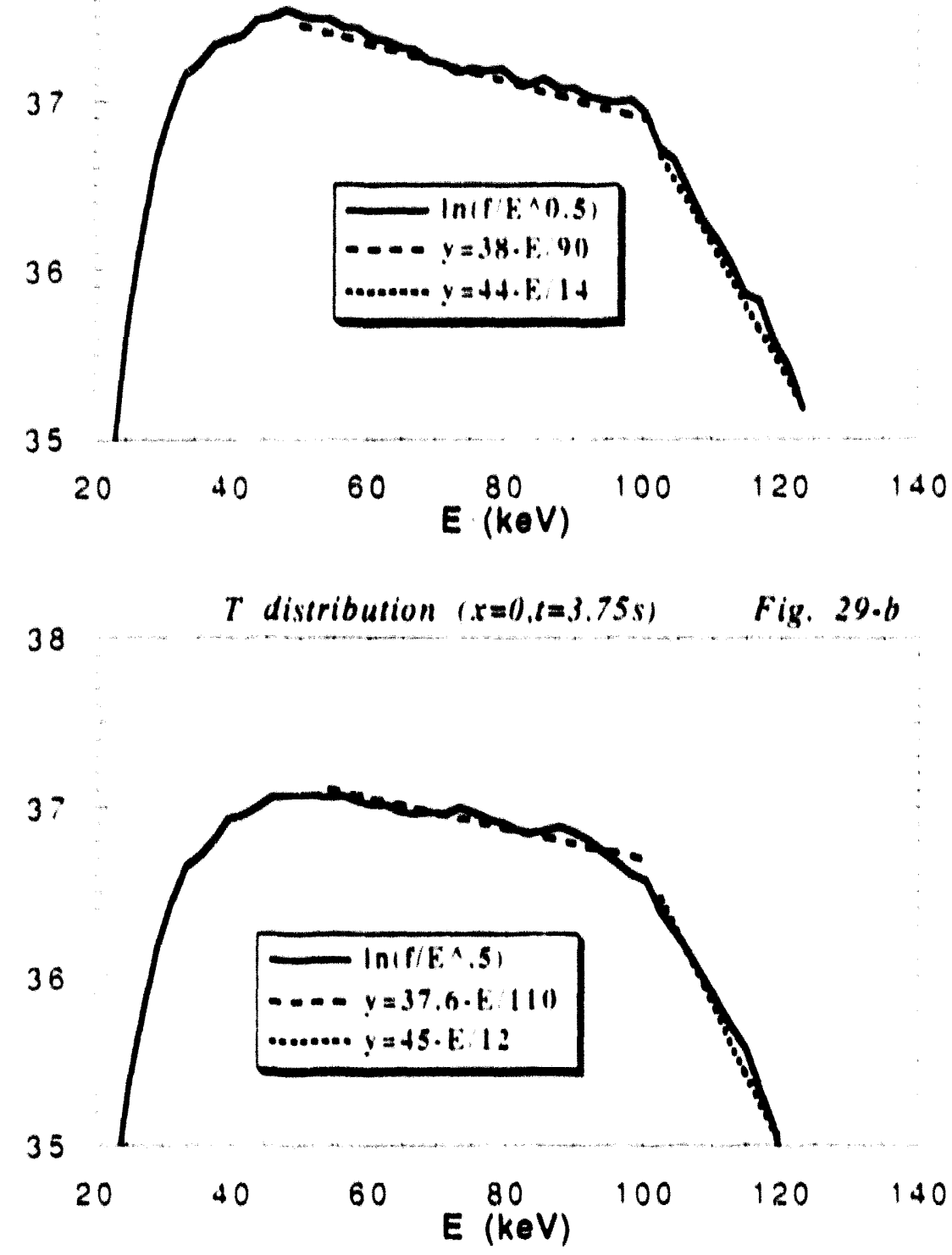

alpha distribution $(x=0,1=3.75 s) \quad$ Fig. $29 \cdot c$

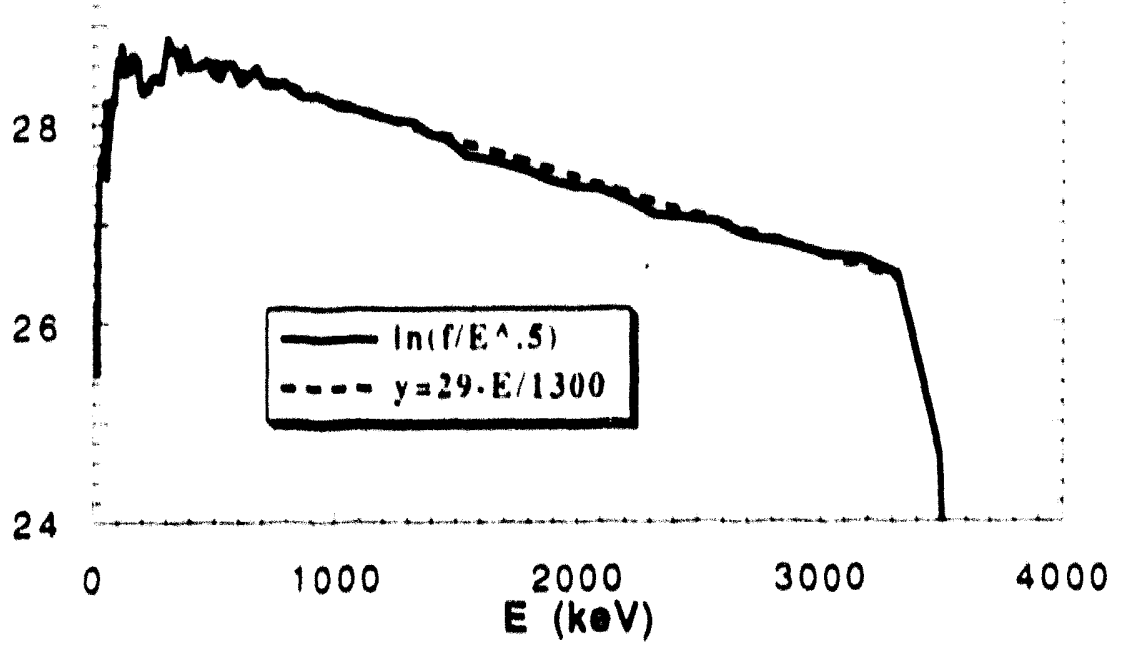




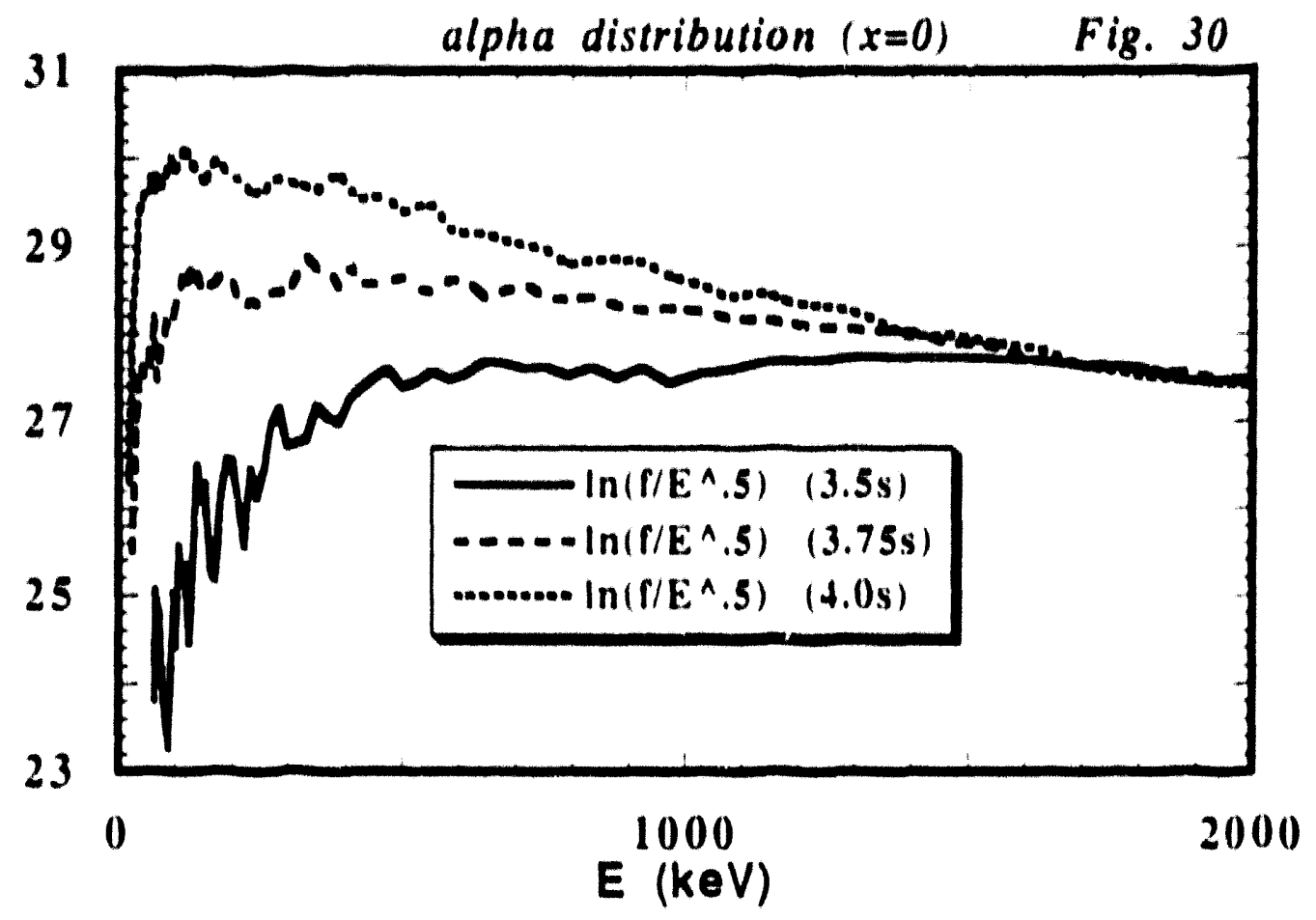


Fig $31 \cdot a$

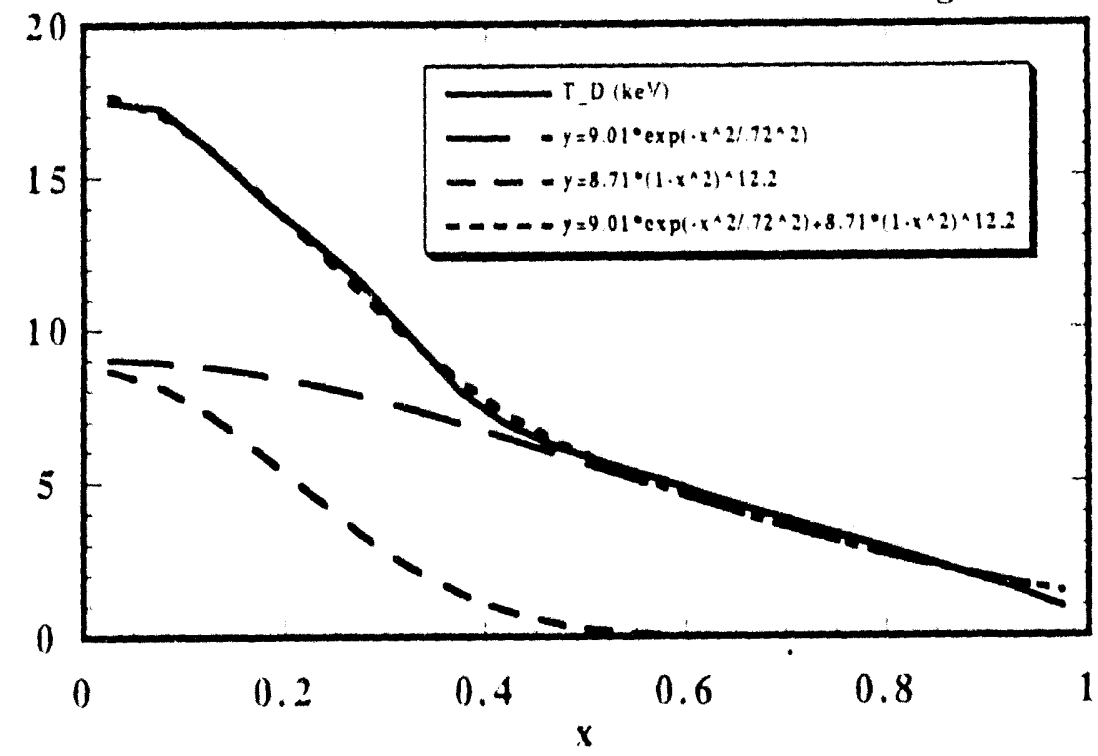

Fig. $31 \cdot b$

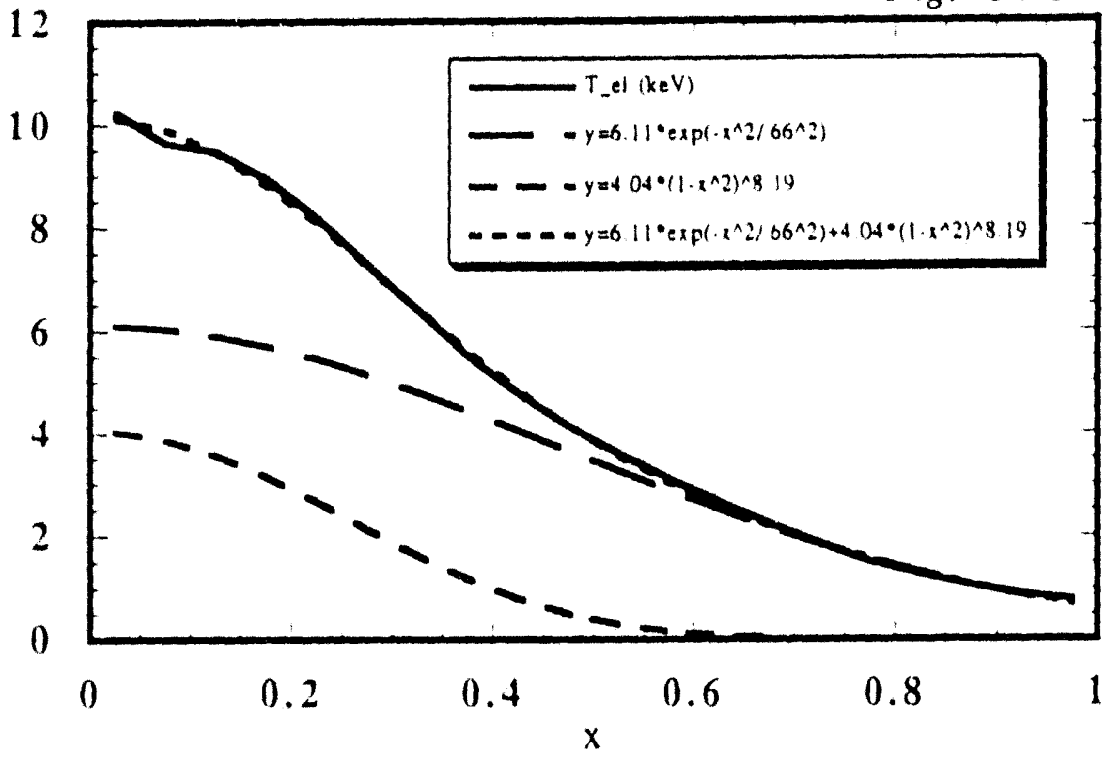

Fig. 31-c

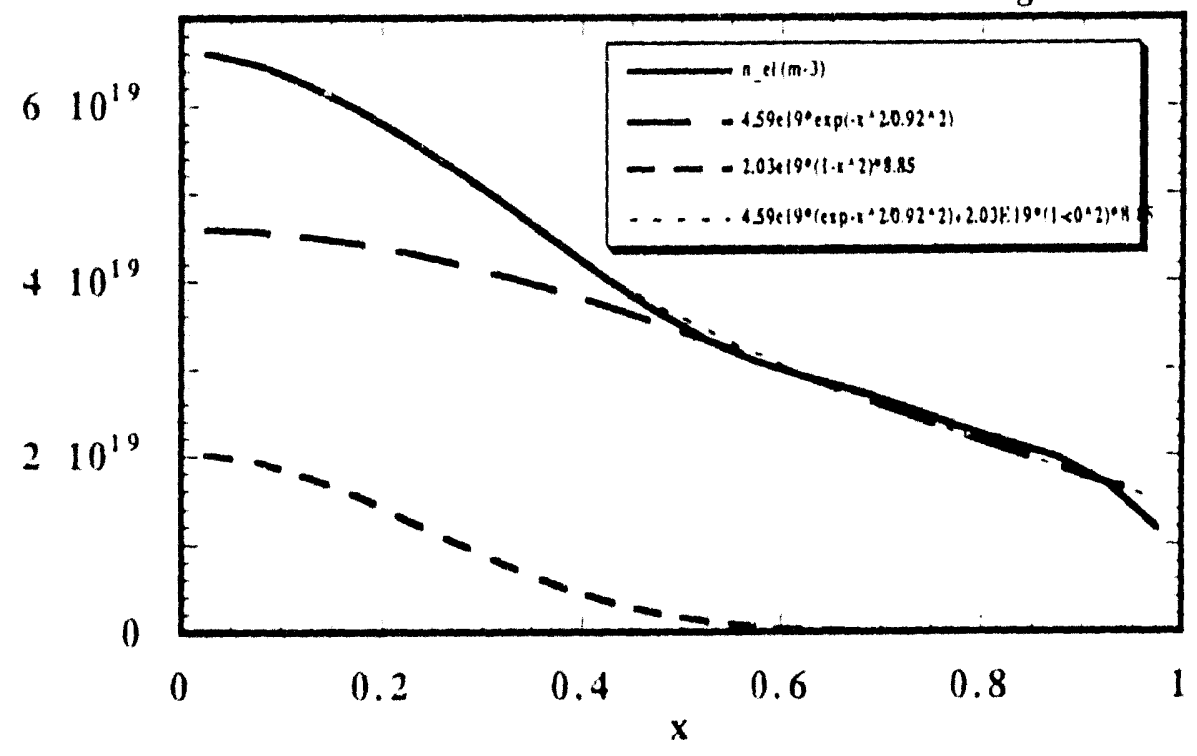



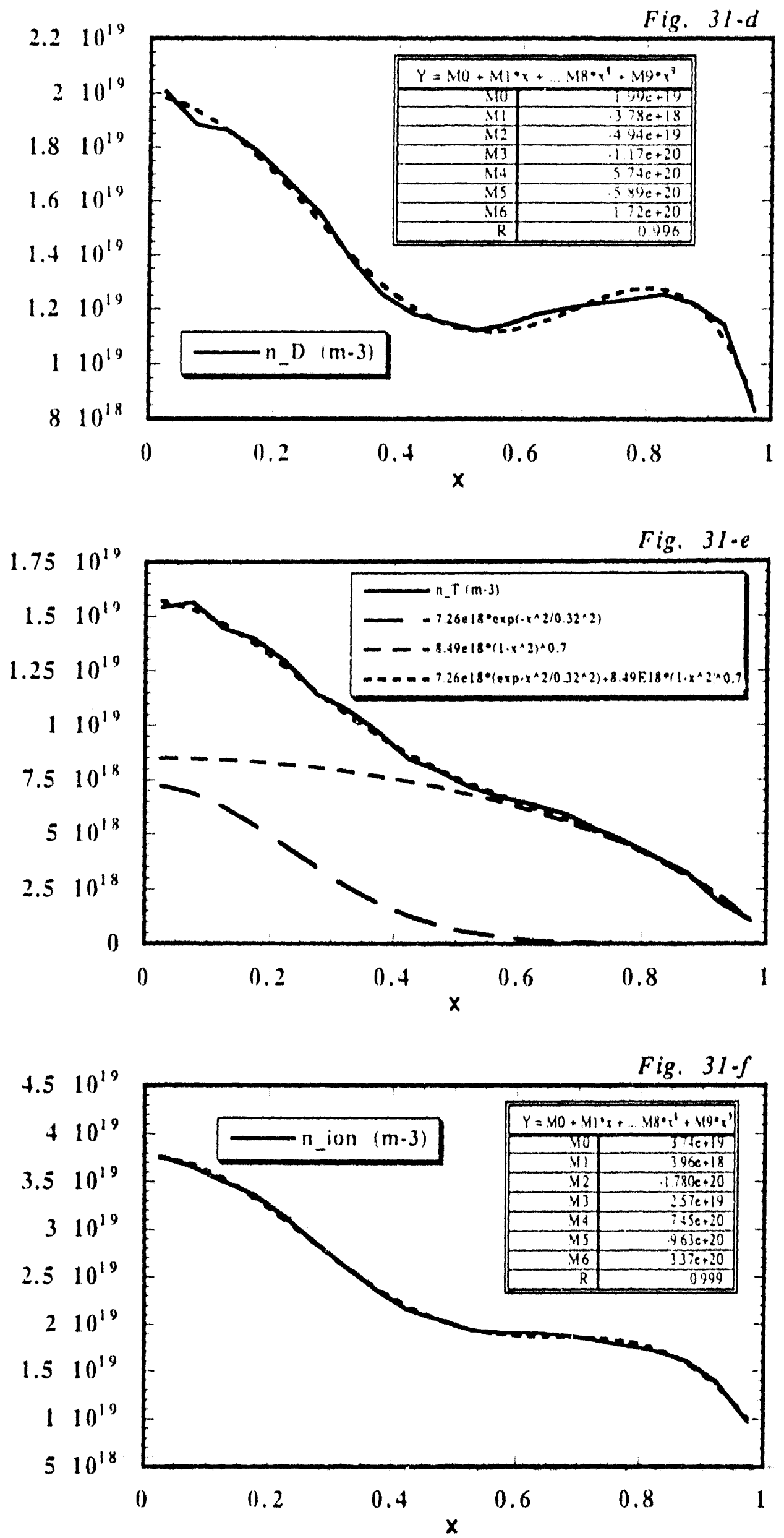

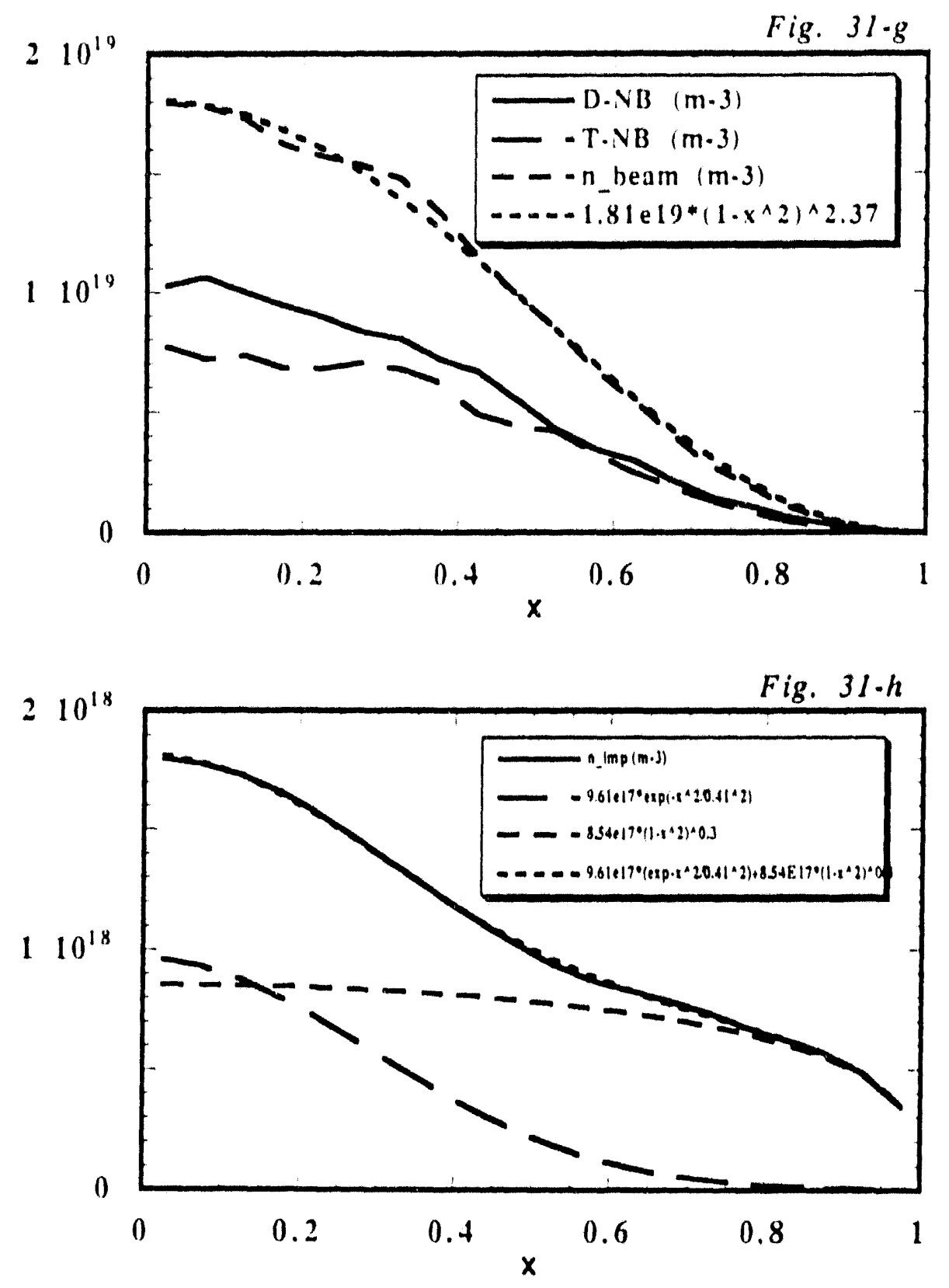

Fig. $31 \cdot i$

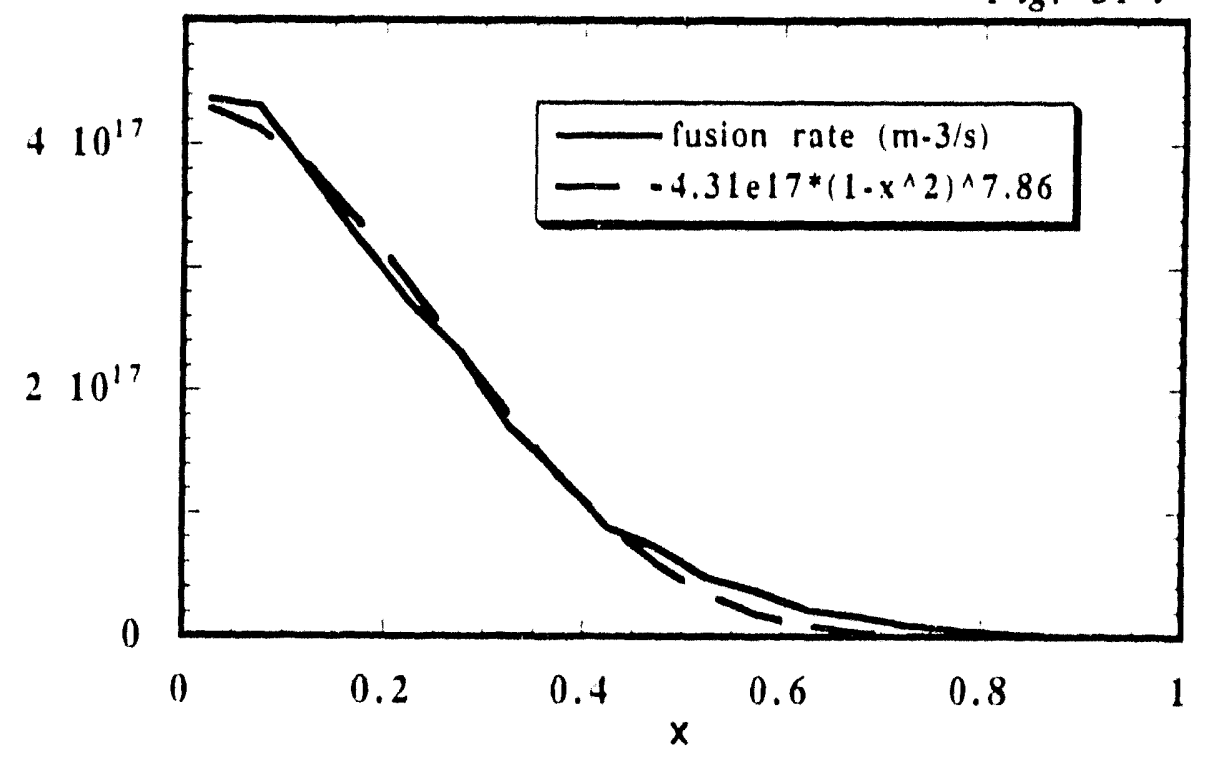



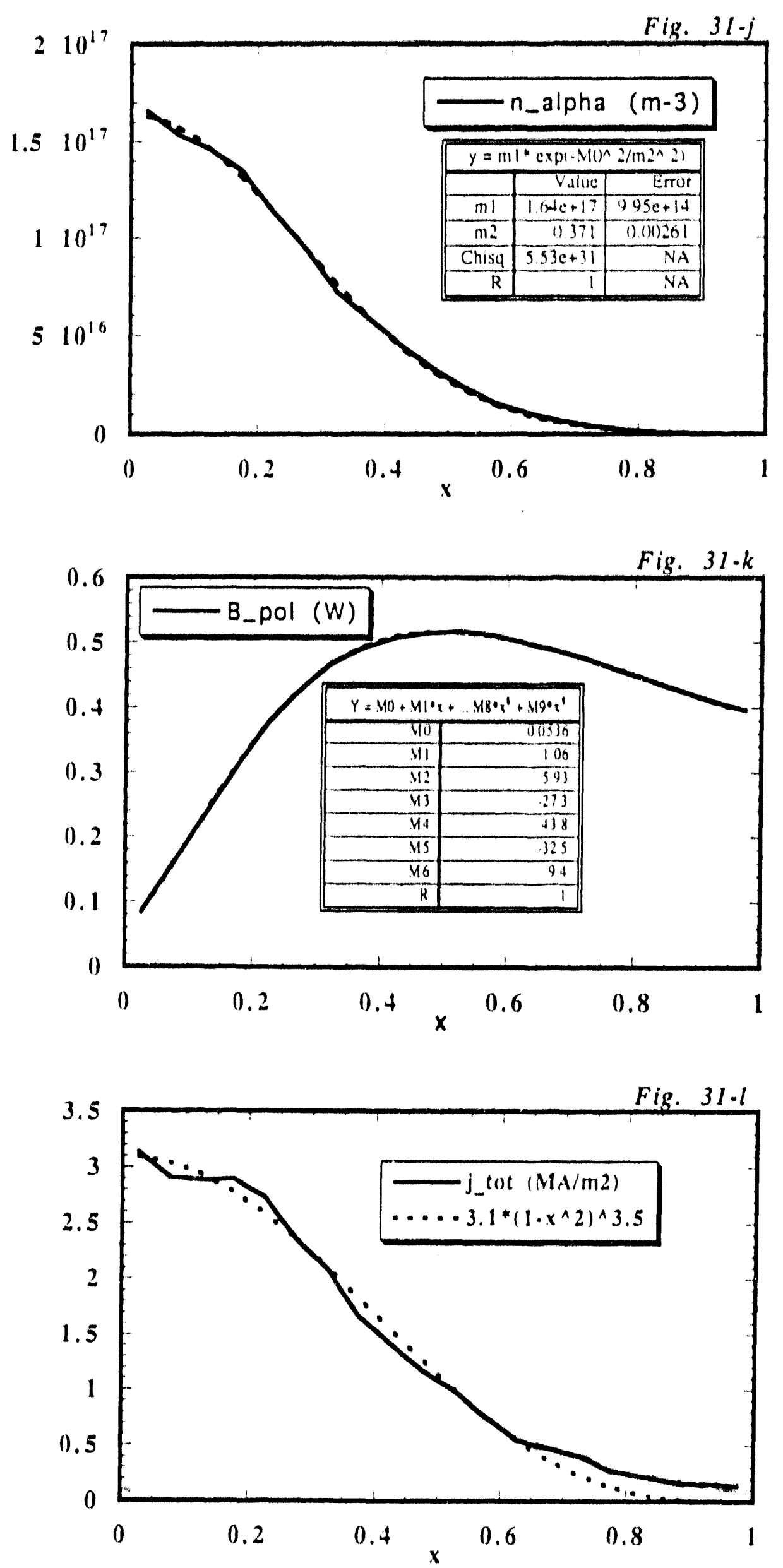
Fig. $3 l-m$
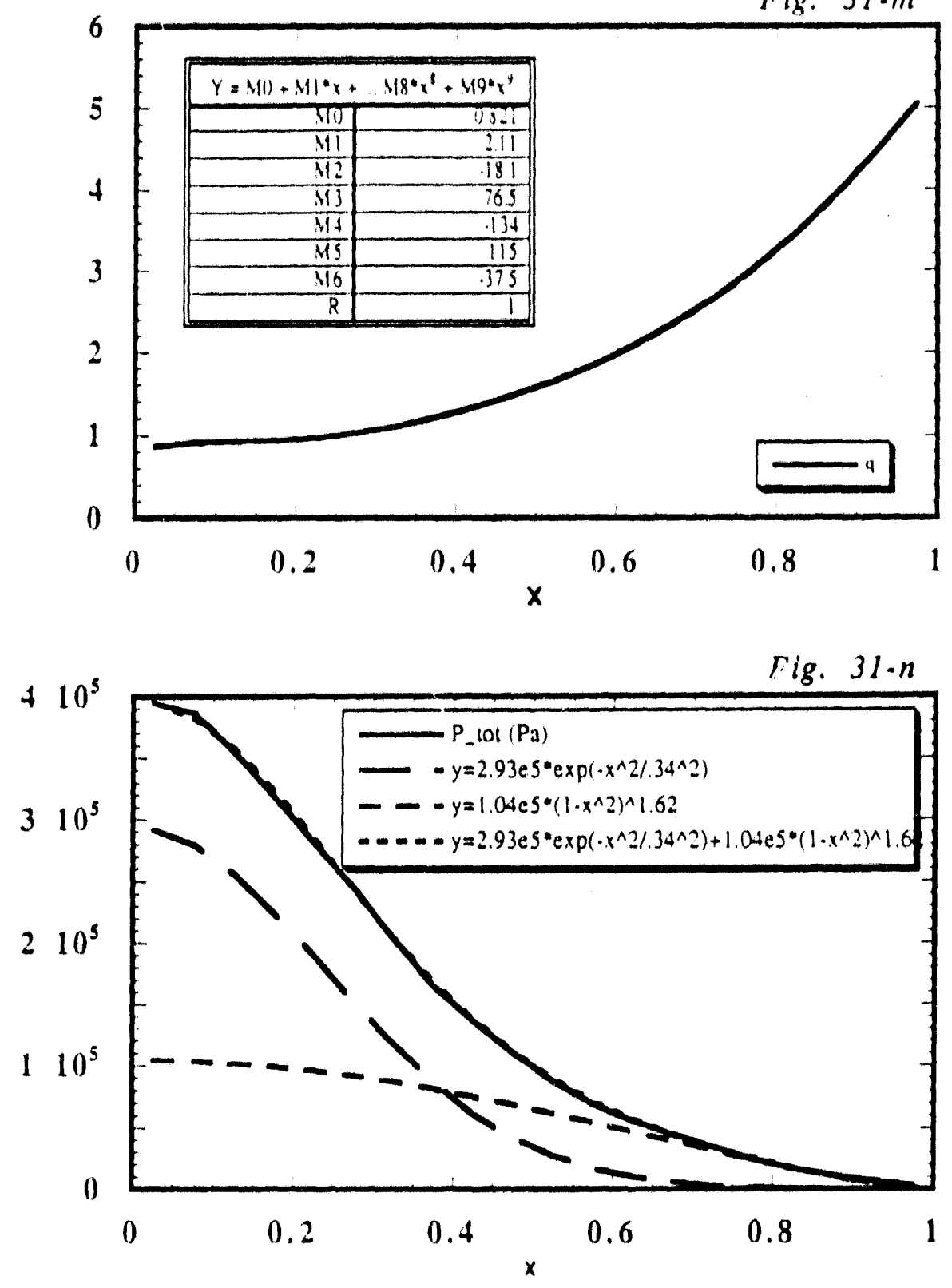

Fig. 31.0

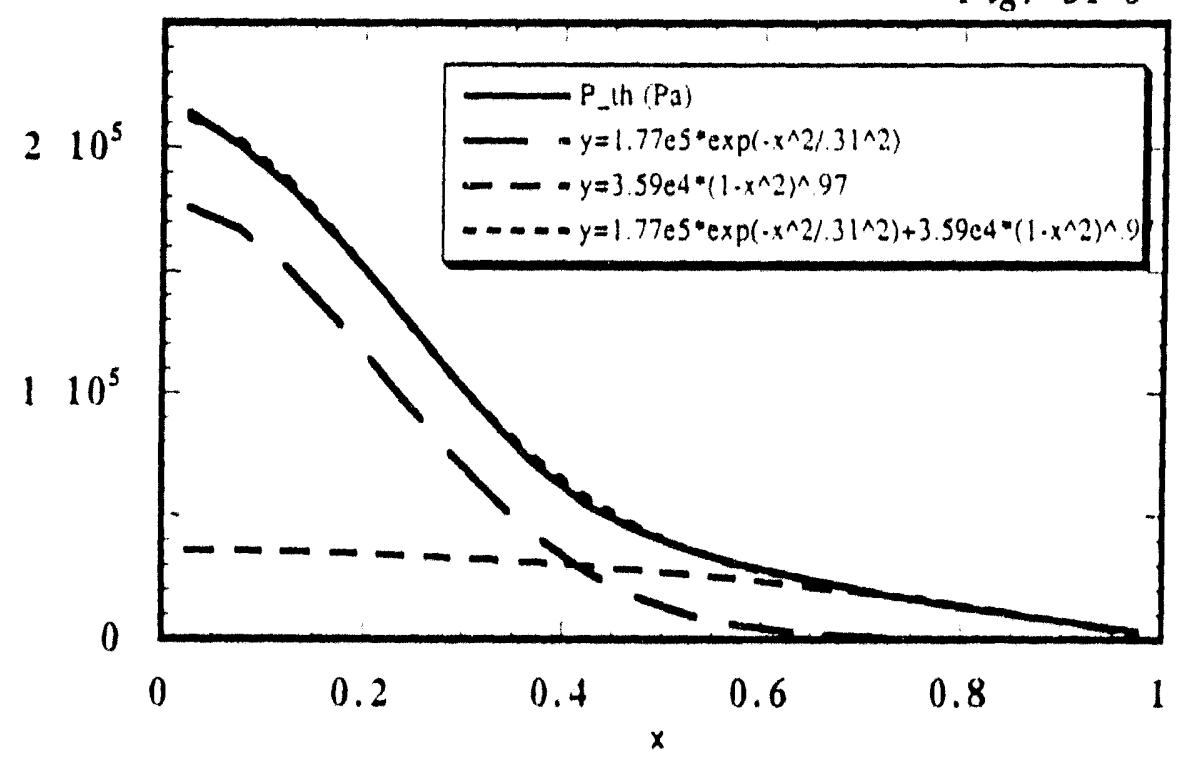



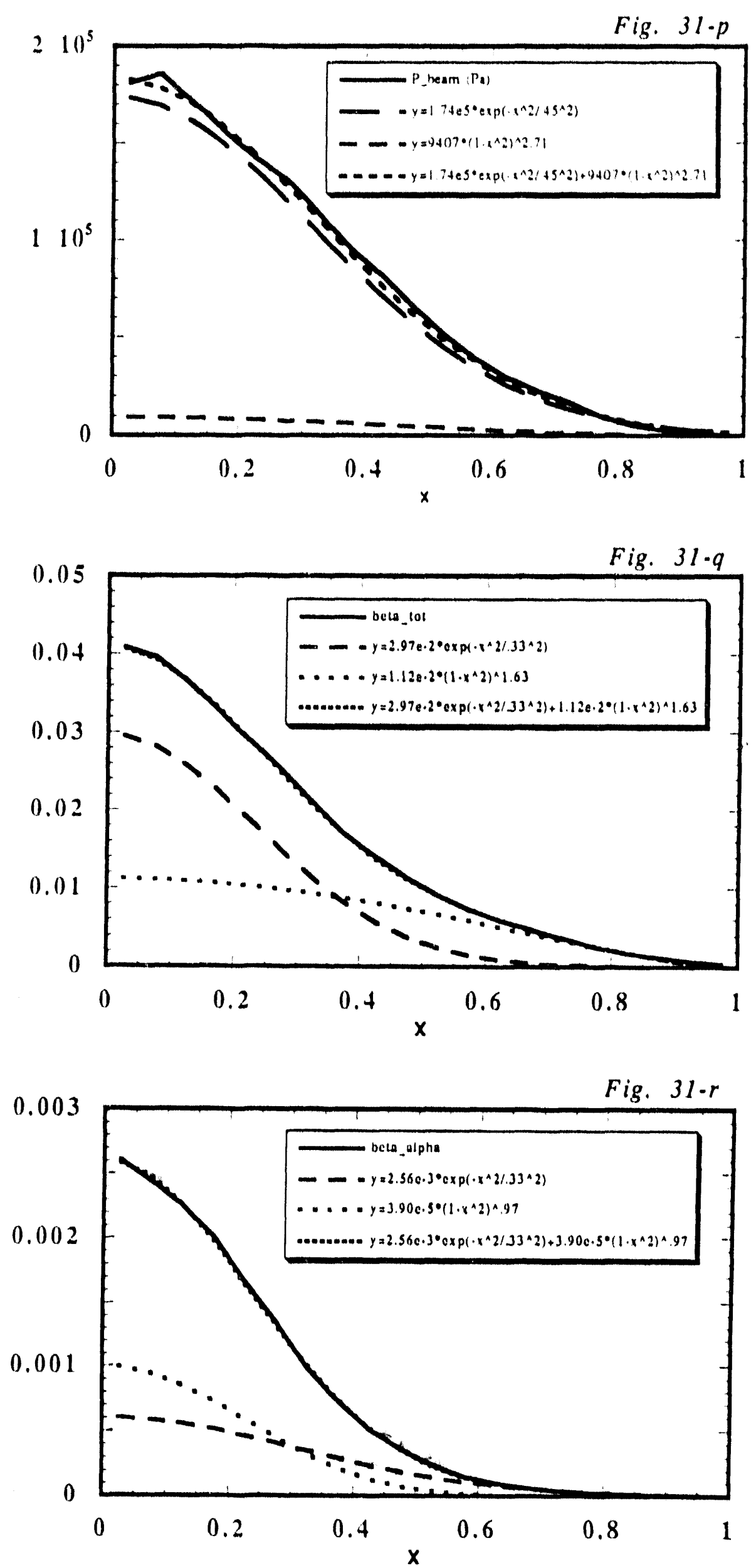

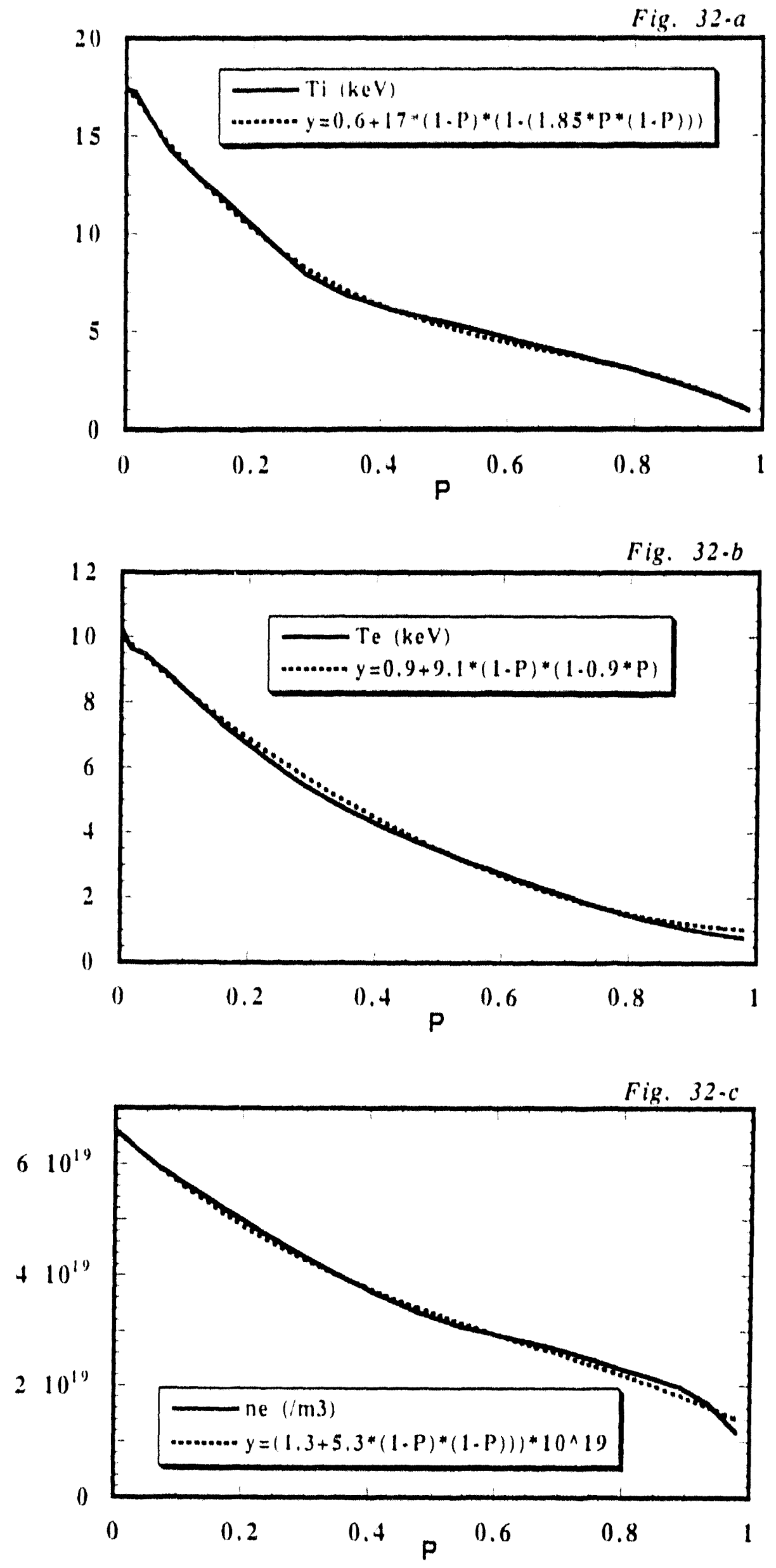


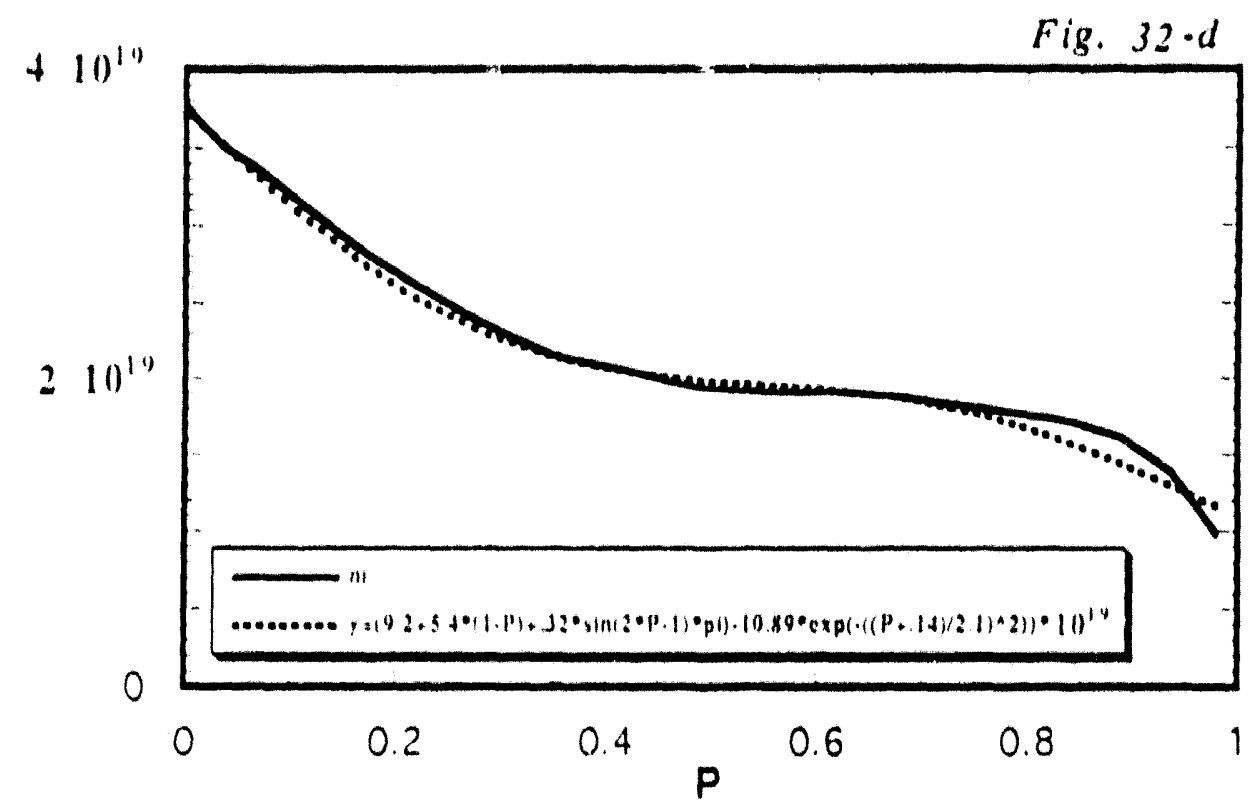

Fig. $32 \cdot e$
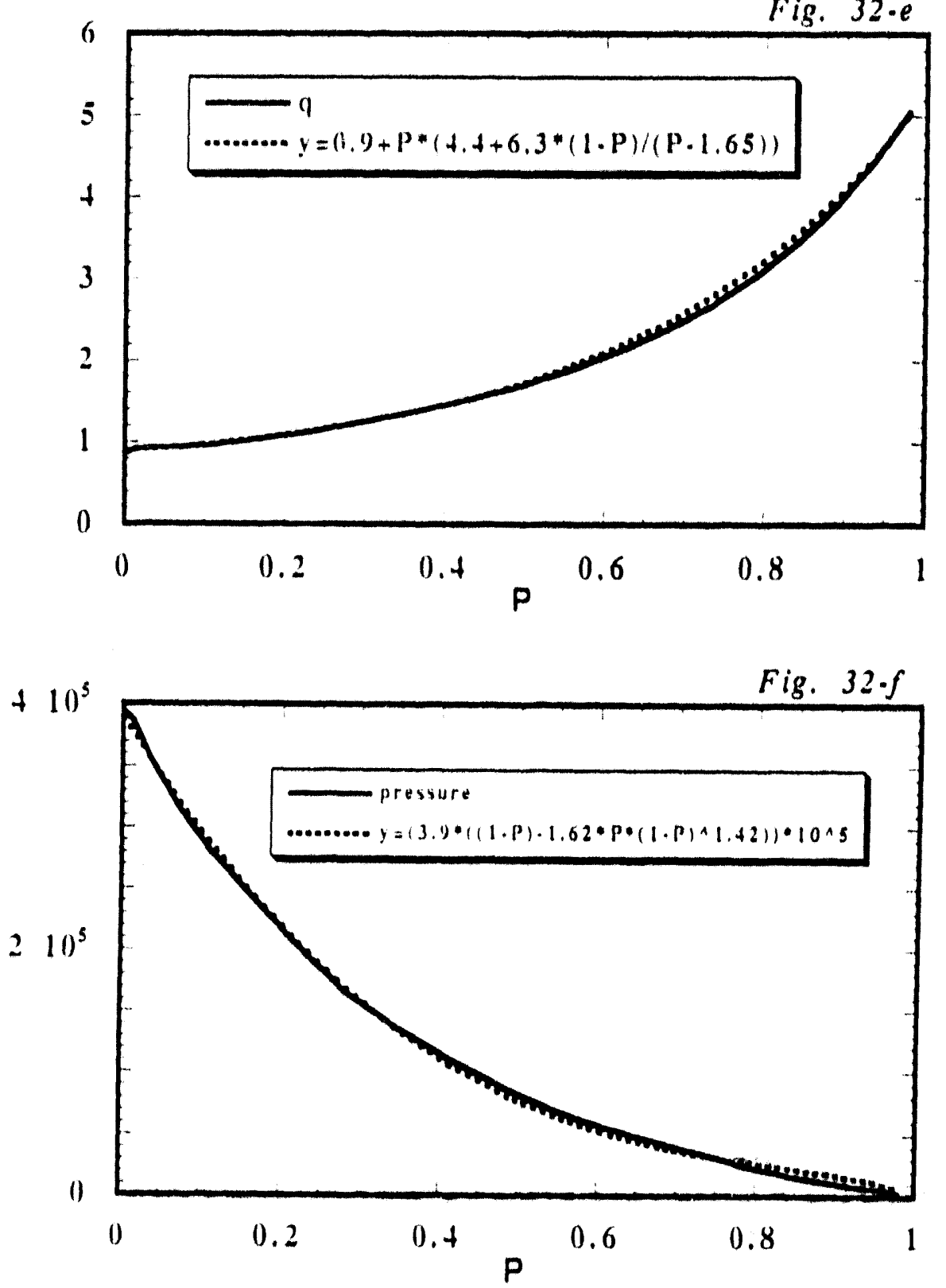

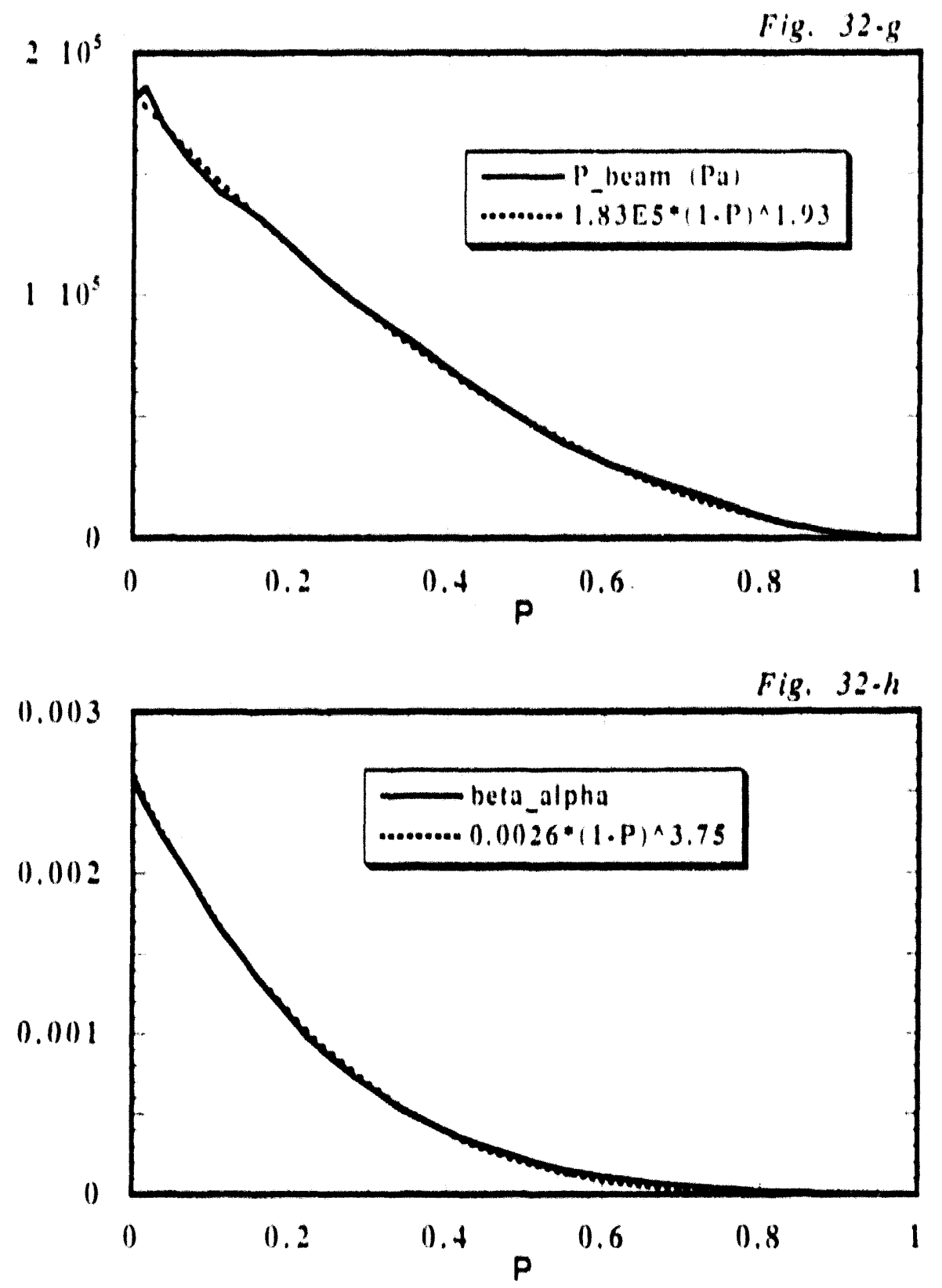
De F Peolom. Unn of Wollongong. AUSTRALIA

Prol MH Brennan, Unir ol Sydnay, AUSTRaLIA

Plasma Rosearon los, Austrien Nat Univ. AUSTRALIA

Prol IR Jonat. Finders UnN, AUSTRALIA

Prol F Cap. Inst tor Theoroted Physics. AUSTRIA

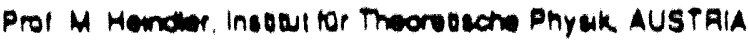

Prot M Coosiens. Astronomisch insbouth BELOIUM

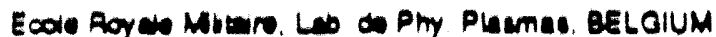

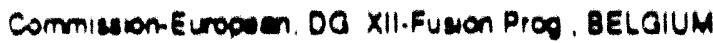

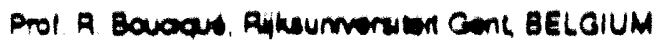

D PH Sakerave, Inoturo Face, BAWIL

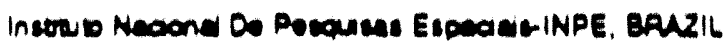

Document Orios. Alomic Energy ol Cenede Lo. CAMAOA

O MP Bechyndw, MPB Technologes, Inc. CANADA

Or H.M Staragerd. Univ of Suckatorawen, CANAOA

Prof. d. Tochmam, UnN of Montred, CANADA

Prol SR. Srommeen. Univ or Celgary, CANADA

Prof T.W Jomiton, INASEMTrg, CANADA

Or R Bction, Contro cansden de Nusion meonsuous. CANAOA

D. C R Jemes. UnV OA NDETE. CANAOA

Or $P$ Lukle, Komenckeno Unwenat C2ECHOSLOVAKIA

mo Luraran. Cutham Luoribry. ENOLAND

Lorery. AS1, Ruthertord Apdeon Laboralory. ENGLANO

the SA HUtorineon, JET Lormy, ENGLAND

Or SC Shame UnN ol Soun Peofic. FIJIISLANDS

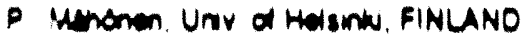

Prol MN Busece Ecolm Parmonnqua., FRUNCE

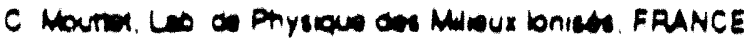

$J$ RACUL CENCADARACHE - BII506. FHANCE

Prol E Economou UnN al Croto GAEECE

Mo $C$ RnN UnN of laemna, GAEECE

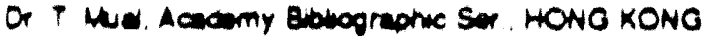

Preomi Luray. Hungeman Academy a Sa, HUNGAAY

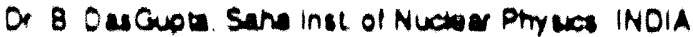

Or P Kaw. Inst for PAasma Rosearen. INOIA

O. P Rocenes. I wae inst ol Tectinotogy, ISPAEL

Lorenen intemevone Conter lor Thoo Physca ITALY

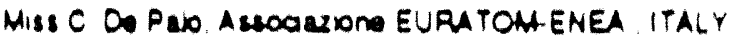

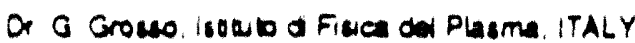

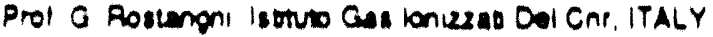

D. M Yamato. Tounion Ros I Dond Conter, JAPAN
Prol I Kawakemi. Hroshma Univ, JAPAN

Prol K. Nianivawe, Hrootum UnN JAPAN

Orecter Jeaen Alomic Enargy Rosearch inst JAPAN

Prol s Ion. Kyusmu Unn, JAPAN

Raweren into CV. Nabone insol tor Fusen Scance JAPAL

Prot 5 Tenake, Kyod Unir. JAPAN

Librey, Krob Univ, JAPAN

Prol $N$ Inow. UnN of Totyo. JAPAN

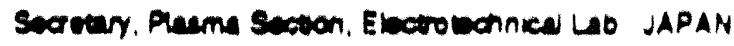

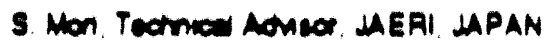

Dr O Anera. Kumenots Inst ol Technotogy JAPAN

J. Hroon-Sook. Konva A tomk Enory Rasearon Inat, KOAEA

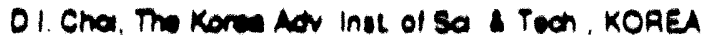

Prol B.s Lioy. UnN of Wakno. NEW ZEALAND

Inth of Phrues. Chinewe Acad Sa PEOPLE S REP OF GHINA

Lurry. Inat of Phama Physa. PEOPLES REP OF CWINA

TAnghu UNN LETEY PEOPLES SREPUBLIC OF CHINA

Z L. SW InA Phyea, PEOPLE'S REPU⿴囗十C OF CHINA

Prol JAC Card, Insubro Supenor Teanico POATUCAL

Or O Ponu. Al I Cuza Unn, ROMania

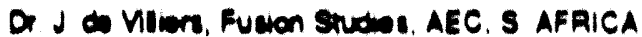

Prol MA Hedberg. Unn ol Nates S AFaICA

Prol OE Km. Pohang inut of Sa I Tech, SO KOAEA

Prol CIE MA.T, Fuson Omsion Lubrary. SPAIN

O L SWMn. UNN OI UMEA SWEOEN

Lorery. Roy inst. ol Tectnology, SWEOEN

Prol $H$ Withamion. Chamers UnN of Tech, SWEDEN

Contro PMys Des Pleamas Ecow Podnech. SWITERUANO

Buboum, InUt Voo Hama.Fyica THE NETHERLANOS

Asul Prol or $s$ cakr, Mode Easi Teon UnN, TUAKEY

Or VA Cubiwh.Sa Aos inst Elactrophys I Apoaratus USSA

O OD Avur Sibanan Branch ,I Aeacamy a SO USSA

O. GA Elieer, IV Kurchator InBt. USSA

Lbrenen, Thu UkS SSA Acodemy of Sarnces. USSA

D LM Komathmykh, Inst of Conare Physica USSA

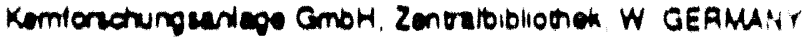
Bubotak, Inst For Phimatorsoning. W GERMANY Prol $x$ Schinder. Rum. Unmerwat Bochum. W GERMANYY

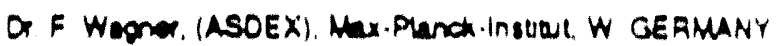
Lormen. Max.Plench.Inavou, W GERMANY

Prol RK Janer. Inst of Prysica YUCOSLAVIa 
.

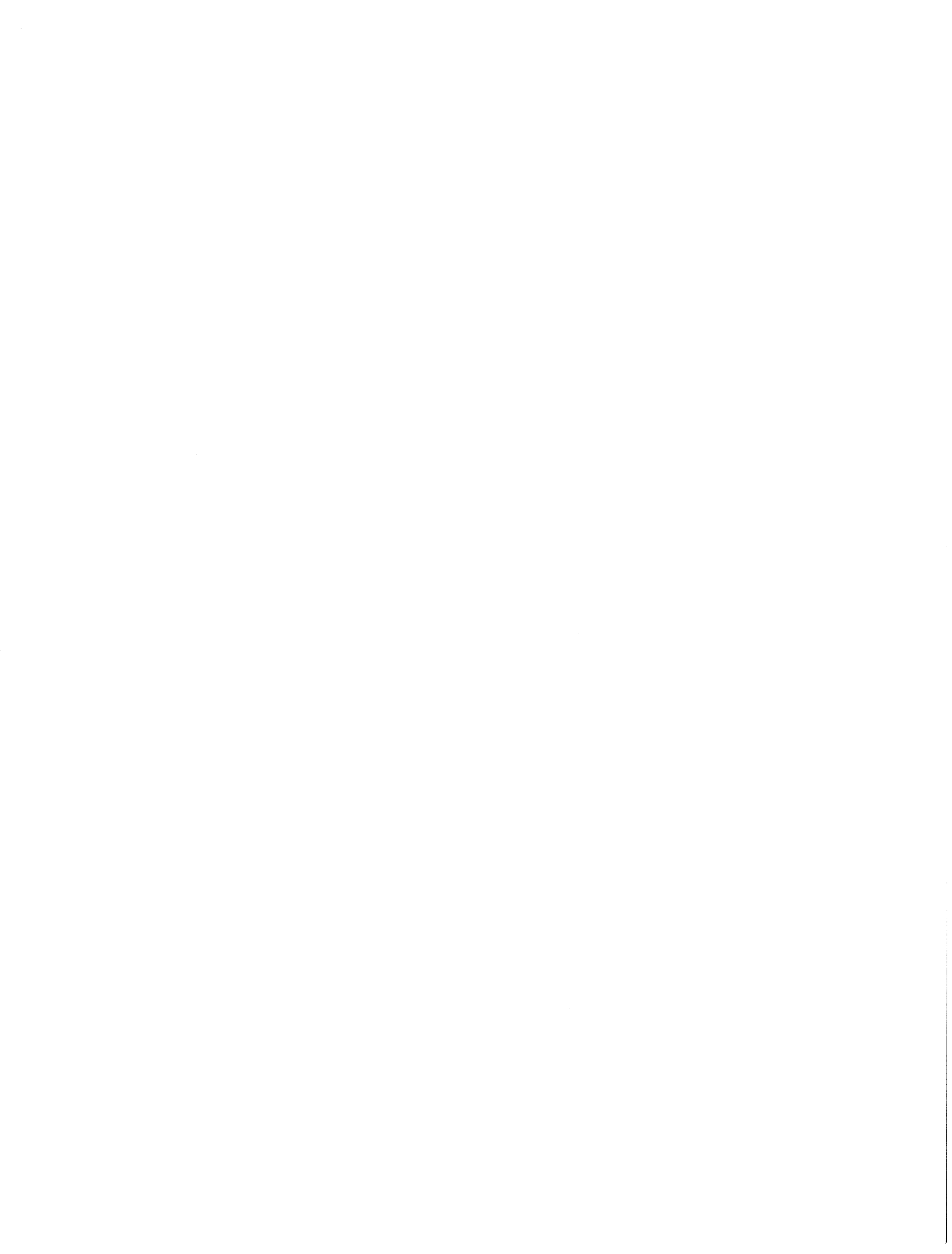

